\title{
The effect of Council decision making on the ability of Cambridgeshire communities to develop initiatives that lessen the need for formal health and social care services
}

Tarrion Baird, Alice Fletcher-Etherington, Jennie Leggat, Kirsty Mackinlay, Charlotte Rendina, Ivan Simpson-Kent

Cambridge University Science and Policy Exchange (CUSPE) in collaboration with Cambridgeshire County Council

November 2020 


\section{Contents}

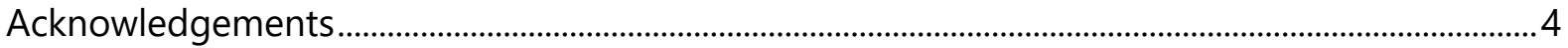

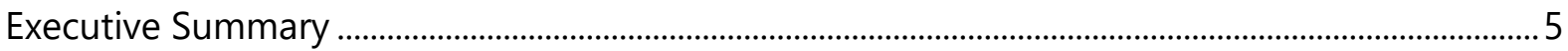

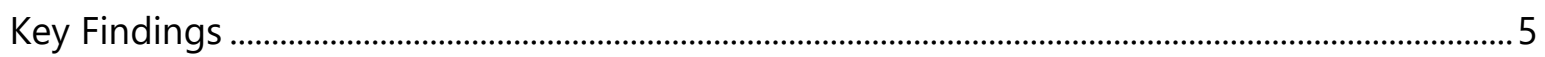

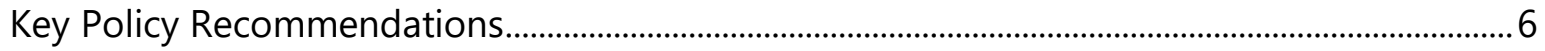

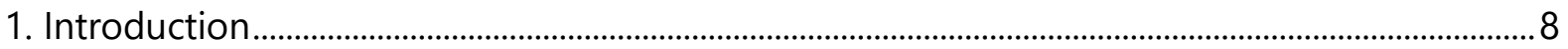

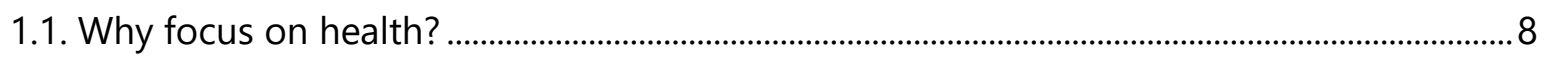

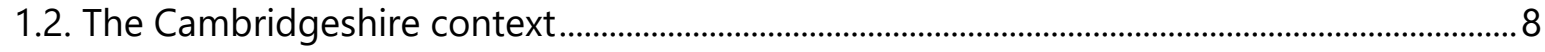

1.3. Demographic and Economic Growth .........................................................................................

1.4. Public Health Outcomes and needs in Cambridgeshire...................................................... 14

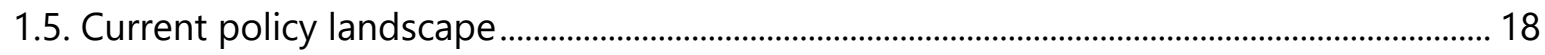

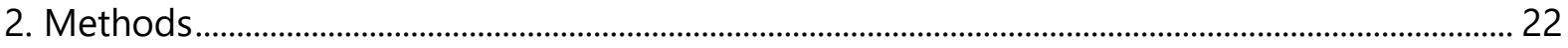

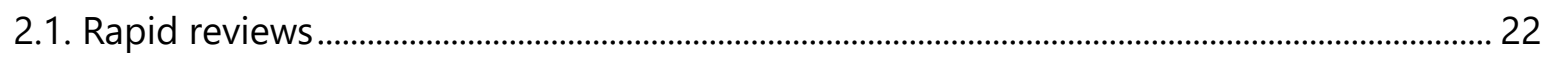

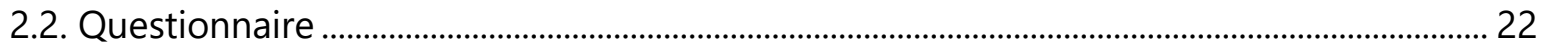

2.2.1. General information about the respondents ......................................................................... 22

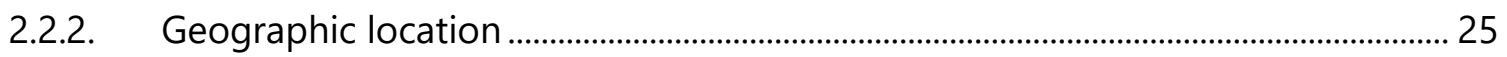

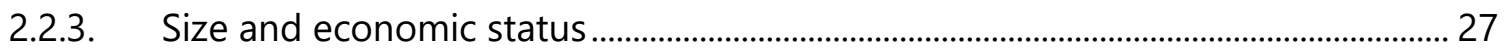

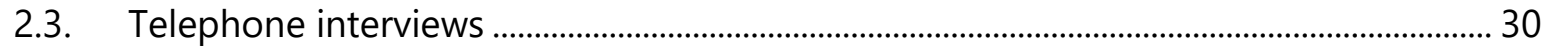

3. Community-led initiatives lessen the need for formal health and social care services......... 31

3.1. Community engagement in healthcare commissioning .......................................................... 31

3.2. Community development for health and wellbeing ................................................................ 32

3.3. The ways in which community development improves health and wellbeing .................. 33

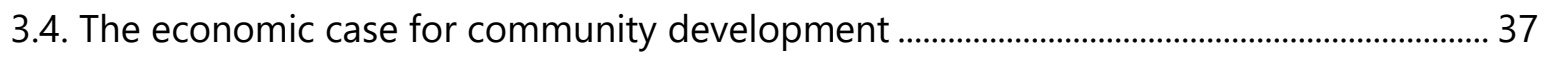

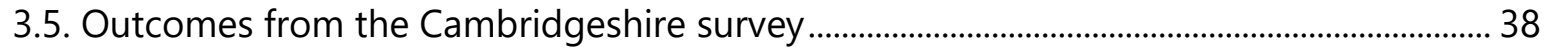

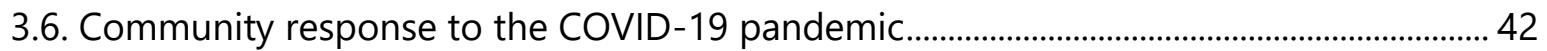

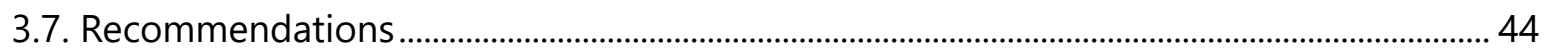

4. The effect of growth on health, wellbeing and community-led initiatives................................. 46

4.1. Avoiding "New Town Blues": Mitigating the impacts of growth within communities ... 46

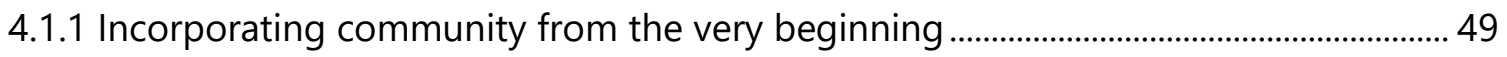

4.1.2 Community building throughout development ................................................................... 51 
4.1.3 Long-term investment for long-term communities: the role of Master Developers in

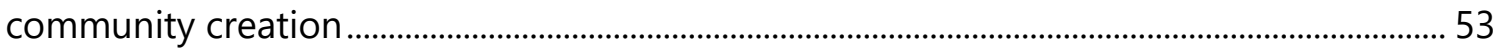

4.2. Perceptions of Cambridgeshire community groups on the effects of growth .................. 56

4.3. Recommendations 62

5. With great devolution of power, comes great responsibility: localism that empowers rather than exacerbates. 67

5.1. Localism in the UK 67

5.2. Neighbourhood Planning: localism in action 68

5.3. Devolution vs democracy: giving everyone a voice 69

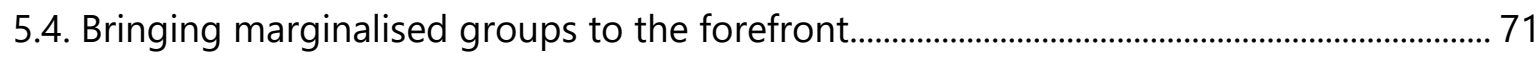

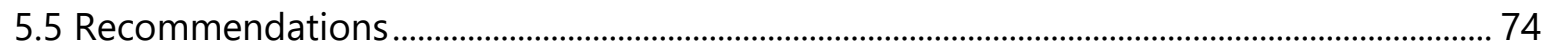

6. The effects of CCC decision making on community-led initiatives .76

6.1. Opinions of Cambridgeshire-based community-led initiatives on County Council

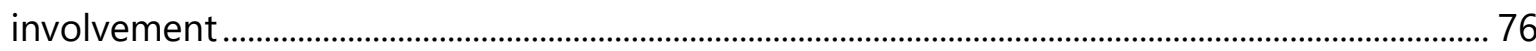

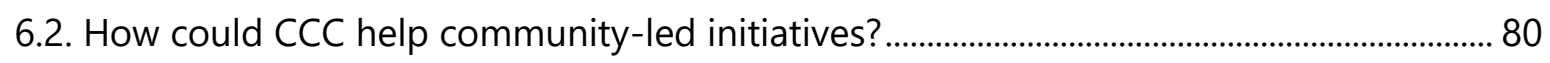

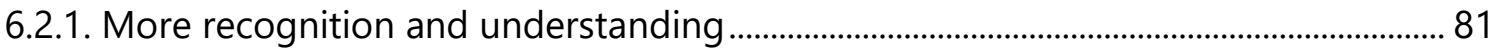

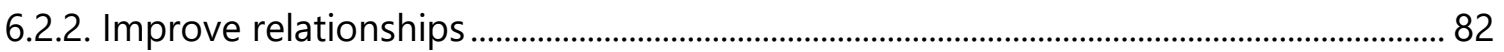

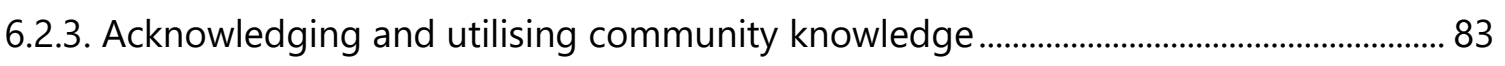

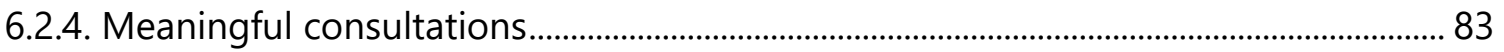

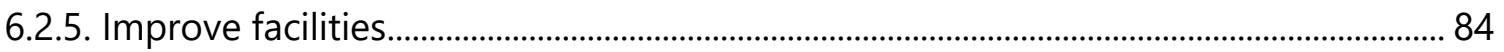

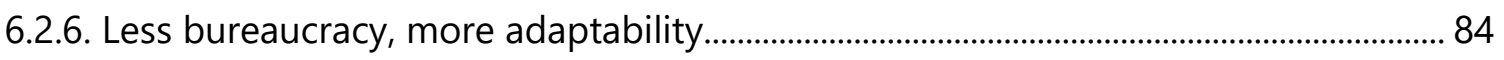

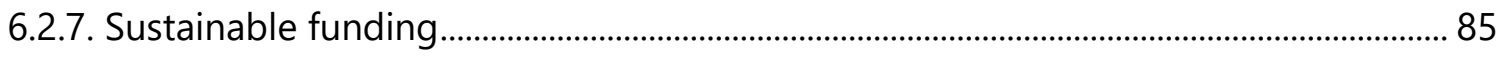

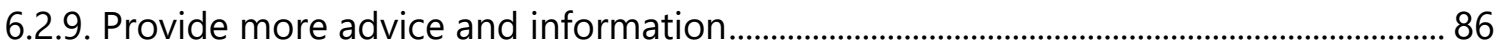

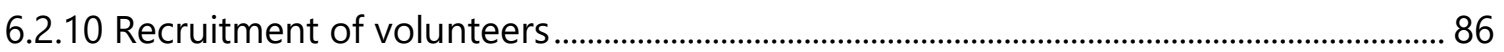

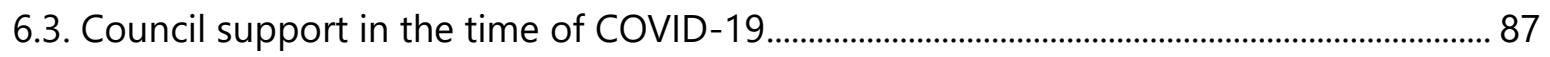

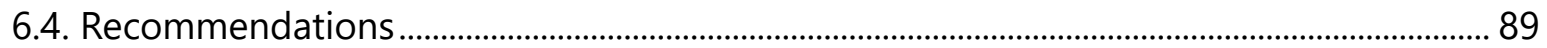

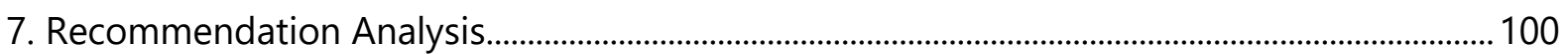

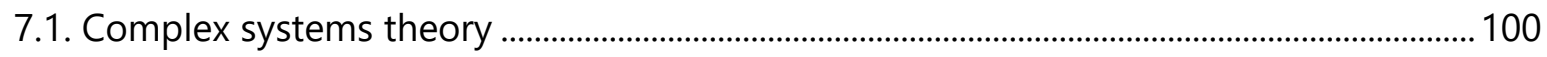

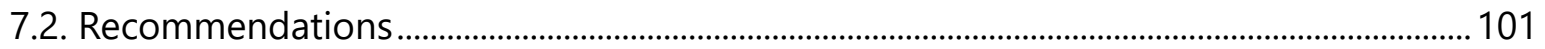

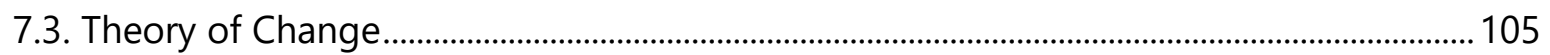

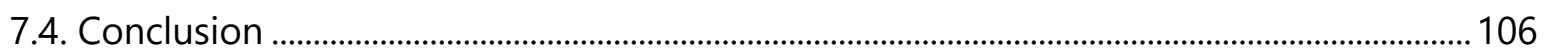




\section{Acknowledgements}

The report was conceptualised, researched and written with the help of Dustin McWherter, Amanda Askham and Cllr Mark Goldsack. We are extremely grateful for your invaluable support, which you gave despite the immense pressure on Council officers and members resulting from the COVID-19 pandemic. Thank you also to the many Council officers who gave anecdotal evidence for this report, and to the hard working and extremely committed community volunteers who gave up their time to respond to our questionnaire and take part in telephone interviews. 


\section{Executive Summary}

The health of our population is one of our nation's most important assets. Optimal health not only forms a central component of our happiness, but it is also vital for a strong economy. Despite this, reports suggest that population health is declining, with the average adult expected to spend $20 \%$ of their life in ill-health. Given the ever-increasing burden of noncommunicable disease, such as cardiovascular disease and obesity-related conditions, alongside our growing and ageing population, the need for adequate strategies to prevent illhealth has never been greater. However, as our healthcare model is relatively centralised, the development, coordination and delivery of comprehensive prevention strategies is incredibly difficult. This is not only because a central system cannot make strategies that are flexible enough to cater for every demographic, but also because the average person spends very little time engaged directly with formal healthcare services. To circumvent these issues, focus has turned to the communities in which people live, work and play as an asset to prevent ill-health and promote wellbeing.

By combining rapid literature reviews with surveys of Cambridgeshire-based community groups, this report aims to investigate the role that community-led initiatives play in improving the health and wellbeing of the communities they serve, and to further identify policies that can be updated or implemented in order to support communities in this pursuit.

\section{Key Findings}

Research from the UK and beyond has shown that: (1) communities can be empowered to provide their own solutions to health and social care issues affecting the local population; (2) supporting communities to improve population health and social care is largely beneficial, both socially and financially; and (3) community development can have a greater impact on population health and wellbeing than the healthcare system itself. This is supported by our survey of Cambridgeshire community groups, in which the majority stated that their initiative improves the mental and physical health of both service-users and volunteers. This is despite the rapid rate of growth in Cambridgeshire, which may hinder the success of community groups due to a relative reduction in social infrastructure and community cohesion. Nonetheless, growth has in fact been perceived to be largely beneficial by Cambridgeshire community group leaders due to increased participation and diversity. The COVID-19 pandemic further highlighted the flexibility, resilience and resourcefulness of such groups, with the voluntary, community and social enterprise sector being firmly at the forefront of the response. However, issues of inclusivity were highlighted within the research, with socioeconomically deprived communities having less support in this regard, and those individuals who form a minority in their community being underrepresented in community groups. Finally, although implementation of the Think Communities approach is transforming relationships between Cambridgeshire County Council (CCC) and community-led groups, our 
survey has identified a number of ways in which CCC could improve their support for such initiatives, through the Think Communities approach and beyond.

\section{Key Policy Recommendations}

From our research, we have identified a number of areas in which Council policy could be adapted in order to promote the creation of community-led initiatives and support them in the long-term by limiting the negative impacts of growth, with the ultimate aim of improving the health and wellbeing of the local population.

Our recommendations, which are introduced throughout the report and summarised in Section 7, are illustrated in our Theory of Change logic model on the following page. 


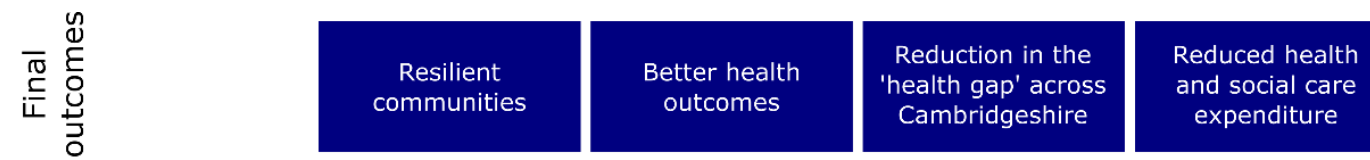

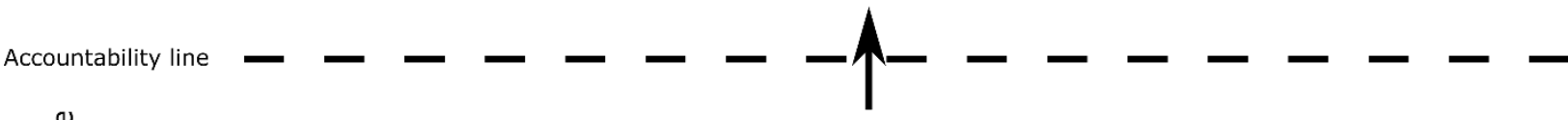

Community groups that are well-supported, accessible to all, working effectively and resilient in a context of rapid growth

A coordinated preventative health and social care network, consisting of the VCS, private and public sectors

Reduced burden on formal health and social care

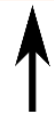

A coodinated County, District and Town Council workforce that understands the importance of community development and the utility of community-led groups

\begin{tabular}{l} 
The Think Communities partnership and place-based workforce \\
Volunteers who are educated about the needs in their community \\
\hline$\frac{1}{2} \quad$ VCS support infrastructure services that are well advertised, funded and accessible \\
\hline The NHS, linked to other enablers through social prescribers \\
Appropriate and affordable facilities \\
Developers \\
Private care providers
\end{tabular}

\begin{tabular}{|c|c|}
\hline \multirow{14}{*}{ 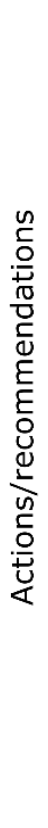 } & Support communities to devise their own solutions to local health and social care issues \\
\hline & $\begin{array}{l}\text { Map local community assets alongside needs in the Joint Strategic Needs Assessment to understand where the community } \\
\text { can add value, with additional insight work with marginalised communities }\end{array}$ \\
\hline & Support community centres and infrastructure in new developments \\
\hline & Include family homes in all new developments \\
\hline & Consider the effects of business growth on communities \\
\hline & Improve the provision of affordable venues in existing communities \\
\hline & Improve the advertisement of community-led groups to boost volunteer recruitment \\
\hline & Improve the County Council Directory of Services \\
\hline & Support volunteer continuity post-pandemic \\
\hline & Increase volunteer diversity \\
\hline & The Think Communities Partnership should prioritise provision of a framework for coordination and cohesion \\
\hline & Continue to expand Think Communities to cover all Council sectors, above and beyond Social Care \\
\hline & Support the provision of sustainable and accessible funding \\
\hline & Strengthen and assist voluntary and community sector (VCS) infrastructure support services \\
\hline
\end{tabular}




\section{Introduction}

\subsection{Why focus on health?}

The standard model of healthcare - in which an individual accesses centralised care when they become ill - is no longer working. With a population of almost 67 million $^{1}$, the United Kingdom can no longer rely on solely treating illnesses and must instead emphasise prevention of ill health. This is particularly relevant in relation to non-communicable diseases such as cardiovascular disease, obesity and type 2 diabetes, as the prevalence of these conditions is growing across the country. Likely due in large part to this 'epidemic of noncommunicable disease', we are predicted to spend around $20 \%$ of our lives in ill-health, and reports suggest that overall population health is declining, whilst health inequalities between affluent and socioeconomically deprived areas are growing rapidly ${ }^{2,3}$. By turning our focus to the prevention of these conditions instead of their treatment, we could not only improve the health and wellbeing of the population, but also save significant sums of money in the process. Reviews of international research suggest that investment in prevention has significant longterm benefits, with each $£ 1$ invested resulting in approximately $£ 14$ of social savings ${ }^{2}$. However, currently only $5 \%$ of healthcare funding is spent on disease prevention in the UK ${ }^{2}$. This is partially explained by the fact that the vast majority of the population spends less than $0.1 \%$ of their time within healthcare settings and thus do not have significant opportunities to engage in prevention strategies that are developed and delivered within the centralised healthcare system ${ }^{4}$. However, given that the average person spends the majority of their time in the community, and that a number of factors that can impact health and wellbeing are determined at the community level, such as feeling safe, valued and connected, it is reasonable to suggest that the key to health promotion may lie within our communities. This is the conceptual basis of our report, which focuses on how Cambridgeshire County Council (CCC) can better support community-led groups and initiatives to improve health outcomes around the County.

\subsection{The Cambridgeshire context}

\footnotetext{
1 'Population Estimates - Office for National Statistics', accessed 11 October 2020, https://www.ons.gov.uk/peoplepopulationandcommunity/populationandmigration/populationestimates. 2 'Prevention Is Better than Cure: Our Vision to Help You Live Well for Longer', GOV.UK, accessed 11 October 2020, https://www.gov.uk/government/publications/prevention-is-better-than-cure-our-visionto-help-you-live-well-for-longer.

3 'Health Equity in England: The Marmot Review 10 Years On', The Health Foundation, accessed 11 October 2020, https://www. health.org.uk/publications/reports/the-marmot-review-10-years-on.

4 'Head, Hands and Heart: Asset-Based Approaches in Health Care', The Health Foundation, accessed 11 October 2020, https://www.health.org.uk/publications/head-hands-and-heart-assetbased-approaches-in-health-care.
} 
In this section we will provide a brief introduction to the county of Cambridgeshire, focusing on population growth predictions and health needs and comparing them to the overall picture in England and the single districts within the county.

Generally, both Cambridgeshire and Peterborough are considered to be relatively rural areas, in which $50 \%$ of the UK's best quality agricultural land can be found, together with other natural assets such as wetlands, woodlands, natural grassland and freshwater sources. These are of both economic and social importance as they benefit the economy and provide recreation and health benefits to communities ${ }^{5}$. In addition to its many natural assets, Cambridgeshire and Peterborough are also business innovation rich and, during the last decade, they have both seen strong economic growth, which has surpassed that of the UK as a whole. There are substantial innovation opportunities in the area as well as financial support, especially in the sectors of informatics, software development, telecommunications and life sciences. In particular, Peterborough is the fourth fastest growing city in the UK and has a young population which brings further economic dynamism to the area. However, this growth pattern is not even across Cambridgeshire, and, even in areas of high growth, issues of deprivation and inequality persist, making Cambridge itself the most unequal city in the UK ${ }^{5}$. In general, it is not uncommon for wealthy countries to contain poorer regions. However, compared to most other wealthy countries, the UK seems to be exceptionally unbalanced regionally ${ }^{6}$, which is also reflected at a more local level in Cambridgeshire and Peterborough.

\subsection{Demographic and Economic Growth}

Each local authority (LA) can be classified as more or less deprived based on 7 main domains of deprivation:

1. Income

2. Employment

3. Education

4. Health

5. Crime

6. Barriers to housing and services

7. Living environment

These same rates can also be applied to health and disability deprivation in Cambridgeshire as shown in Table $1^{7}$.

\footnotetext{
5 'CPIER - Final Report', accessed 12 October 2020, https://www.cpier.org.uk/final-report/.

6 'Why Britain Is More Geographically Unequal than Any Other Rich Country', The Economist, 30 July 2020, https://www.economist.com/britain/2020/07/30/why-britain-is-more-geographically-unequalthan-any-other-rich-country.

7 'Cambridgeshire's Annual Public Health Report 2019', 2019, https://cambridgeshireinsight.org.uk/wp-content/uploads/2020/01/CCC-APHR-2019-final.pdf.
} 


\begin{tabular}{|c|c|c|c|}
\hline \multirow[t]{6}{*}{ Peterborough } & \multirow{6}{*}{$\begin{array}{c}20 \% \text { most } \\
\text { deprived LA } \\
\text { nationally and } \\
30 \% \text { most } \\
\text { deprived LA for } \\
\text { health and } \\
\text { disability }\end{array}$} & Cambridge & $\begin{array}{c}\text { 10-20\% least } \\
\text { deprived LA } \\
\text { nationally }\end{array}$ \\
\hline & & Cambridge City & $\begin{array}{c}\text { 30-40\% least } \\
\text { deprived LA }\end{array}$ \\
\hline & & $\begin{array}{c}\text { East } \\
\text { Cambridgeshire }\end{array}$ & $\begin{array}{c}10-20 \% \text { least } \\
\text { deprived LA }\end{array}$ \\
\hline & & $\begin{array}{c}\text { South } \\
\text { Cambridgeshire }\end{array}$ & $\begin{array}{c}10 \% \text { least } \\
\text { deprived LA }\end{array}$ \\
\hline & & Huntingdon & $\begin{array}{c}20-30 \% \text { least } \\
\text { deprived LA }\end{array}$ \\
\hline & & Fenland & $\begin{array}{c}20-30 \% \text { most } \\
\text { deprived LA }\end{array}$ \\
\hline
\end{tabular}

Table 1: Illustrates the deprivation scores assigned to Peterborough and Cambridgeshire, including at a district level, ranking them nationally?

The population density in Cambridgeshire and Peterborough is lower compared to the rest of England with an estimated population of 855,796 in 3,400 sq. $\mathrm{km}$, which is equal to $1.28 \%$ of the UK population ${ }^{5}$. However, there are pockets in both counties in which the population is denser compared to the national average. In fact, since 2011, the population has been consistently growing and is estimated to reach $1,029,940$ by $2036^{8}$. The driver of population change has been found to be almost equally natural population change and migration. Currently, the population is equally distributed amongst females and males, with a tendency of those living in Peterborough to be younger as opposed to those living in Cambridgeshire ${ }^{8}$. As the population increases, the proportion of individuals from each age group is also set to change, with a predicted decrease in the younger population and an increase in the older one as illustrated in Figure 1 below.

\footnotetext{
8 'Cambridgeshire Insight - Population - Local Population Estimates and Forecasts', accessed 12 October 2020, https://cambridgeshireinsight.org.uk/population/populationforecasts/?geographyld=3f57b11095784e27969369a52f7854ef\&featureld=E05002702.
} 


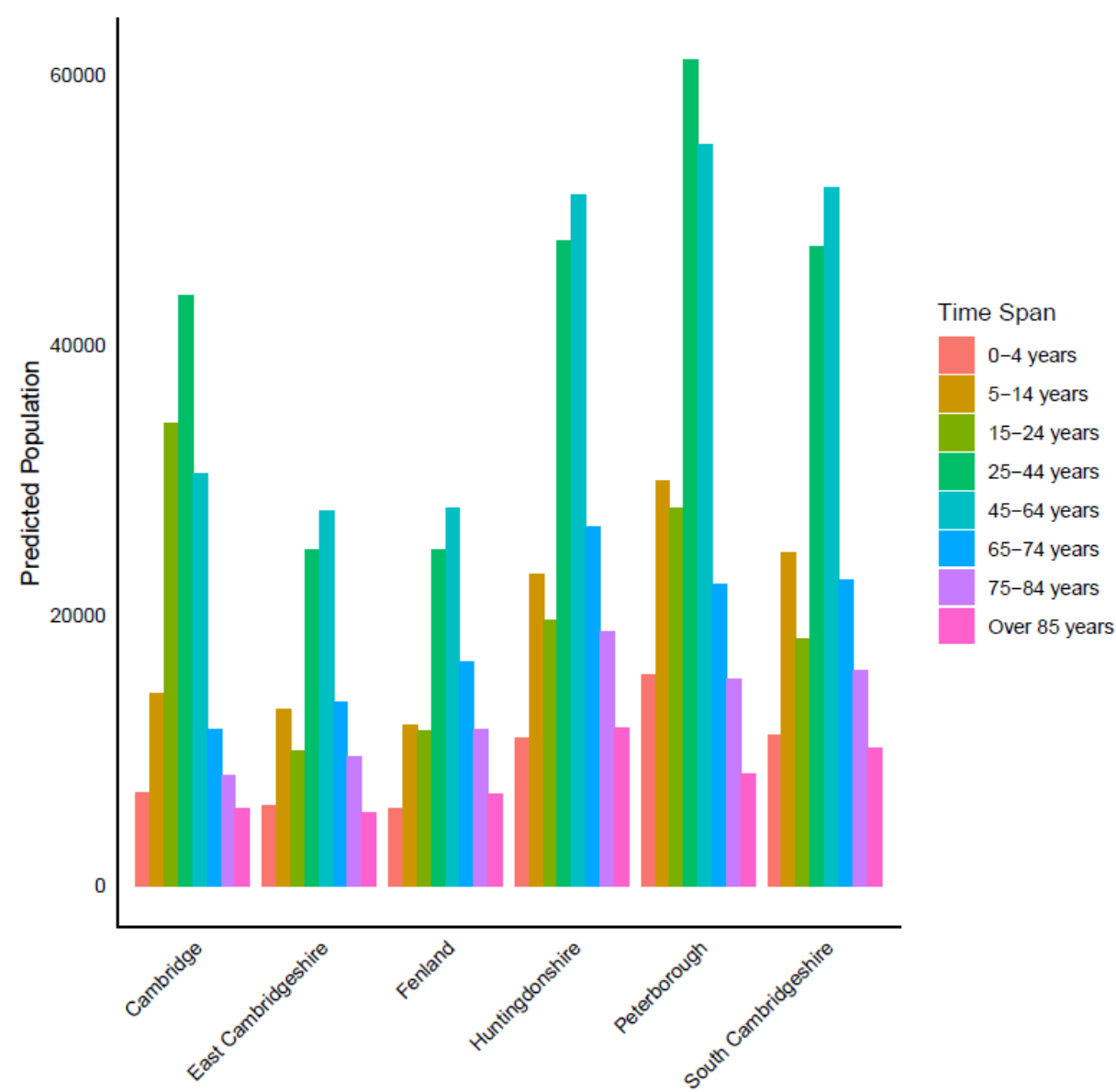

Figure 1: Predicted population growth for Cambridgeshire County. Data taken from ${ }^{9,10}$.

When considering ethnic diversity amongst the population, there are fewer people from ethnic minority groups in Cambridgeshire and Peterborough combined compared to the national average, despite the fact that, taken alone, Peterborough is more diverse and similar to the rest of England compared to Cambridgeshire, as illustrated in Figure $2^{9,10}$.

Following the release of land by Cambridge City Council and South Cambridgeshire District Council, Cambridgeshire has seen an expansion in housing and employment, in part sustained by the creation of the Cambridge Science Park, which has incentivised both national and international research institutes and laboratories to move to the area. These high value industries have contributed to increasing employment, resulting in an average employment growth rate of 3.3\% from 2010 to 2016 (details per district can be found in Figure 3), and an increase of the Gross Disposable Income per head of 11\% between 2011 and $2016^{5}$.

\footnotetext{
9 'Cambridgeshire Insight - Population - Census 2011', accessed 13 October 2020, https://cambridgeshireinsight.org.uk/population/census-2011/.

10 'Peterborough City Council Census 2011', Peterborough City Council, accessed 13 October 2020, peterborough.gov.uk/council/about-peterborough/census-2011.
} 


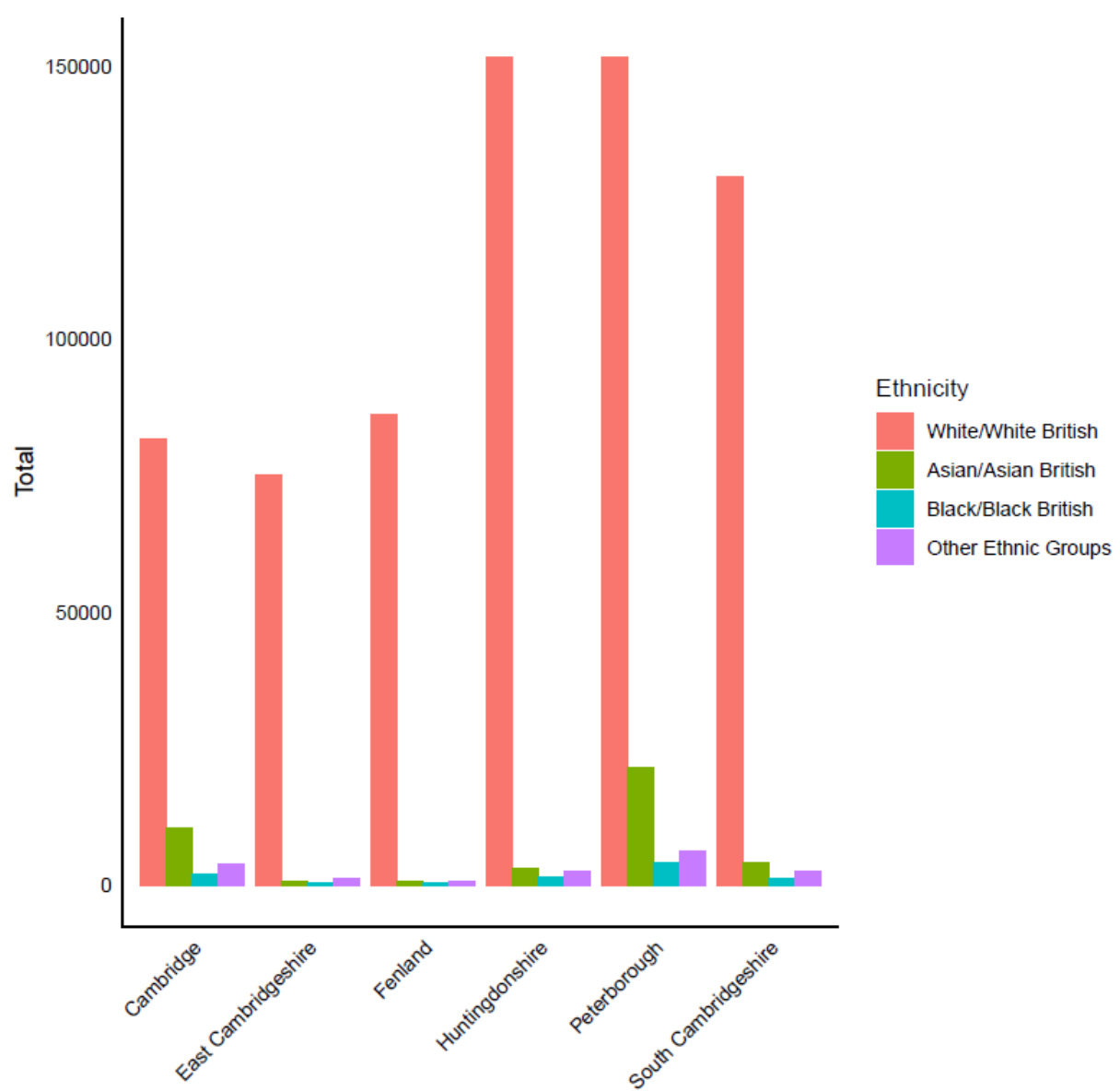

Figure 2: Ethnicity estimates for Cambridgeshire County. Data taken from ${ }^{9,10}$.

With regards to economic growth it is important to note that there are three main economic groups in Cambridgeshire and Peterborough: 1) The Greater Cambridge area, 2) The Greater Peterborough area, and 3) The Fens. However, when defining the main economic groups, it is also important to recognise that market towns also have a prominent role in defining the socio-economic pattern of Cambridgeshire, acting as a central hub for rural communities.

There are also limitations to growth which must be considered. These include the limited possibility of economic development in the fens, which have been classified as a flood zone 3 (where the land has a 1 in 100 or greater annual probability of river flooding, or a 1 in 200 or greater annual probability of sea flooding), and drought risks in both Cambridgeshire and Peterborough, but also the lack of infrastructure and affordable housing, which drives both the population and businesses away from the area. In fact, in both counties housing affordability has worsened compared to other areas of England, especially in Cambridge, South Cambridgeshire, and East Cambridgeshire, with a high proportion of income being spent on rent ${ }^{5}$. 


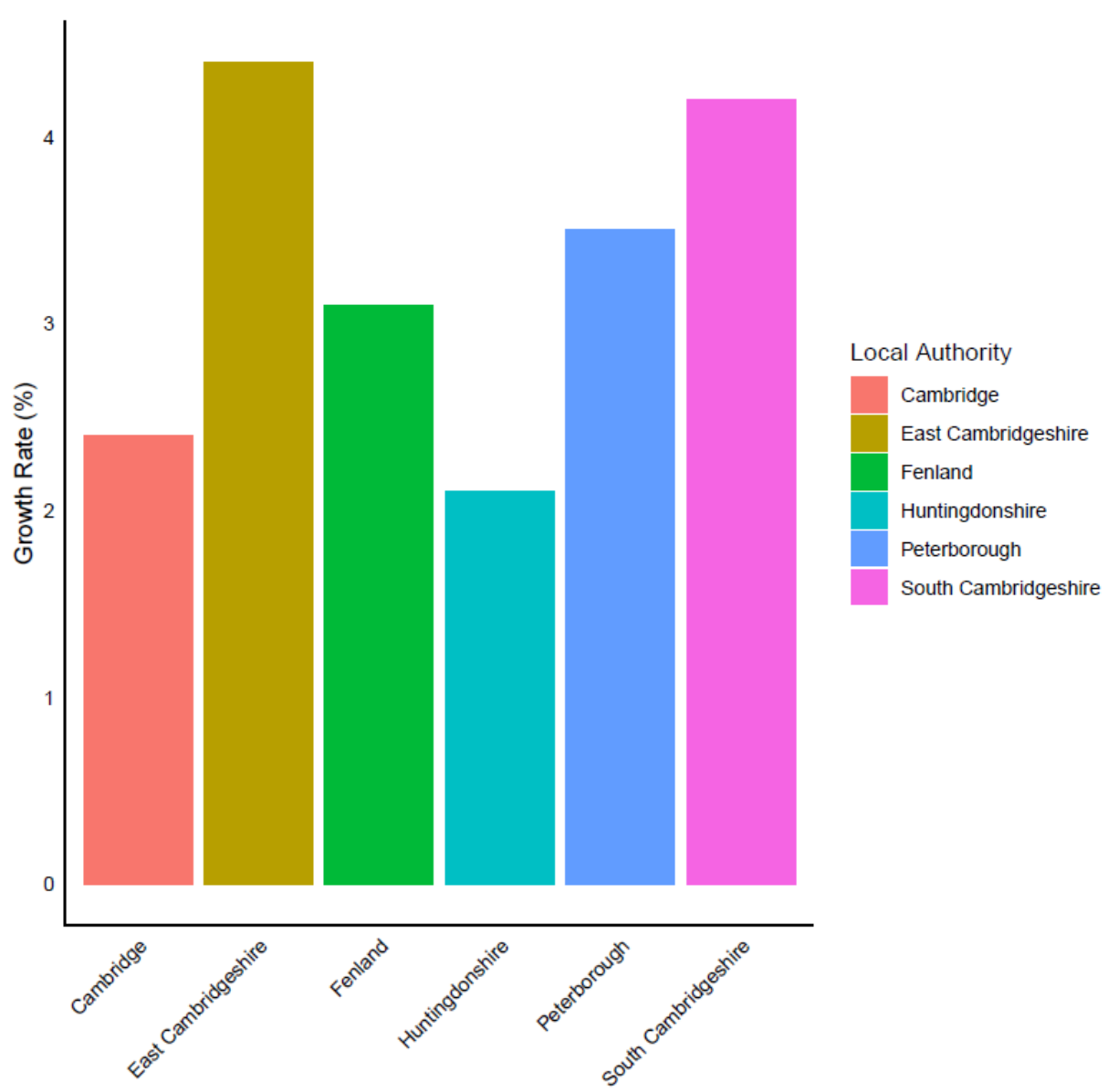

Figure 3. Employment growth rates for Cambridgeshire County. Data taken from ${ }^{9,10}$.

Particular attention should also be given to the increasing number of people who commute to work on a daily basis, which is known to have a detrimental effect on both health and wellbeing, not only does it affect the sleep cycle but it also represents an expenditure in time, cost and effort, as well as exposing people to pollution and potential travel related injuries. In addition, the effects of commuting impact the commuter both before, during and after the actual journey, with the potential of determining long-term related health issues ${ }^{11}$. In this respect, a significant number of people living and working in Cambridgeshire commute for over an hour a day, making Cambridge the fastest growing Travel to Work Area in the UK.

Another important economic and social issue is health and wellbeing, with the impact of health inequalities estimated to amount to national productivity losses of between $£ 31-£ 33$ billion per year, as well as lost taxes, higher welfare payments and additional NHS health care costs. These additional costs can be found amongst the extra spending associated with issues related to obesity, sedentary lifestyles, drugs and alcohol harm, mental health and cardiovascular disease, which reflects a systemic problem, requiring a solution which takes this into consideration $^{5}$.

${ }^{11}$ Kiron Chatterjee et al., 'Commuting and Wellbeing: A Critical Overview of the Literature with Implications for Policy and Future Research', Transport Reviews 40, no. 1 (2 January 2020): 5-34, https://doi.org/10.1080/01441647.2019.1649317. 


\subsection{Public Health Outcomes and needs in Cambridgeshire}

When considering the population overall, health and social determinants for Cambridgeshire and Peterborough combined are above national average, however there are disparities which must be taken into account. In fact, while Cambridgeshire compares well with England when considering health and wellbeing determinants, Peterborough presents more widespread issues. Great variability is also seen between Cambridgeshire districts, with particularly poor health outcomes in Fenland. Therefore, it becomes necessary to improve health determinants and outcomes in order to reduce health inequalities across the county, as illustrated in the following graph ${ }^{12,13}$.

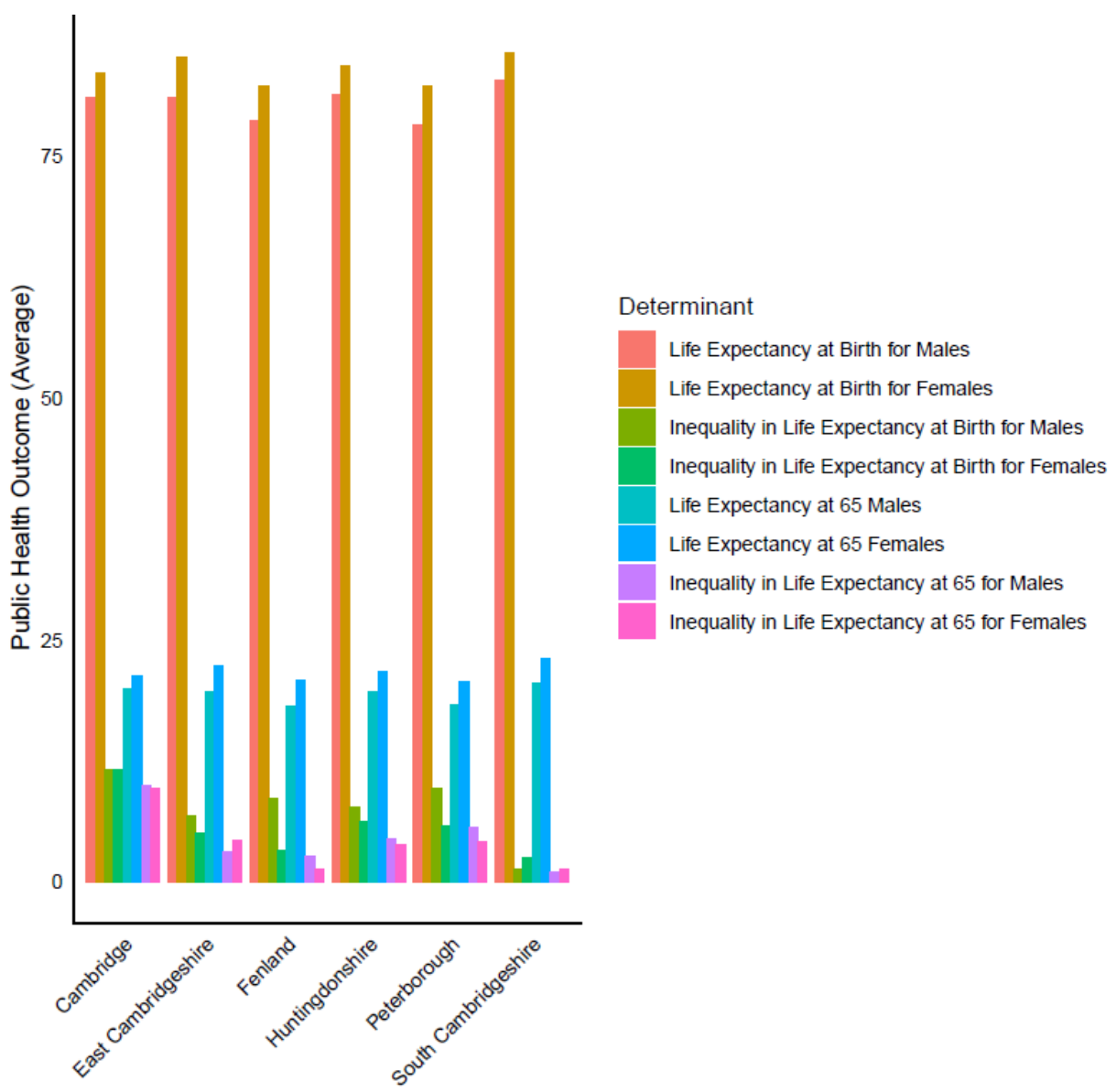

Figure 4: Public Health Outcomes for Cambridgeshire County. Data taken from ${ }^{12,13}$.

12 'Cambridgeshire and Peterborough Joint Strategic Needs Assessment, Core Dataset 2020', 2020, https://cambridgeshireinsight.org.uk/wp-content/uploads/2020/07/CP_JSNA_CDS_DRAFT_2020FINAL_PUBLISHED20200706.pdf.

13 'Public Health Outcomes Framework - PHE', accessed 12 October 2020,

https://fingertips.phe.org.uk/profile/public-health-outcomesframework/data\#page/0/gid/1000049/pat/126/ati/301/are/E06000015/cid/4/page-options/ovw-do-0. 
Different health priorities have been identified for both Cambridgeshire and Peterborough, as well as the indicators which have improved, remained the same or worsened since the last public health evaluations in 2019 and $2020^{12,14,15}$.

- For Peterborough there is a need to improve various health determinants and outcomes to reduce health inequalities such as child poverty, educational attainment, homelessness, violence, breastfeeding uptake, infant mortality, obesity in children and adults, physical activity, smoking prevalence, self-harm, incidence of hip fractures, incidence of TB, STI, life expectancy at birth, mortality due to cardiovascular disease and cancer, as well as premature mortality ${ }^{12}$.

The main health outcomes, which are statistically worse compared to England, are:

- Hospital admissions due to self-harm

- Average life expectancy for men and women

- Premature death from cardiovascular disease

- School readiness

- Percentage of adults who smoke and/or are overweight

Since the 2018 Annual Public Health report, there has been an improvement in teenage pregnancy rates, a reduced percentage of women who smoke during pregnancy and an increase in school readiness thanks to the development of the "Best Start in Life" strategy. However, these positive trends still need to be monitored to ascertain that the improvement will be sustained over time ${ }^{15}$.

- For Cambridgeshire, there is a need to improve various health determinants and outcomes to reduce health inequalities, especially amongst specific districts such as Cambridge and Fenland. Some of the main issues which need addressing are: school readiness, gap in the employment rate between those with a disability or in need of mental health services and overall employment rates, emergency hospital admissions (including self-harm and alcohol-related admissions), cancer and STI screening and vaccination coverage ${ }^{14}$.

Within Cambridgeshire, healthy life expectancy for females at 65 and the conception rate for under $16 \mathrm{~s}$ are significantly better than national average.

\footnotetext{
14 'Public Health Outcomes Framework: Key Changes and Updates for Cambridgeshire and Its Districts: May 2020', 2020, https://cambridgeshireinsight.org.uk/wp-content/uploads/2020/05/May2020-PHOF-update_Cambridgeshire.pdf.

15 'Peterborough Annual Public Health Report', Peterborough City Council, accessed 12 October 2020, peterborough.gov.uk/healthcare/public-health/annual-public-health-report.
} 
Factors which continue to be similar to national averages are disability-free life expectancy at birth for females, adults classified as overweight and the percentages of both physically active and inactive adults.

The main areas for which improvement is needed and values are below national averages are: hospital admissions for alcohol-related conditions, injuries on roads and self-harm ${ }^{12}$.

As mentioned above, within Cambridgeshire, differences can be found at a district level, as illustrated in Table 2, especially with regards to Fenland, in which there are many health and socio-economic issues ${ }^{14}$.

\begin{tabular}{|c|c|}
\hline DISTRICT & MAIN AREAS OF CONCERN \\
\hline Cambridge & $\begin{array}{l}\text { Homelessness, emergency hospital admissions (self-harm, } \\
\text { alcohol-related and falls in people over } 80 \text { years), cancer } \\
\text { screening coverage, abdominal aortic aneurysm screening } \\
\text { coverage, STI and diabetes diagnosis rates, tuberculosis } \\
\text { incidence. }\end{array}$ \\
\hline $\begin{array}{c}\text { East } \\
\text { Cambridgeshire }\end{array}$ & $\begin{array}{l}\text { Emergency hospital admissions (self-harm, road injuries, falls } \\
\text { in people aged } 65 \text { and over), abdominal aortic aneurysm } \\
\text { screening coverage, STI and dementia diagnosis rates, } \\
\text { antibiotic prescribing in primary care and mortality rate from } \\
\text { specific communicable diseases. }\end{array}$ \\
\hline $\begin{array}{c}\text { South } \\
\text { Cambridgeshire }\end{array}$ & $\begin{array}{l}\text { Emergency hospital admissions (unintentional injuries in } \\
\text { young people, self-harm and road injuries), STI detection } \\
\text { rate, estimated diabetes and dementia diagnosis rate. }\end{array}$ \\
\hline Huntingdon & $\begin{array}{c}\text { Percentage of overweight adults, percentage of physically } \\
\text { active and inactive adults, educational attainment, STI } \\
\text { detection rate, antibiotic prescribing in primary care and } \\
\text { excess winter deaths. }\end{array}$ \\
\hline Fenland & $\begin{array}{l}\text { Life expectancy at birth (males and females) and at } 65 \text { (males), } \\
\text { hospital admissions (injury, self-harm, alcohol-related, } \\
\text { emergency readmissions after } 30 \text { days), percentage of } \\
\text { overweight and physically active adults, deaths from drug } \\
\text { misuse, cancer screening coverage, STI detection rate, antibiotic } \\
\text { prescribing in primary care, mortality from preventable causes } \\
\text { and under } 75 \text { mortality rate for cancer (female) and respiratory } \\
\text { diseases, estimated dementia diagnosis rate. }\end{array}$ \\
\hline
\end{tabular}

Overall, in the Cambridgeshire and Peterborough Joint Strategic Needs Assessment various priority areas were identified across both counties ${ }^{12}$ :

Table 2: Main areas of concern related to health and wellbeing, for each district, which do not meet regional or national targets. Data adapted from ${ }^{12,14}$. 
- Improving health determinants and outcomes as well as reducing health inequalities (Peterborough, Fenland and Cambridge)

- Educational attainment (Fenland, Huntingdon and Peterborough)

- Alcohol abuse (Cambridge and Fenland) and smoking

- Mental health

- Severe road injury rates

- Percentage of overweight adults and physical inactivity as well as diabetes diagnosis (Peterborough and Fenland)

- Falls and hip fractures in older people

We must also consider which indicators that were better than national averages, are now more similar to the rates in England as a whole. In fact, different issues have been identified as a matter of concern, because although they generally remain better than the national average, their rates are increasing over time. In addition, it is possible to find pockets, at the small area level, of deprivation which are worse for certain determinants compared to the larger area or county they are part of. It is also important to consider that although some indicators are better than national averages, they can still affect many people, and may disproportionately affect those belonging to vulnerable groups or living in more deprived areas ${ }^{12}$.

Currently, healthcare services for Cambridgeshire and Peterborough are provided by the National Health Service (NHS) and Public Health England, and at a community level, by the local authorities for social care issues and the Cambridgeshire Community Services NHS Trust, which covers services for children and young people, dental care, physiotherapy and rehabilitation, neuro-rehabilitation, contraception and sexual health and immunisation services $^{16}$. Moreover, there are numerous healthcare initiatives, such as Everyone Health Cambridgeshire, which are supported by the council and have been established to support the community by promoting healthy lifestyle choices ${ }^{17}$.

There is a great opportunity for integrated health and social care in Cambridgeshire given the presence of a combined authority, strong presence of private health companies and the worldclass University of Cambridge School of Clinical Medicine, meaning that the Academic Health Network is incorporated in the health system itself 5 .

The CCC has already set up specific initiatives and policies to meet the growth predictions and consequent healthcare needs of a growing population, as well as to address some of the main issues mentioned above. These will now be described in more detail.

\footnotetext{
${ }^{16}$ Cambridgeshire and Peterborough Clinical Commissioning group, 'Community Services | Cambridgeshire and Peterborough Clinical Commissioning Group', accessed 13 October 2020, https://www.cambridgeshireandpeterboroughccg.nhs.uk/your-health-and-services/other-localservices/community-services/.

17 'Everyone Health', Everyone Health (blog), accessed 13 October 2020, https://www.everyonehealth.co.uk/cambridgeshire-county-council/.
} 


\subsection{Current policy landscape}

The CCC has established several policies to meet the growth and care needs across Cambridgeshire and Peterborough. These programs are numerous and vary in terms of their goals and scopes. However, in accordance with the central aims of this report, we will only review four of these initiatives: Adult Learning and Skills, Be Well Cambridgeshire, Let's Get Moving Cambridgeshire, and Safe+Well.

- Adult Learning and Skills (ALS) is a community learning service for adults, which due to the COVID-19 pandemic, has moved its services online. The program offers a wide range of courses, including but not limited to improvement of English and Maths proficiency, vocational skills and family learning. In addition to the paid services provided by ALS, several courses are also offered online at no cost (e.g. 'Employability Bootcamp - Get That Job', 'Food Safety - Lockdown Style', and 'Art History'). Importantly, both the proprietary and free courses are extremely diverse in their content, which bodes well for the future growth of Cambridgeshire by equipping residents with the skills and knowledge necessary to contribute to the economy and prosper in their personal lives ${ }^{18}$.

- Be Well Cambridgeshire (BWC) is a public health service covering all constituent counties except for Peterborough, which is instead covered by Peterborough City Council. In total, BWC performs five public health functions (list reproduced from the official website):

1. Helping protect people from the dangers of communicable diseases and environmental threats

2. Organising and paying for sexual health services

3. Providing specialist public health advice to primary care services: for example GPs and community health professionals

4. Organising and paying for height and weight checks for primary school children

5. Organising and paying for regular health checks for the population of Cambridgeshire

The program offers advice and directs residents to resources regarding mental health \& wellbeing, smoking, active living, alcohol, and healthy eating. Moreover, BWC provides links to various websites where Cambridgeshire residents can find pertinent health information and campaigns, including relevant reports organised by the County Council $^{19}$.

\footnotetext{
18 'Cambridgeshire Skills', Adult Learning and Skills, accessed 13 October 2020, cambsals.co.uk/.

19 'Be Well in Cambridgeshire', Be Well in Cambridgeshire, accessed 13 October 2020, bewellcambridgeshire.co.uk/.
} 
- Let's Get Moving Cambridgeshire is an initiative that encourages people of all ages to participate in physical activity (e.g. exercise and sport). Each district has an area representative as well as a list of the sports and events that are being organised locally. Its website contains resources with the latest government recommendations regarding ways to keep active and support for families as well as individuals ${ }^{20}$.

- Safe+Well is a living aid service that provides relief to individuals who are elderly, have a disability, have recently been discharged from hospital, or are carers for others. The website links to a questionnaire that enables those seeking help to identify the appropriate aid for them. Their offered services include occupational therapy, an advice line, and "local demonstration", the latter two being at no cost ${ }^{21}$.

Over the last few years, Cambridgeshire County Council has also begun to explore new ways of developing resilient, healthy communities through people-centred and place-based approaches that empower individuals to exercise greater autonomy in decisions affecting their own communities without substantial influence from the Council itself. In this report, we will frequently refer to two such initiatives. The first, Neighbourhood Cares, was a pilot project operational from October 2017 to October 2019 in two Cambridgeshire communities, St Ives and Soham ${ }^{22}$. The second, Think Communities, is a collaboration between CCC, the Cambridgeshire District Councils, and Peterborough City Council that works on a shared vision, approach and priorities for building community resilience across the county ${ }^{23}$.

The concept behind the Neighbourhood Cares Pilot (NCP) was for people to be able to access support from within their own communities, rather than having to rely on the NHS, Council or private health care services. This allowed support to be "tailored to meet their individual needs" whereby individuals were able to seek help in various forms including medical (e.g. stroke), social (e.g. loneliness), and mental (e.g. mourning a loved one).

An external evaluation of the NCP, which altogether serviced around 1,000 people, documented the program's effectiveness as well as provided suggestions for future improvement ${ }^{24}$. The report indicated that the NCP was regarded by many of the people it

\footnotetext{
20 'Home | Cambridgeshire | Let's Get Moving Cambridgeshire', accessed 13 October 2020, https://www.letsgetmovingcambridgeshire.co.uk/.

21 'Safe and Well - Cambridgeshire', accessed 13 October 2020, https://www.safeandwell.co.uk/cambridgeshire.

22 'Neighbourhood Cares', Cambridgeshire County Council, accessed 13 October 2020, cambridgeshire.gov.uk/residents/adults/organising-care-and-support/types-of-support/neighbourhoodcares.

23 'Think Communities', 2018, https://www.cambridgeshire.gov.uk/asset-library/importedassets/Think\%20Communities\%20Approach.pdf.

${ }^{24}$ Charlotte Black, 'Neighbourhood Cares Pilot: Final Report', 2019, https://cambridgeshire.cmis.uk.com/CCC_live/Document.ashx?czJKcaeAi5tUFL1DTL2UE4zNRBcoS hgo=Tqp4S7dAMXm\%2BDG\%2F7cMxmV5y3Rouc7ld6SqBAS7vigDWH5P3\%2Bd\%2FyaNA\%3D\%3 D\&rUzwRPf\%2BZ3zd4E7lkn8Lyw\%3D\%3D=pwRE6AGJFLDNIh225F5QMaQWCtPHwdhUfCZ\%2FL
} 
served, as "reliable and accessible" with the caregivers being labelled as "non-judgemental", "tenacious", "resilient" and "polite" (p. 17). Furthermore, in terms of effectiveness, the NCP was estimated to have prevented approximately 50 "unplanned hospital admissions", reduced need for residential care (for 7 clients), and significantly decreased client loneliness (p. 18). Last, but not least, the NCP carers themselves reported greater life satisfaction due to the autonomy afforded by the Council and the increased opportunity for novel skills development (p.18). The report hypothesised that one of the main causes underlying this success was the capability of direct and constant contact between carers, possibly due to the community-led nature of NCP (p. 18).

However, despite the overall positive impact and reception of the pilot, three main challenges emerged: 1) Lack of training, 2) Client engagement and 3) Assessment consistency. Carers expressed that they had hoped to have received more or earlier training related to team decision-making and management. Moreover, specifically for the Soham site, client engagement was thought to be greater due to the team being located at the local library, which was perceived by clients as "neutral, safe and non-stigmatised" (p. 18). Lastly, due to logistical inadequacies, monthly analysis was not readily available until late in 2018, which hindered quicker adjustment to issues that may have arisen. The Neighbourhood Cares pilot heavily inspired the formation of the Think Communities partnership in 2018, which seeks to change traditional approaches to service delivery by developing a framework that is peoplecentred, place-based and solutions focussed ${ }^{23}$. Prior to the COVID-19 pandemic, significant progress had been made in introducing the concepts of Think Communities across the sector, forming connections between the partners, and establishing a set of service delivery areas. Community engagement and the development of place-based data profiles and a workforce development programme had also begun. In order to deliver the objectives of Think Communities, CCC and health partners are forming a core team of place-based staff, including one Think Communities Coordinator for each District, and ten 'community connectors'.

Upon the onset of the COVID-19 pandemic, the Think Communities workforce were directed towards outbreak management and community support. They are currently working on 8 priorities:

1. Outbreak management

2. Support for carers

3. Support for older people

4. Increased take-up of Technology Enabled Care (TEC)

5. Support for children and adolescents

UQzgA2uL5jNRG4jdQ\%3D\%3D\&mCTIbCubSFfXsDGW9IXnlg\%3D\%3D=hFflUdN3100\%3D\&kCx1An S9\%2FpWZQ40DXFvdEw\%3D\%3D=hFflUdN3100\%3D\&uJovDxwdjMPoYv\%2BAJvYtyA\%3D\%3D=ct NJFf55vVA\%3D\&FgPIIEJYlotS\%2BYGoBi5olA\%3D\%3D=NHdURQburHA\%3D\&d9Qjj0ag1Pd993jsyO JqFvmyB7X0CSQK=ctNJFf55vVA\%3D\&WGewmoAfeNR9xqBux0r1Q8Za60lavYmz=ctNJFf55vVA\%3 D\&WGewmoAfeNQ16B2MHuCpMRKZMwaG1PaO=ctNJFf55vVA\%3D. 
6. Tacking food and fuel poverty and security

7. Improving social mobility

8. Implementing place-based commissioning

Another CCC initiative that is incorporating a Think Communities approach is the Future Libraries Initiative project. As part of this project, the Libraries First vision has been developed, which will put libraries at the centre of a person-centred, place-based model of service design and delivery. In collaboration with Think Communities, there are plans for a pilot to test a radical new approach to commissioning preventative services, with libraries as the commissioner.

In this report, we will investigate the effect of community development on the health and wellbeing of the local population, the effect of growth on said community development, and the ways in which the Council can support community development to effect positive change while decreasing the current socio-economic disparities which characterise the region. 


\section{Methods}

The research methods for this report consisted of a rapid literature review and a communitybased questionnaire which collected both qualitative and quantitative data. Lastly, five community groups were chosen based on their questionnaire responses for telephone interviews.

\subsection{Rapid reviews}

The rapid reviews aimed to relay a bird's eye view of the ways in which community-led initiatives can support the health and wellbeing of their members and in turn how growth can impact the formation and functioning of said community-led initiatives. Grey literature published by NGOs, charities and governing bodies were identified either through finger searching or upon recommendations from interviewees. Data gathered includes regional, national and international data, with the literature being presented not being exhaustive.

\subsection{Questionnaire}

The aim of our questionnaire was to gain insight into the opinions of people that run community-led initiatives in Cambridgeshire on three topics: 1) The effect of the CCC's decision making on their initiative, 2) The effect of growth on their initiative, and 3) The effect of their initiative on the health of their volunteers and service users. While surveys of Cambridgeshire community groups have been conducted frequently by the Cambridge Council for Voluntary Service (CCVS), data from these surveys were too general to answer our specific research questions. Furthermore, these surveys have been predominantly aimed at Support Cambridgeshire member organisations and, therefore, may not reach groups who are unaware of such support networks.

Community-led initiatives were contacted by email and identified using a combination of random and non-random sampling. Two databases of community-led initiatives were used the 2014 CCVS directory of Voluntary and Community groups in Cambridgeshire, and the CCC Directory of Services. Both databases were screened based on two criteria: 1) Cambridgeshirebased (including Cambridgeshire-based branches of national charities) and 2) Community-led (with no affiliation to CCC). Random sampling was additionally used on the basis that groups listed by the CCVS and CCC directories may have more contact with CCC than those which are not. In total, 606 groups were contacted and 146 responses (24.1\% response rate) were received, including 16 partial responses. Consent to collect and store the responses was requested at the beginning of the questionnaire. All data was stored and processed in accordance with the General Data Protection Regulation 2016, as detailed in our privacy policy.

\subsubsection{General information about the respondents}


A range of general information was collected from each of the respondents so that associations could be made between variables (age of group, type of group, size of group etc.) and particular opinions or problems. Most of the groups that responded were reasonably well established, with $76.6 \%$ of the groups being founded before 2015 (Figure 5). Nine groups had been set up in response to the COVID-19 pandemic.

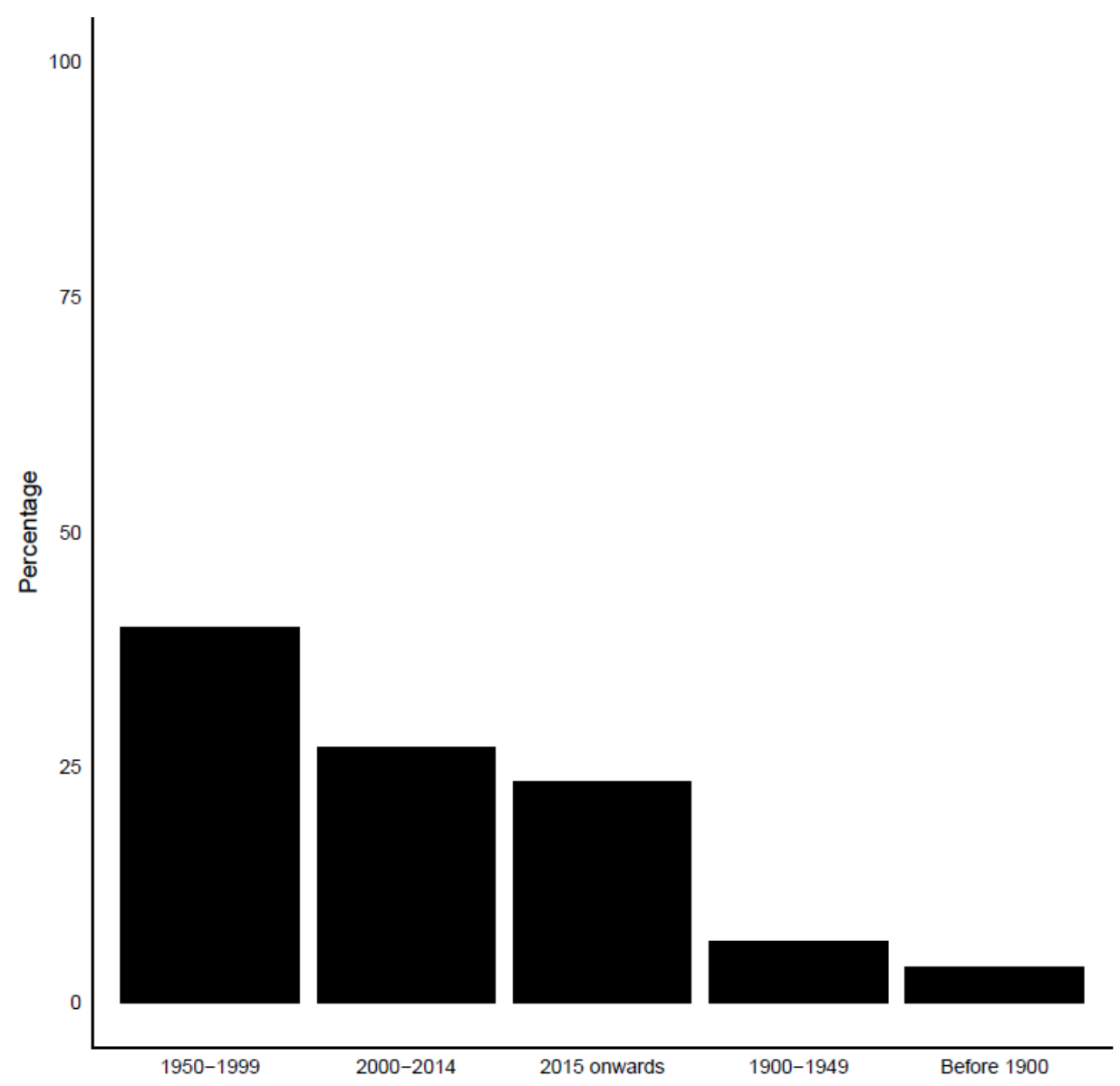

Figure 5. In what year was your organisation founded?

Although the majority of respondents were registered charities, a larger proportion of respondents were either unregistered charitable groups or clubs in comparison to the 2019 survey by the CCVS (Figure 6). We received responses from a wide range of groups based on both the category they come under (Figure 7) and the beneficiaries that they work with (Figure 8). 


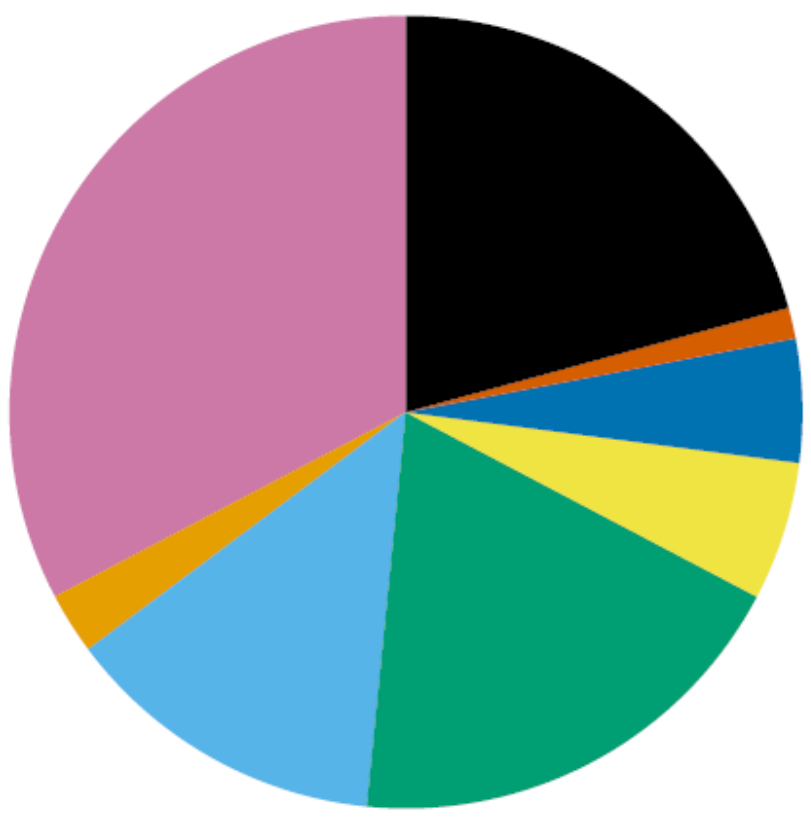

\section{Response}

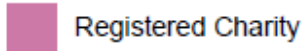

Company Limited by Guarantee

Unregistered Charitable Group

Club

Charitable Incorporated Organisation

Community Interest Company

Town or Parish Council

Other

Figure 6: What type of organisation is your initiative? Respondents were able to select more than one option.

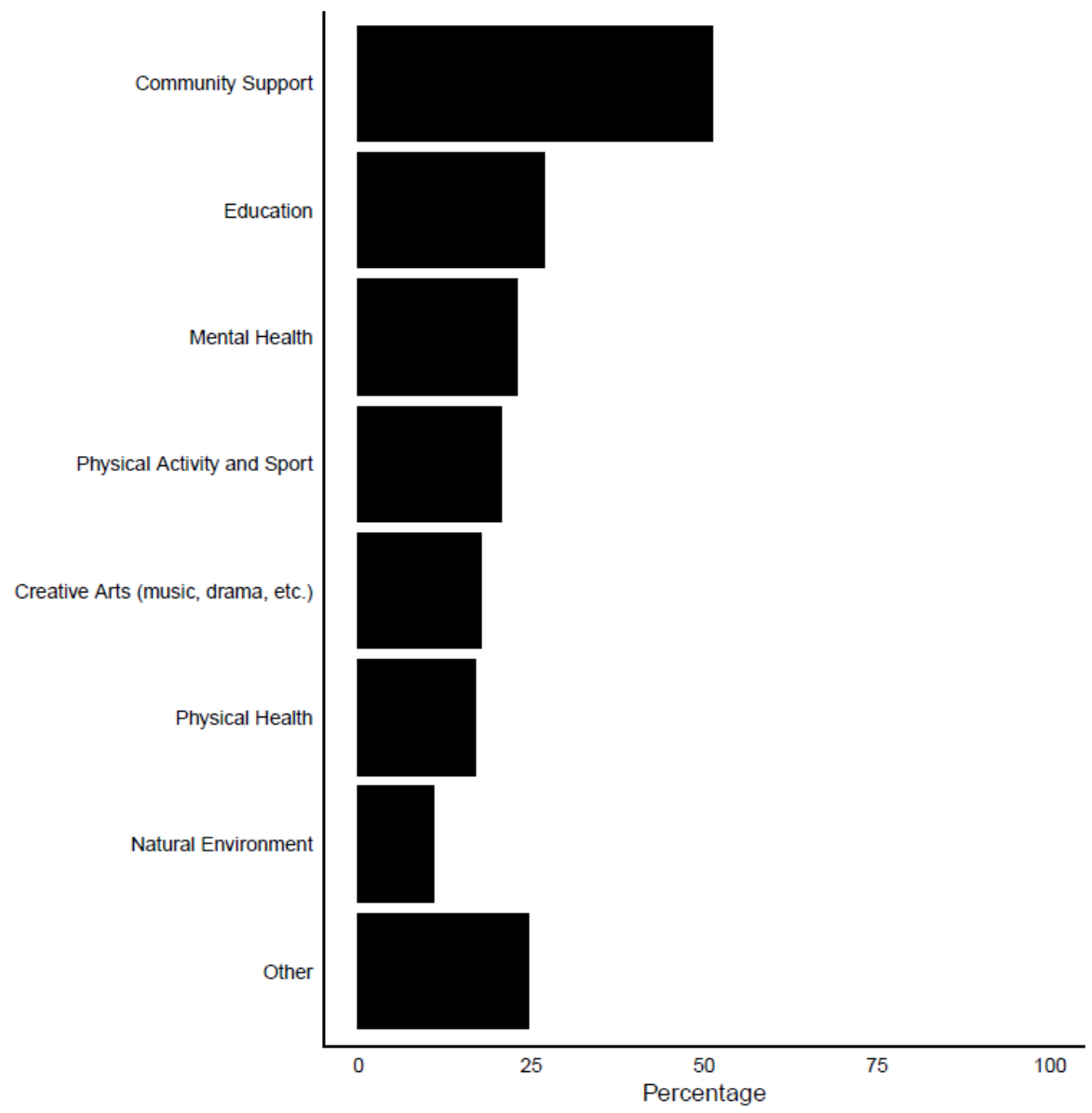

Figure 7: Which of these categories does your initiative fall under? Respondents were able to select more than one option. 


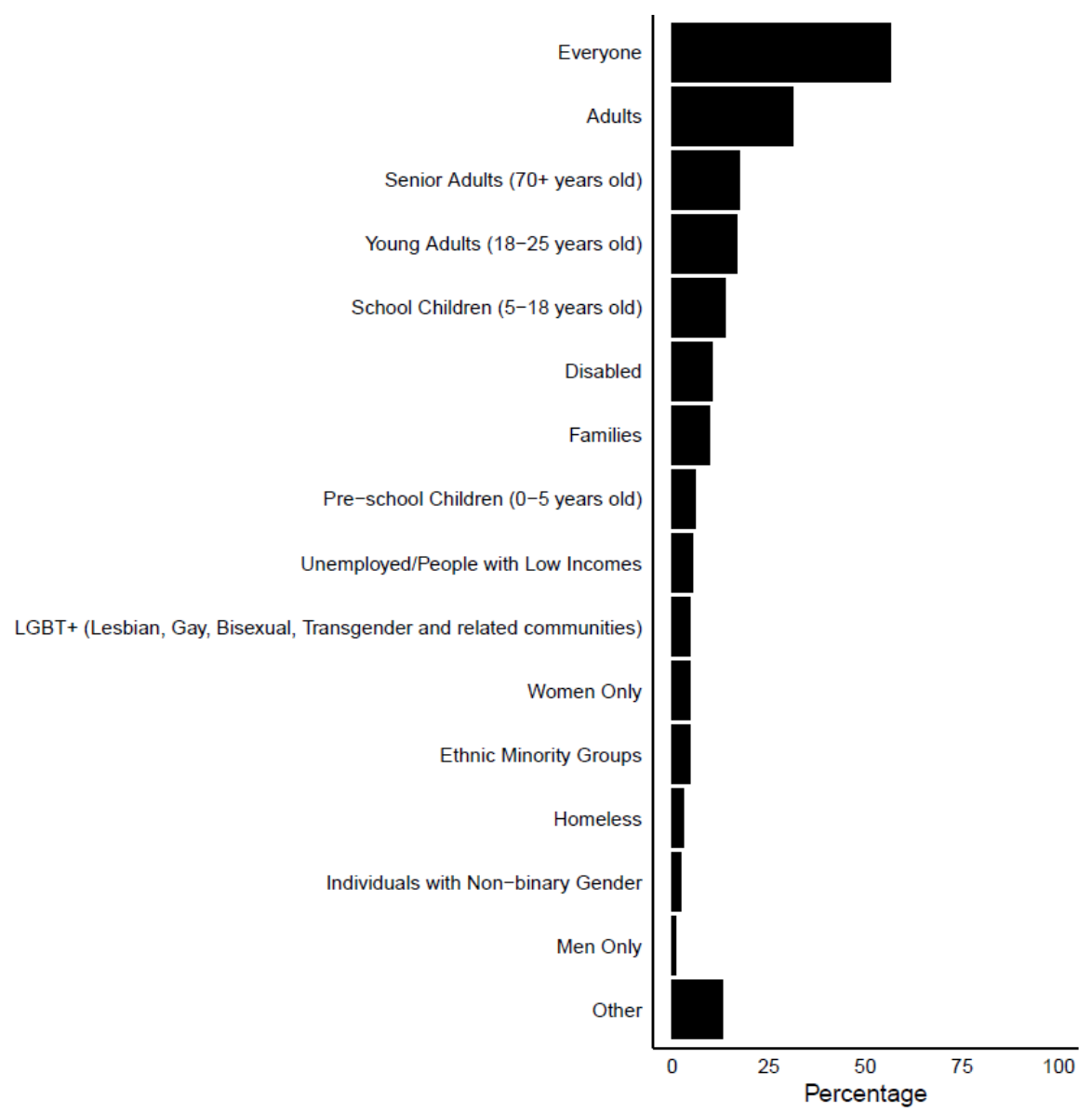

Figure 8: Which of these groups of people is your initiative aimed at? Respondents were able to select more than one option.

\subsubsection{Geographic location}

We also asked respondents which Districts their organisations operate in (Figure 9). As Cambridgeshire County Council (CCC) forms a Combined Authority with Peterborough, we included Peterborough as an option, although as the audience for our recommendations will be the County Council and not the Combined Authority, we did not actively seek out answers from groups that worked solely in Peterborough.

24.8\% of respondents said their organisation additionally works outside of Cambridgeshire (Figure 10). Out of these, most worked in the surrounding counties. Others noted that although their physical activities may be based in Cambridge, their online activities were open to all around the UK. 


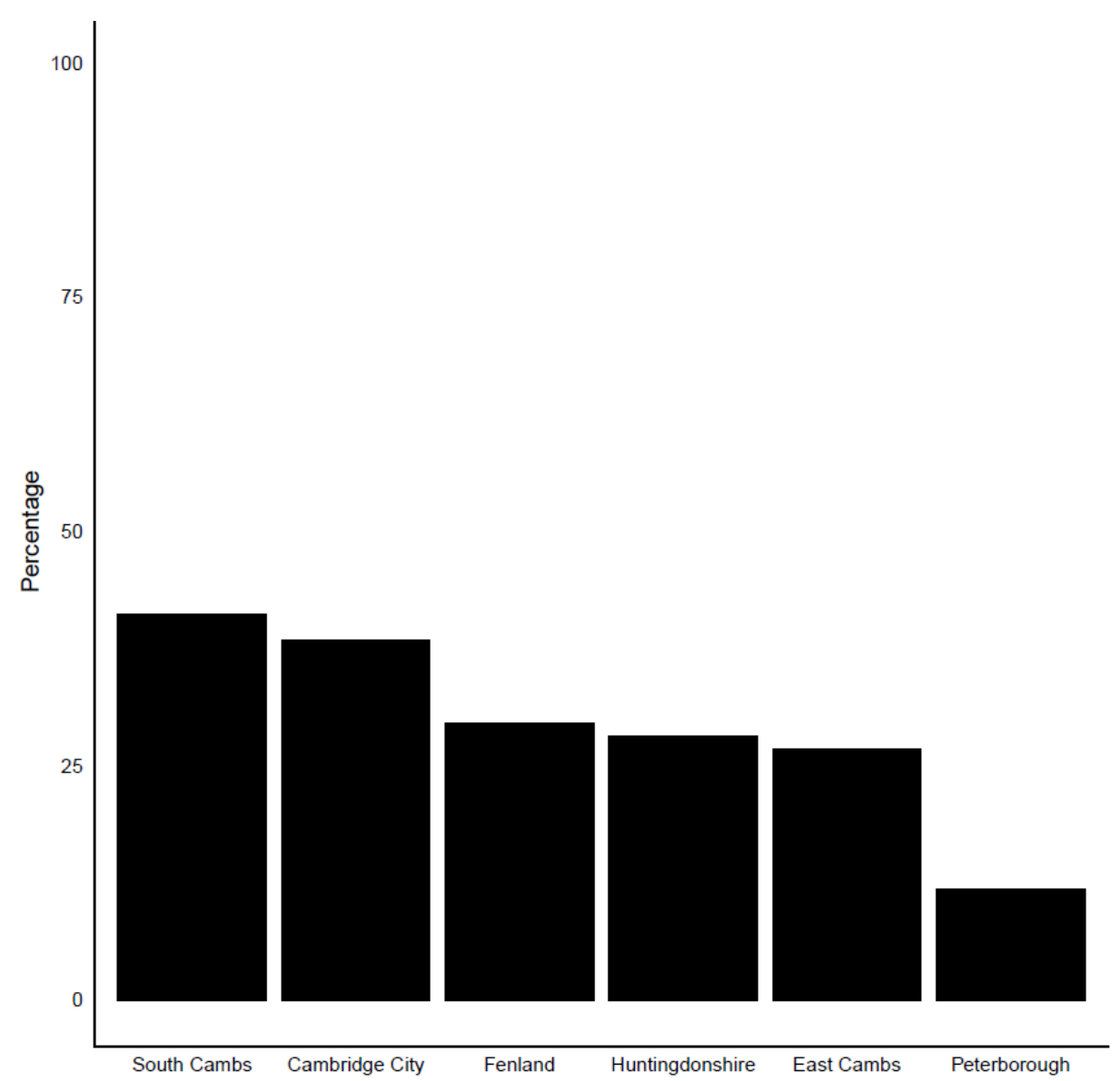

Figure 9: In which of these Districts does your organisation operate? Respondents were able to select more than one option.

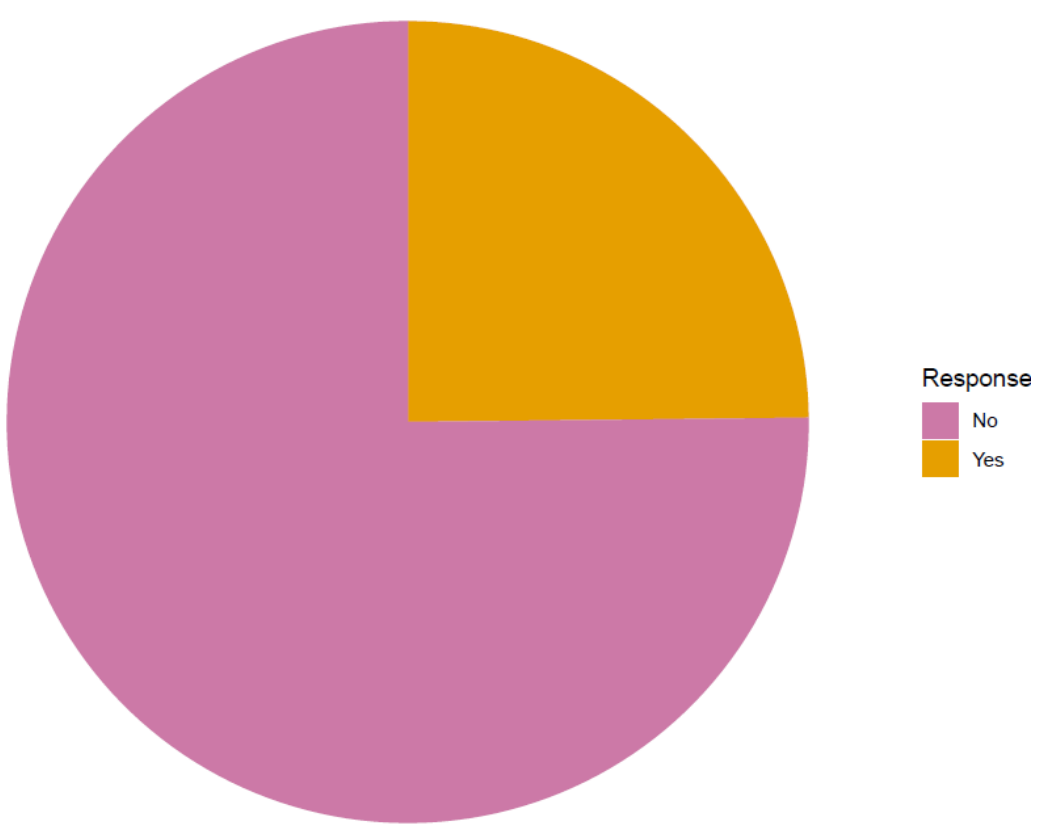

Figure 10: Does your work extend out of Cambridgeshire? 


\subsubsection{Size and economic status}

We then asked the organisations about their workforce and monetary income. The majority (71.0\%) of responding groups are run entirely by volunteers (Figure 11). Only $3.4 \%$ of the groups are run exclusively by paid staff, while over $40 \%$ of the groups reported having over 20 volunteers (Figure 12). Nearly half of all the groups said they have more than 50 beneficiaries of the service they provide (Figure 13).

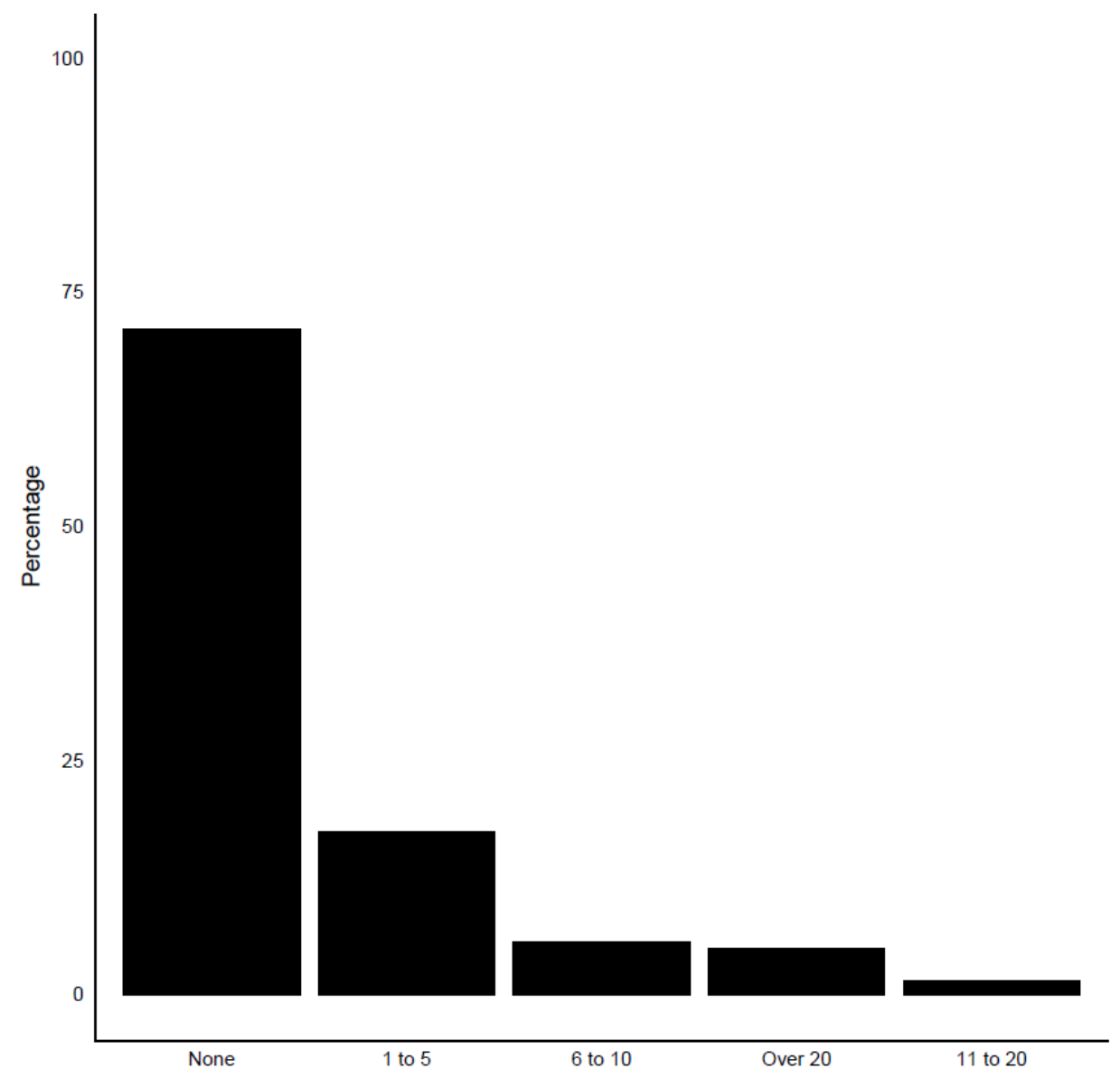

Figure 11: How many paid staff does your initiative employ? 


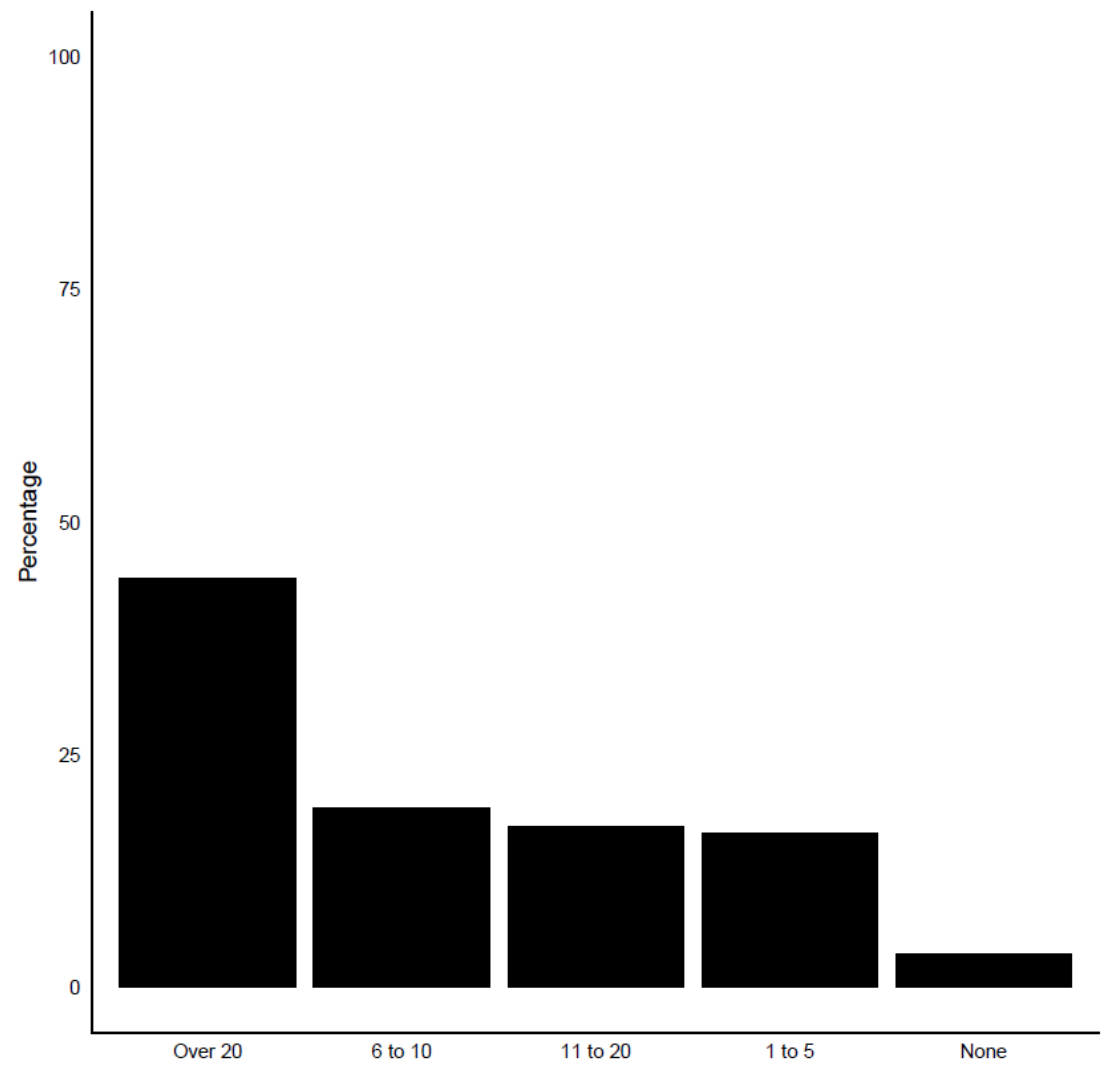

Figure 12: How many people volunteer for your initiative?

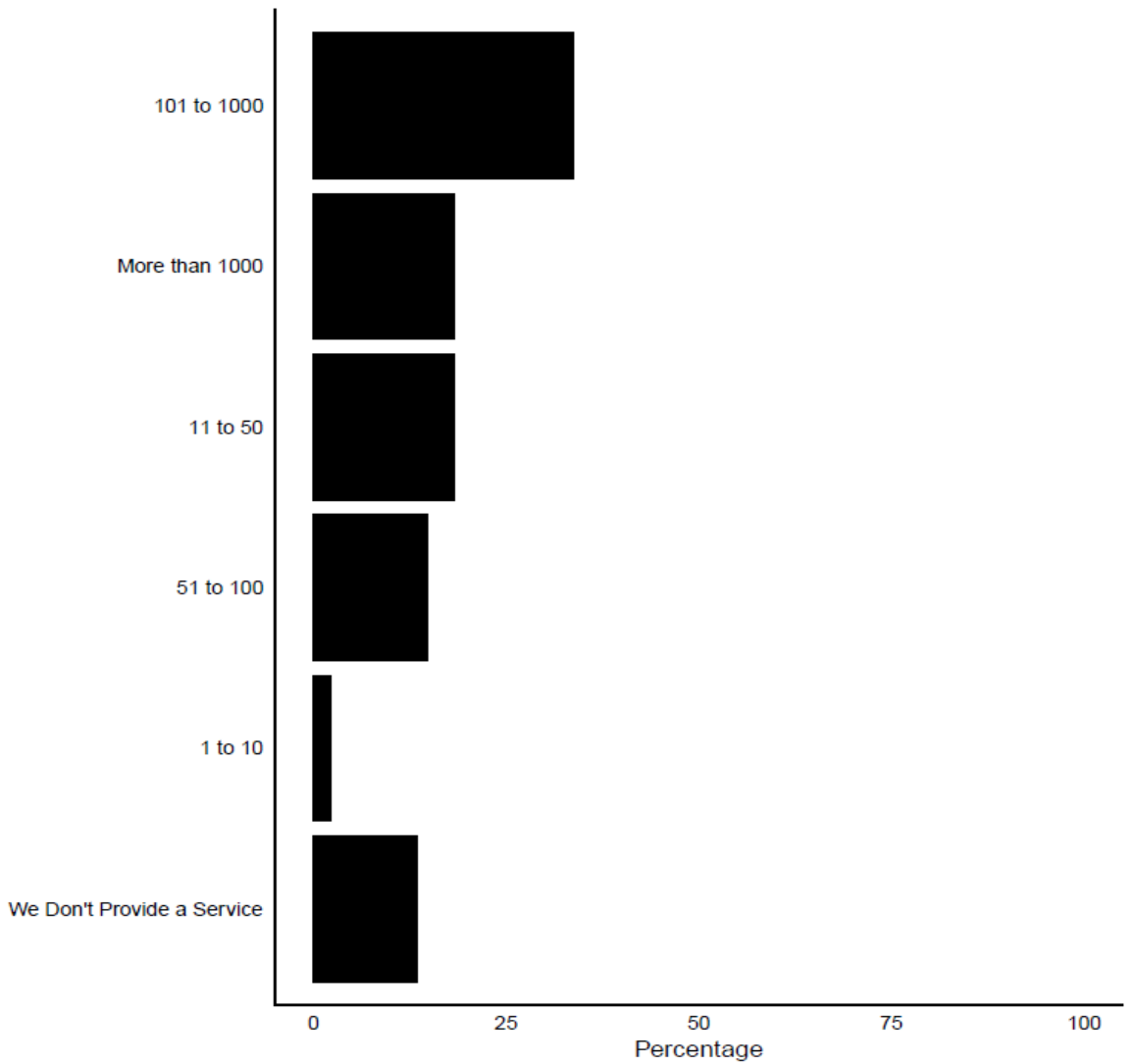

Figure 13: If your initiative provides a service, how many people benefit from your service? 
The annual income of the responding groups varied widely from none to more than $£ 100,000$ (Figure 14). The majority of groups that responded reported receiving either no income (16.8\%) or less than $£ 5,000$ per annum (37.8\%). Moreover, $29.0 \%$ of groups received funding from the Council (although it should be noted that respondents may have considered this to include District and Town councils), whilst the most common source of funding was from fundraising (Figure 15). Out of the groups that selected 'Funding from other sources' or 'Other', sources that were noted included Parish Councils, District Councils, Town Councils, donations, sponsorships, National Lottery funds, central government grants, selling products, social enterprise and personal funds.

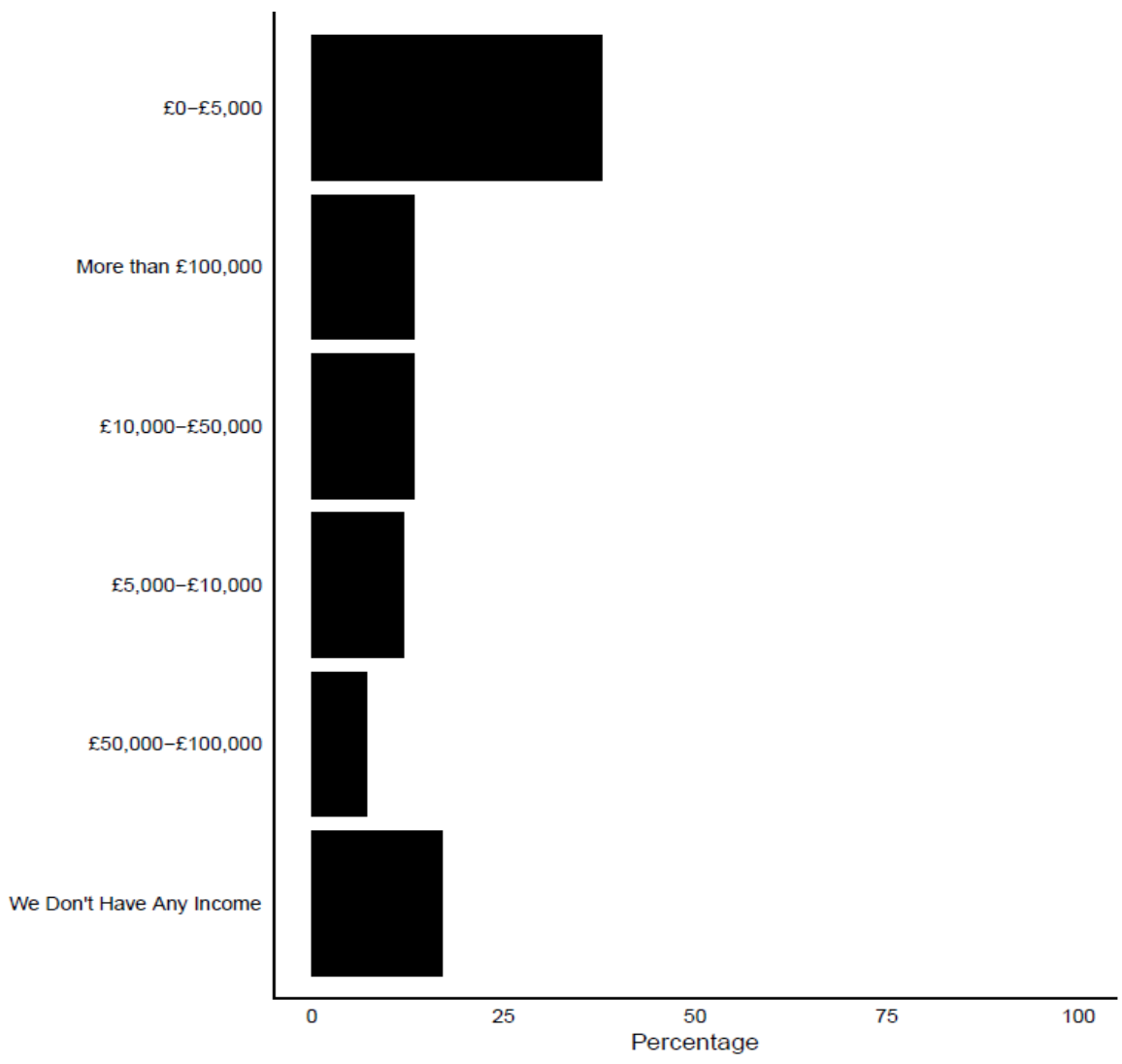

Figure 14. What is the annual income of your organisation? 


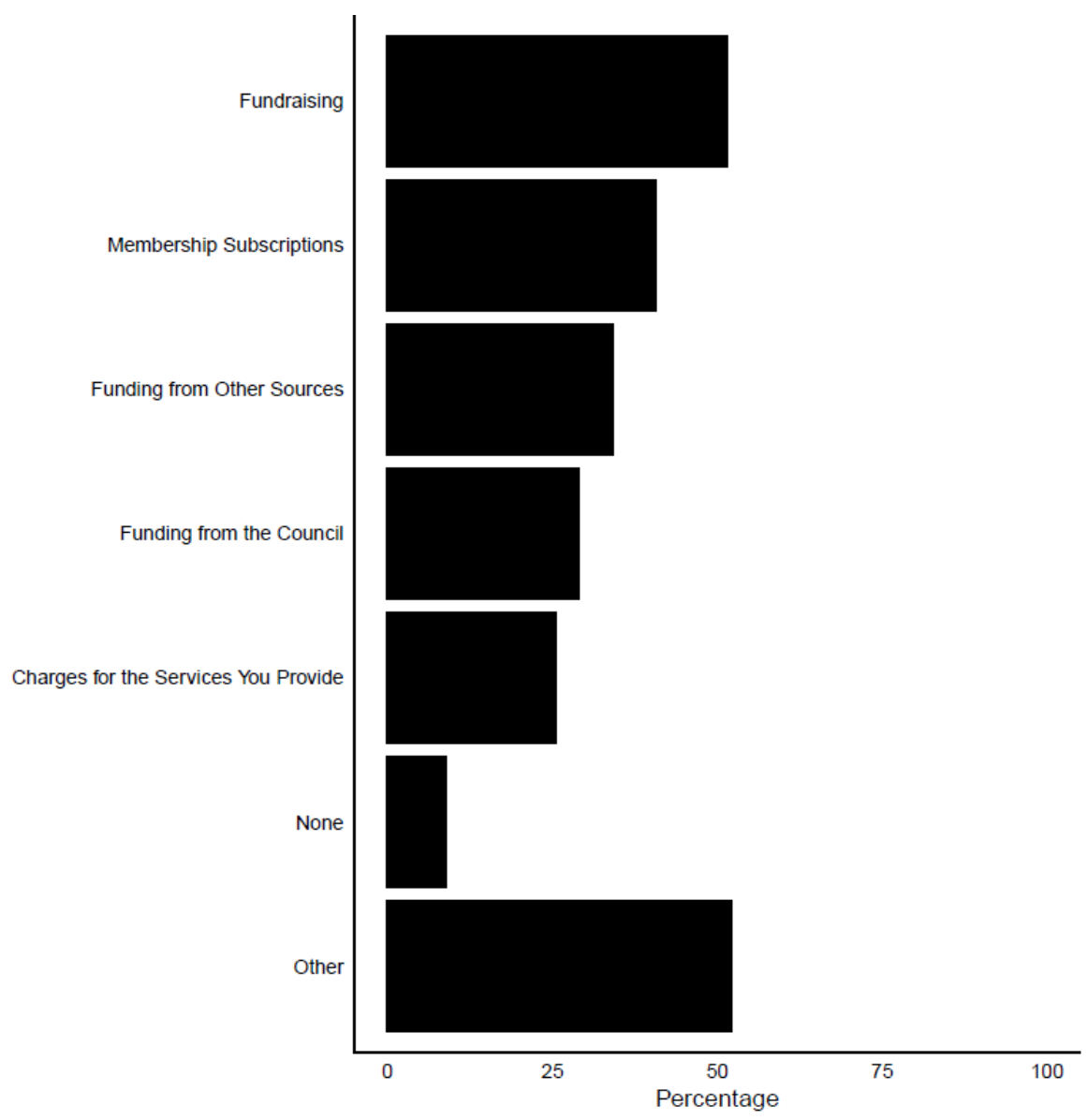

Figure 15: What forms of income do you receive? Respondents were able to select more than one option.

Together, these results indicate that we were reaching our target audience of small to medium community-led initiatives run predominantly by volunteers based in the community.

\subsection{Telephone interviews}

Based on survey responses, a number of community group leaders were selected for telephone interviews. Five people from five different community groups which came under the category of 'community support' (Figure 7) were interviewed. Two of these groups were based in Huntingdonshire, two in Cambridge City and one in South Cambs. These interviews were designed to gather more in-depth information about how each group operates, including the challenges that they face - particularly with respect to community growth and COVID-19 - and how Council policy may affect their initiative going forward. We also gathered anecdotal evidence of how the outcomes of each group may impact on the health and wellbeing of both volunteers and service-users. Opinions from these interviews are embedded throughout this report.

For sections 4-6, further insights were gained from interviews with workers from CCC and Urban and Civic, with anonymity of the interviewees being respected throughout the report. 


\section{Community-led initiatives lessen the need for formal health and social care services}

When the NHS was established in 1948, a centralised model of healthcare was adopted. Local authority and volunteer hospitals were taken over and incorporated into a single national hospital service. This meant that support within the community was largely limited to general practitioners and family members. However, in the modern world where chronic, lifestyleassociated conditions prevail, and in which our population is not only ageing but is growing ever-faster, a 'one size fits all' approach that focuses solely on treatment and largely ignores prevention will no longer suffice. A focus on prevention of ill-health is required, within a system that is sufficiently flexible to address the varying needs and priorities of disparate communities across different areas of the country. As this is not possible in a traditional centralised model of healthcare, we need to rapidly develop an alternative model to prevent the health of the nation from deteriorating irrevocably. One such alternative approach is to adopt and develop community-based healthcare.

\subsection{Community engagement in healthcare commissioning}

A community is defined as a group of people that share a geographic location, or as a group of people united by more abstract factors such as ideology, demography, ethnicity, or common goals $^{25}$. Communities were identified as 'major drivers of service improvement' in healthcare by a Labour government White Paper that demonstrated that individuals were no longer satisfied with the centralised model, and wanted to make choices about their own health and wellbeing ${ }^{26}$. As such, the National Institute for Health and Care Excellence (NICE) added recommendations to their national guidance in 2008 to promote community engagement in the design and development of health and social care services in order to address the needs of the community it serves ${ }^{27}$. Since then, a number of studies have found significant benefits in involving communities in the development of health services. One systematic review of 49 studies demonstrated that community involvement in this capacity has a positive impact on health at both the individual and community level ${ }^{28}$. An excellent example of this approach -

\footnotetext{
${ }^{25}$ Committee on Valuing Community-Based, Non-Clinical Prevention Programs, Board on Population Health and Public Health Practice, and Institute of Medicine, An Integrated Framework for Assessing the Value of Community-Based Prevention (Washington (DC): National Academies Press (US), 2012), http://www.ncbi.nlm.nih.gov/books/NBK206926/.

26 'Our Health, Our Care, Our Say: A New Direction for Community Services', GOV.UK, accessed 14 October 2020, https://www.gov.uk/government/publications/our-health-our-care-our-say-a-newdirection-for-community-services.

27 'The Effectiveness of Community Engagement Approaches and Methods for Health Promotion Interventions', 2008, 226, https://www.nice.org.uk/guidance/ph9/documents/health-promotionevidence-review-final2.

${ }^{28}$ Victoria Haldane et al., 'Community Participation in Health Services Development, Implementation, and Evaluation: A Systematic Review of Empowerment, Health, Community, and Process Outcomes', PLOS ONE 14, no. 5 (10 May 2019): e0216112, https://doi.org/10.1371/journal.pone.0216112.
} 
albeit outside of the United Kingdom - is the Southcentral Foundation in Alaska; a not-forprofit that provides generalist community healthcare in a decentralised model. The community is actively involved in the design and management of its own care, participating in advisory groups and taking part in strategic planning. This model has transformed the community from being simply service users to being 'customer-owners' of their own care, and as a result has strengthened community relationships, improved care coordination and has led to substantial reductions in A\&E attendances and hospital admissions, with health outcomes in this region being among the best in the United States of America ${ }^{29}$. On the basis of outcomes such as these, the British government is running programmes to facilitate community engagement in the design and commissioning of health services, such as championing 'Community Organisers' and 'Citizen Commissioners' to listen to the problems of the community, come up with shared solutions and advocate for the community on commissioning decisions ${ }^{30}$. However, whilst this is all certainly positive, there is an argument to go even further than this, by supporting community development in order to empower communities to provide their own health and social care solutions themselves.

\subsection{Community development for health and wellbeing}

Studies show that the communities we are born, live, work, and socialise in have a greater impact on our health than the healthcare system itself ${ }^{31}$. This suggests that the community itself could serve as an asset that can contribute to the health and wellbeing of those belonging to it, outside of the formal health services provided for that community. In fact, the NHS 5 Year Forward View of 2014 set out a vision for the NHS as a 'social movement', stating that the NHS would be unsustainable without community support, and setting out a priority to strengthen communities in order to improve factors that affect their health without relying on formal health and social care services ${ }^{26}$ The key to communities being a tool to improve health and wellbeing is the fact that communities not only have health needs, but they also have health assets. These assets not only include the built environment, such as community centres and green spaces, but also the skills, knowledge and social networks of the people who belong to the community. Given that the average person spends less than $1 \%$ of their time interacting with formal healthcare services, it is not surprising that relying on these services to effect health promotion and ill-health prevention is often ineffective. However, empowering communities where individuals spend the majority of their time - to use their assets to achieve this same goal promises to be a much more constructive strategy, as individuals can generally access support from their community more easily than from formal health services. Communities tend

\footnotetext{
29 'Reimagining Community Services', The King's Fund, 23 January 2018, https://www.kingsfund.org.uk/publications/community-services-assets.

30 'Civil Society Strategy: Building a Future That Works for Everyone', GOV.UK, accessed 14 October 2020, https://www.gov.uk/government/publications/civil-society-strategy-building-a-future-that-worksfor-everyone.

31 'Communities and Health', The King's Fund, 14 February 2018, https://www.kingsfund.org.uk/publications/communities-and-health.
} 
to have greater insight into, and understanding of, the needs and desires of their own community than local government or local healthcare providers and, as such, are often able to identify and address the root causes of health and social care issues in a more direct manner than any formal service. Consequently, empowering members of a community to work together can produce numerous benefits to community health and wellbeing.

\subsection{The ways in which community development improves health and wellbeing}

The term 'health' does not only describe the absence of illness; it is also the ability of individuals to achieve their potential throughout their lifetime. It has long been recognised that human beings have various needs that should be met to facilitate this pursuit. Abraham Maslow posited the 'Hierarchy of Needs' in 1943 to explain what motivates humans and to similarly explain the needs that must be fulfilled to achieve happiness, wellbeing and, by extension, health ${ }^{32}$. Whilst recent advancements in psychological research have suggested that these needs are more interdependent than previously assumed, they are still considered vital for optimal human health and wellbeing (Figure 16) ${ }^{33}$.

When considering community development in the context of health, we can use this hierarchy to posit why community-led initiatives may be beneficial:

- The act of coming together as a community in a common pursuit, whatever that pursuit may be, is highly likely to address the 'Belongingness and love needs' by generating friendships and social networks. As such, this is likely to improve health and wellbeing, as societal need fulfilment has been shown to be predictive of subjective wellbeing (see 'Case Study: Forever Manchester, Manchester') $)^{34}$.

- Depending on the output of the initiative, it may also address 'Esteem needs', for example, if the initiative encourages participants to make things that will then give the participant a sense of accomplishment when complete. This could include sewing groups, Men's Sheds (see Section 3.5), cookery clubs etc.

- Initiatives may even support the pursuit of 'Self-actualization' if they consist of creative activities that align with the beliefs and desires of the participants.

In this way, community initiatives in almost any form are likely to have a positive impact on the health and wellbeing of those who take part.

\footnotetext{
${ }^{32}$ A. H. Maslow, 'A Theory of Human Motivation', Psychological Review 50, no. 4 (1943): 370-96, https://doi.org/10.1037/h0054346.

${ }^{33}$ Craig Harper, 'Transcending Maslow's Pyramid: A New Hierarchy of Human Needs', Medium, 14 April 2020, https://medium.com/open-psychological-science/transcending-maslows-pyramid-a-newhierarchy-of-human-needs-2ca50a49af35.

${ }^{34}$ Louis Tay and Ed Diener, 'Needs and Subjective Well-Being around the World', Journal of

Personality and Social Psychology 101, no. 2 (2011): 354-65, https://doi.org/10.1037/a0023779.
} 
Belongingness and love needs, esteem needs and self-actualisation all rest above as they rely on physiological and safety needs to be met before they can be achieved. However, they are placed next to each other and overlapping as they are interdependent.

The aspect of 'Belongingness and love needs' is worth considering further. Community groups provide, almost regardless of output, an opportunity for community members to come together and socially interact. This social interaction is notoriously undervalued as a tool to improve wellbeing and, by extension, health, but it is essential. Loneliness increases the risk of mortality by $26 \%$, thus community-led interventions are important tools to prevent social isolation and associated premature death ${ }^{35}$. Social interaction has also been shown to improve health behaviours, such that people engage more in health-seeking behaviours such as exercise and healthy eating, as well as engage less in risk behaviours such as smoking and drinking ${ }^{36}$. Given that such behavioural patterns are estimated to be responsible for $40 \%$ of all premature deaths, and that social networks are as powerful predictors of mortality as common lifestyle risks

\section{Case Study: Forever Manchester, Manchester}

Forever Manchester was a scheme funded by the National Lottery that commissioned community projects with the aim of building social networks and thereby improving community sustainability. This is a form of asset-based community development, that brings people together over a common passion and therefore empowers them to consider and discuss the assets, needs and desires of the community. Within 18 months of the project, all communities involved reported a dramatic increase in community activity and social networking between residents, and individuals reported increased social trust, self-esteem and sense of purpose.

Source: Rippon, S. \& Hopkins, T. (2015) Head, hands and heart: asset-based approaches in health care. The Health Foundation.

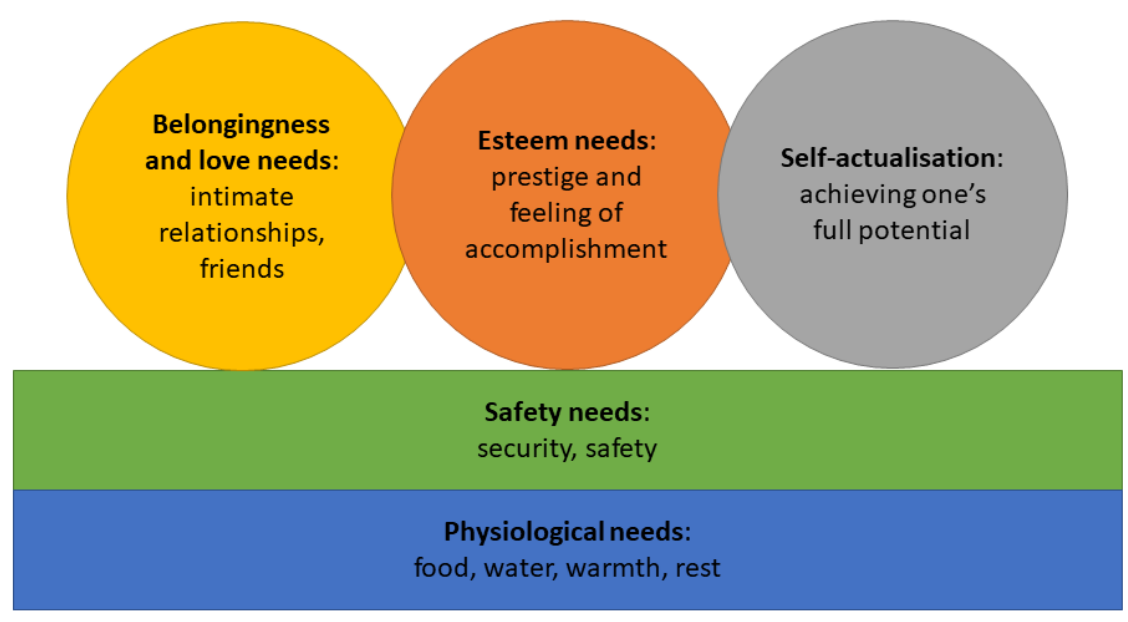

Figure 16: Maslow's Hierarchy of Needs. Physiological needs and safety needs are displayed as the bedrock upon which the other needs rest as they are regarded as essential.

\footnotetext{
35 'Health Matters: Community-Centred Approaches for Health and Wellbeing', GOV.UK, accessed 14 October 2020, https://www.gov.uk/government/publications/health-matters-health-and-wellbeingcommunity-centred-approaches/health-matters-community-centred-approaches-for-health-andwellbeing.

${ }^{36}$ Julianne Holt-Lunstad, Timothy B. Smith, and J. Bradley Layton, 'Social Relationships and Mortality Risk: A Meta-Analytic Review', PLOS Medicine 7, no. 7 (27 July 2010): e1000316, https://doi.org/10.1371/journal.pmed.1000316.
} 
such as smoking and obesity, it is likely that these initiatives in themselves could reduce the risk of premature death as well as improve health ${ }^{37,38}$. What's more, social support is critical to improve recovery from illness and increase the resilience of individuals, resulting in higher levels of wellbeing and improved health outcomes. This social capital can also bridge gaps of wealth and status if people from different socioeconomic backgrounds are brought together with a common interest or goal, helping to narrow socioeconomic and health inequalities. This is incredibly important, now more than ever, as communities that experience socioeconomic deprivation or marginalisation have worse health outcomes than more affluent communities, and this 'health gap' is only getting wider ${ }^{39}$. Furthermore, we know that poorer communities tend to have lower levels of voluntary, community and social enterprise activity ${ }^{40}$. The Marmot Review of 2010 recognised these issues and provided evidence that the most efficient way to reduce health inequalities is to improve social capital in the most deprived areas of our country ${ }^{41}$. Providing adequate funding, actively involving citizens in prevention programmes, and strengthening community assets are key to rapid health improvement, particularly in our most socioeconomically deprived areas.

\section{Case Study: Positively UK, London}

Positively UK is a peer-to-peer programme that supports the wellbeing of HIV positive patients in London. By connecting newly-diagnosed patients with those who have been infected with HIV for longer to share experiences, the stigma and fear of the disease can be lessened. Participants generally report improved mental health and emotional wellbeing, whilst data demonstrates that the participants also benefit from a significant increase in health literacy regarding HIV specifically, which empowers participants to selfmanage their condition and reduces their reliance on formal healthcare.

Source: Finnis, A. et al. (2016) Realising the value. Nesta.
Community initiatives that are specifically directed towards health promotion and ill-health prevention, as well as those that are targeted at helping individuals to manage their own chronic health condition, may have an additional benefit to health and wellbeing beyond those described above. It has been shown that community-led initiatives improve critical health literacy amongst participants $^{42}$. This means that participants' understanding of their own health condition, and of how to remain

\footnotetext{
37 'From Evidence into Action: Opportunities to Protect and Improve the Nation's Health', GOV.UK, accessed 14 October 2020, https://www.gov.uk/government/publications/from-evidence-into-actionopportunities-to-protect-and-improve-the-nations-health.

${ }^{38}$ Sherman Folland, 'An Economic Model of Social Capital and Health', Health Economics Policy and Law 3, no. 4 (2008): 333-48.

39 'Community-Centred Public Health: Taking a Whole System Approach', GOV.UK, accessed 14 October 2020, https://www.gov.uk/government/publications/community-centred-public-health-taking-awhole-system-approach.

40 'Rolling Out Social Prescribing | National Voices', accessed 14 October 2020, https://www.nationalvoices.org.uk/publications/our-publications/rolling-out-social-prescribing. 41 'Fair Society Healthy Lives (The Marmot Review)', Institute of Health Equity, accessed 14 October 2020, http://www.instituteofhealthequity.org/resources-reports/fair-society-healthy-lives-the-marmotreview.

${ }^{42}$ Liesbeth de Wit et al., 'Community-Based Initiatives Improving Critical Health Literacy: A Systematic Review and Meta-Synthesis of Qualitative Evidence', BMC Public Health 18, no. 1 (20 July 2017): 40, https://doi.org/10.1186/s12889-017-4570-7.
} 
healthy, is improved by taking part. In turn, this knowledge empowers people to take control of their own condition through self-management and thereby improves health and reduces reliance on formal health services. In addition, self-management education programmes - that aim to empower patients with chronic health conditions to understand their condition and manage it themselves - have consistently proven successful at improving clinical health outcomes in targeted populations, and are known to increase participants' self-confidence and quality of life $e^{43,44}$. What's more, by linking patients up with peers who are affected by a similar condition, self-management groups encourage people to compare themselves positively to their peers rather than negatively to their pre-diagnosis self, further enhancing their sense of wellbeing (see "Case Study: Positively UK, London") 45 . Further benefits can also be seen from initiatives that promote physical activity, e.g. sports clubs, and those that promote healthy living such as cookery clubs, as these initiatives promote the practice of a healthy lifestyle and empower people to maintain it ${ }^{46,47}$.

Nevertheless, it has been shown that there is no need for community groups to specifically focus on health-related outputs in order to positively impact health and wellbeing. In fact, the majority of initiatives studied in this research are simply groups that bring the community together, without any focus on health issues as such, but that improve health and wellbeing in the long-term regardless (see 'Case Study: Altogether Better, UK' and 'Case Study: The Health Empowerment Leverage Project, Devon'). This demonstrates that local government can support volunteering and community development across wide interest areas, not necessarily focused on health-associated outputs, and still see an improvement in community health and wellbeing.

\footnotetext{
${ }^{43}$ Patricia A. Grady and Lisa Lucio Gough, 'Self-Management: A Comprehensive Approach to Management of Chronic Conditions', American Journal of Public Health 104, no. 8 (12 June 2014): e25-31, https://doi.org/10.2105/AJPH.2014.302041.

44 'Realising the Value: Ten Actions to Put People and Communities at the Heart of Health and Wellbeing', nesta, accessed 14 October 2020, https://www.nesta.org.uk/report/realising-the-value-tenactions-to-put-people-and-communities-at-the-heart-of-health-and-wellbeing/.

45 'Building Community Capacity: 7 Economic Case Studies', 7 May 2019, https://www.thinklocalactpersonal.org.uk/Latest/Building-Community-Capacity-Economic-CaseStudies/.

${ }^{46}$ Christer Malm, Johan Jakobsson, and Andreas Isaksson, 'Physical Activity and Sports-Real Health Benefits: A Review with Insight into the Public Health of Sweden', Sports 7, no. 5 (May 2019): 127, https://doi.org/10.3390/sports7050127.

47 Jessica Herbert et al., 'Wider Impacts of a 10-Week Community Cooking Skills Program - Jamie's Ministry of Food, Australia', BMC Public Health 14, no. 1 (12 December 2014): 1161, https://doi.org/10.1186/1471-2458-14-1161.
} 


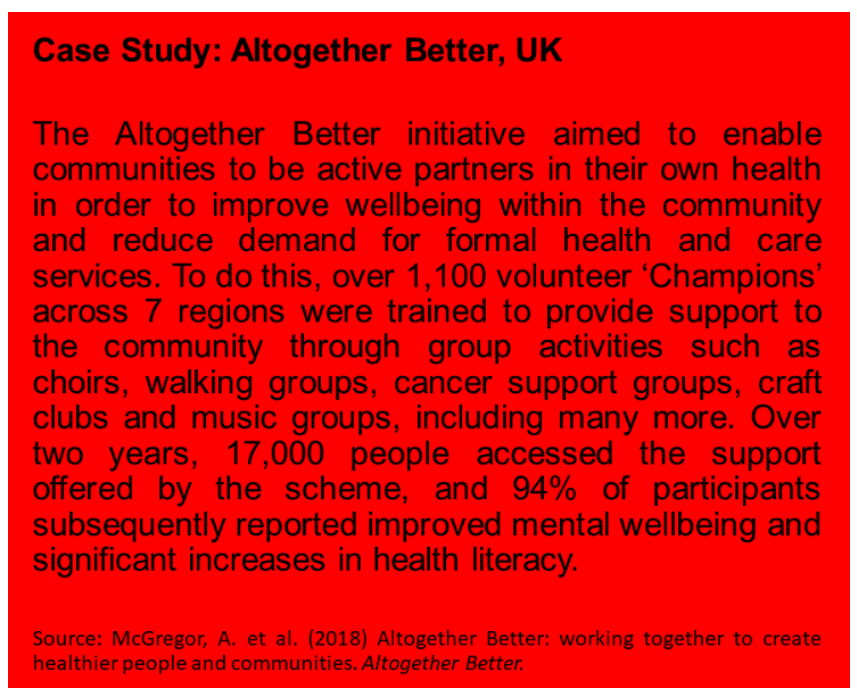

\section{Case Study: The Health Empowerment Leverage Project, Devon}

The Health Empowerment Leverage Project (HELP) was a scheme commissioned by the Department of Health to research the impact of community development on health and wellbeing. The scheme was run across three neighbourhoods in Devon and supported neighbourhood partnerships which boost community activity. Over three years, the scheme generated an estimated saving of $£ 558,714$ for the NHS due to an annual 5\% improvement in health factors, which equates to a 1:3.8 return on investment. The model additionally demonstrated that financial investment in this scheme within the $20 \%$ most deprived neighbourhoods could produce health savings of more than $£ 4$ million over 3 years. These outcomes persist despite the fact that the investment was not specifically directed to health- or socialcare-related initiatives.

Source: Fisher, B. (2014) Community development through health gain and service change - do it now! London Journal of Primary Care 6(6):154-158

\subsection{The economic case for community development}

Community development can also be very positive financially, largely through savings due to a reduction in demand for formal health and care services. Economic modelling of implementing peer support and self-management education, such as the Positively UK initiative (Case Study 4), particularly targeted towards those with long-term conditions, could lead to net savings of $£ 2,000$ per person per year, equating to direct health savings of $£ 5$ million per year for the average Clinical Commissioning Group, with an additional $£ 22$ million of wider social savings ${ }^{48}$. These savings would likely grow with time as hospital admissions for chronic conditions are prevented through self-management, and learning can be passed down through generations. Another similar economic model suggests that each $£ 1$ spent in community development saves $£ 3.80$ in reduced health service use, as $5 \%$ of conditions

\footnotetext{
48 'Supporting Self-Management: A Summary of the Evidence', accessed 14 October 2020, https://www.nationalvoices.org.uk/publications/our-publications/supporting-self-management.
} 
observed in disadvantaged neighbourhoods can be prevented by community development ${ }^{49}$. A price cannot be placed on the improvement in the quality of life of those individuals who benefit from community development, but these savings certainly go some way in demonstrating the potential financial benefits of this approach.

\subsection{Outcomes from the Cambridgeshire survey}

To assess how Cambridgeshire-based community-led initiatives consider their impact on health and social care, the survey enquired as to whether initiatives believed their work affected the physical or mental health of volunteers and service users. 89\% (115/129) of respondents believe that their community group improves the mental health of service users, whilst 72\% (93/129) believe their community group improves their physical health (Figure 17). Regarding volunteers, 83\% (106/128) responded that their group improves volunteer mental health, and $58 \%(74 / 128)$ responded that their group improves volunteer physical health (Figure 18). These results support the above evidence, suggesting that community groups can improve both the physical and mental health of those associated with them, whether participants or volunteers.

The health benefits of some of the surveyed community groups is perhaps more apparent than others. For example, among them were groups that directly supported patient access to medical care, such as collecting prescriptions or driving patients to appointments. Other groups change batteries in hearing aids, allowing people to communicate, or provide meals for patients who have recently left hospital. In addition, several groups endorse healthy lifestyles for particular demographics, for example promoting LGBTQ safe sex practices. A number of community groups also improved health through altering people's diet or nutrition, either by providing food, advising on healthy eating, or providing space for users to grow their own food. The health benefits associated with community sport and exercise groups are also clear and were stated by many respondents to the survey. Lastly, it is also important to note that non-exercise groups highlighted their potential to promote exercise for elderly people by providing a reason for them to leave their homes and walk to the sessions.

\footnotetext{
${ }^{49}$ Mary Reed et al., 'Developing Stroke Rehabilitation and Community Services: A Meta-Synthesis of Qualitative Literature', Disability and rehabilitation (Disabil Rehabil, 2012), https://doi.org/10.3109/09638288.2011.613511.
} 
Mental health is another area directly supported by community groups that provide counselling or signpost users to other available mental health support services. However, in addition to this direct support, community groups not associated with the provision of mental health support are able to recognise and redirect those suffering from mental health problems to appropriate services. In addition, our survey highlights the benefits of like-minded people being able to form a community, with responses from groups as varied as LGBTQ people, carers, parents of young children, and people suffering from similar medical problems.

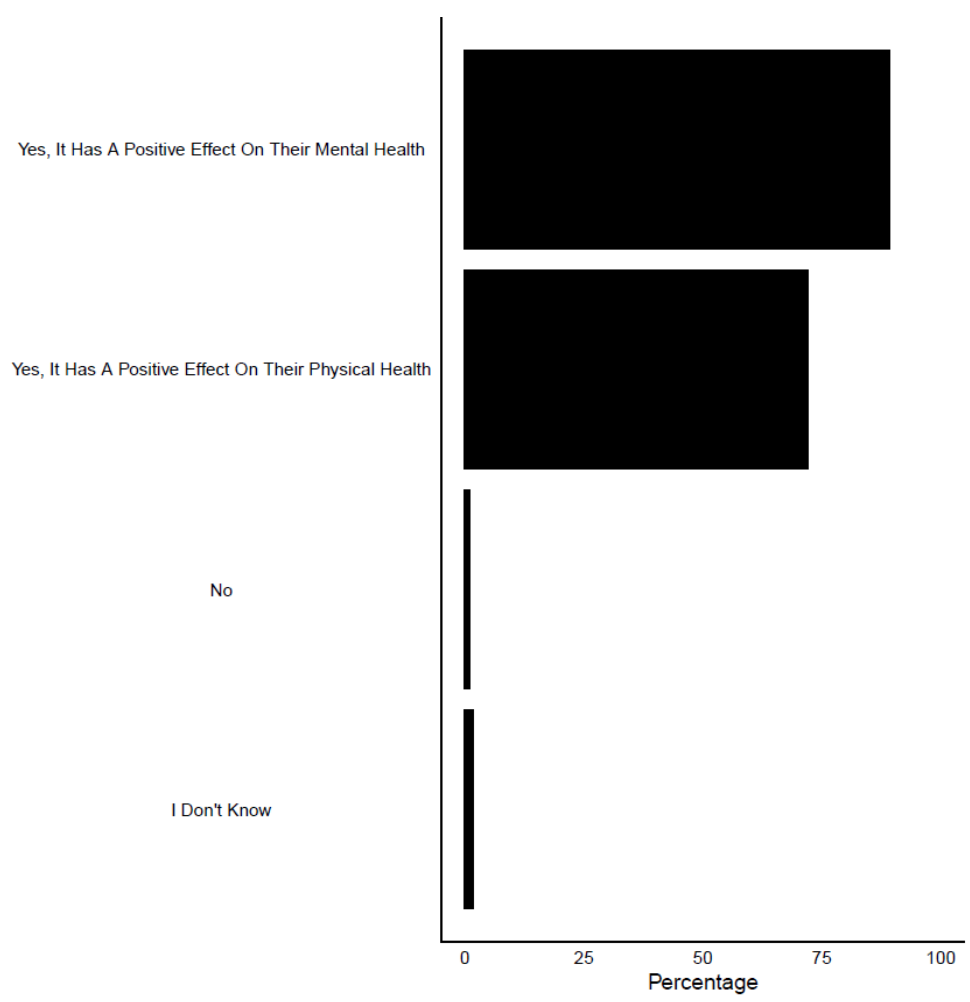

Figure 17: Do you believe your initiative affects the physical or mental health of your service users? Respondents were able to select more than one option. 


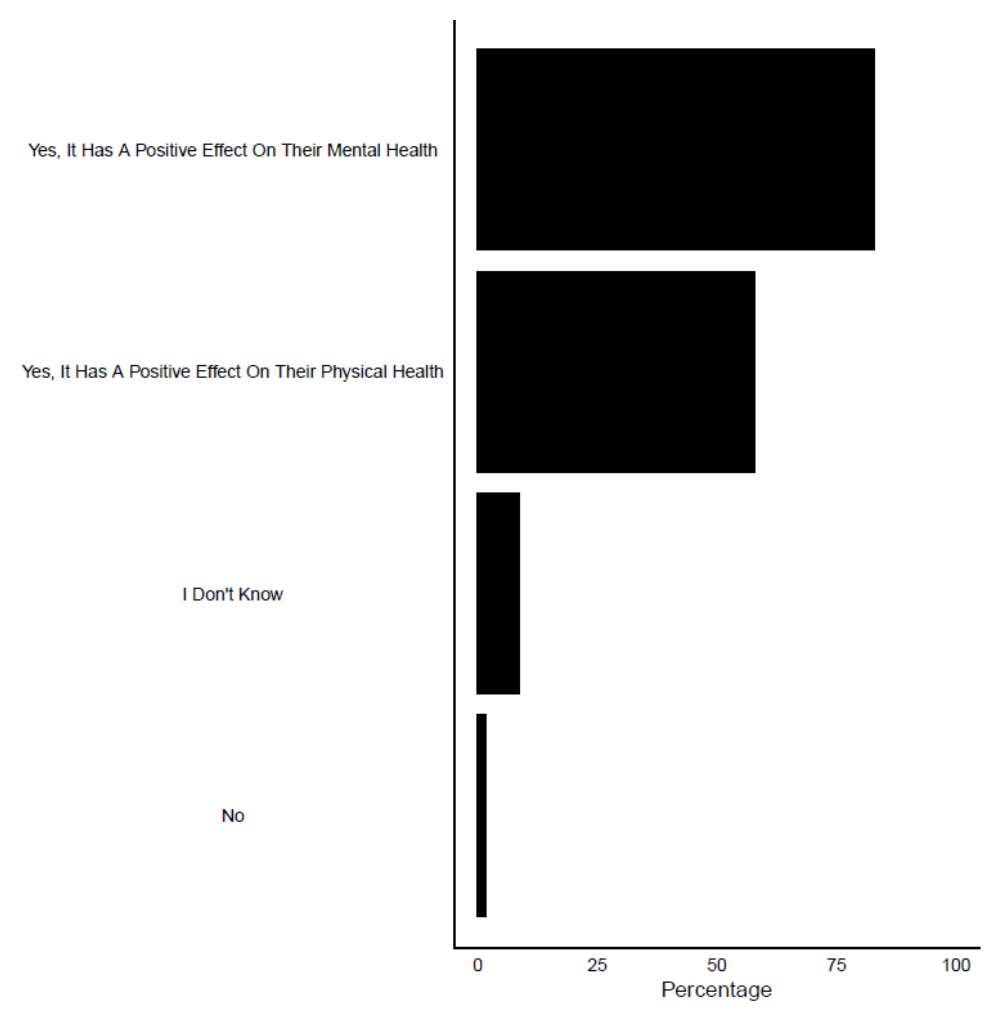

Figure 18: Do you believe your initiative affects the physical or mental health of your volunteers? Respondents were able to select more than one option.

Many respondents stated that their initiative reduces loneliness, can integrate people into their communities, and provide people with communication skills and confidence. Given the aforementioned effects of loneliness and social interaction on mortality rates and health seeking behaviours, these community groups have the potential to provide an enormous benefit to the health of the communities that they serve. For example, Cambridgeshire is home to a number of 'Men's Sheds'. The Men's Sheds initiative began in the 1990s in Australia when men's health became a subject of concern. The model brings men together in an informal environment, often within workshop areas, to allow them to take part in meaningful social and recreational activities, and gives them the opportunity to create a support network. Global research of this initiative suggests that participants tend to increase their physical activity, improve their health literacy, experience greater feelings of contentment and reduced feelings of anxiety, and alter their behaviour such that risk behaviour is reduced and health-seeking behaviour is increased ${ }^{50}$. As such, it is likely that this initiative reduces the need for formal health services, although data has not been generated to this end. One Men's Shed in Cambridgeshire divulged that at least one of their members has been saved from committing suicide directly because of their involvement in the Shed, and that others express "feeling

${ }^{50}$ Danielle Kelly et al., 'Men's Sheds: A Conceptual Exploration of the Causal Pathways for Health and Well-Being', Health \& Social Care in the Community 27, no. 5 (2019): 1147-57, https://doi.org/10.1111/hsc.12765. 
much better" due to the social nature of the Shed. This provides clear evidence of community groups making a positive difference to the lives and wellbeing of those who take part, despite the goals of the initiative not being explicitly directed towards health improvement. Most importantly for this report, this is already being achieved in Cambridgeshire, and should be supported wherever possible.

For volunteers, in addition to reducing loneliness, respondents stated that volunteering provides satisfaction from helping others, therefore community groups may fulfil the 'belongingness and love needs', 'esteem needs' and 'self-actualisation needs' described in the hierarchy of needs above (Figure 16). Respondents also described the opportunities for people to learn new skills in community groups, both for young people who benefit from developing useful life skills, and the elderly who benefit from maintaining their mental agility. Community groups also provide specific opportunities to children and young people; for example, they can learn communication and social skills vital for later life by interacting with their peers, and have access to toys and stimulation which may otherwise be unavailable to them.

The survey also enquired whether respondents believed the Cambridgeshire County Council has a role to play in improving the health of Cambridgeshire residents. Results revealed that $90 \%$ of respondents (116/129) responded with 'Yes,' only 2\% (3/129) said 'No' (Figure 19). Given this research and survey responses, we suggest that supporting community initiatives would be a prudent way to play this role. The Cambridgeshire County Council has already demonstrated that it is able to effectively support community initiatives in order to generate positive outcomes in relation to health and wellbeing through The Neighbourhood Cares pilot

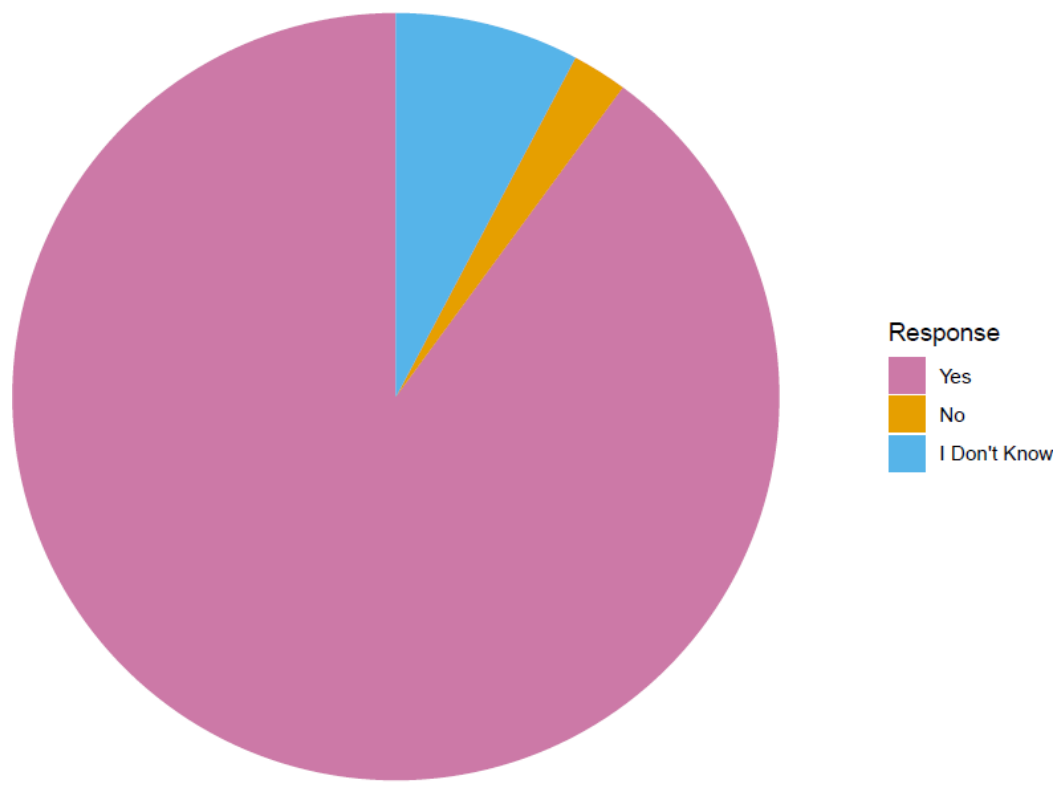

Figure 19: Do you believe the Cambridgeshire County Council has a role to play in improving the health of Cambridgeshire residents? 
(NCP). NCP represented a novel method of adult social care services, aiming to provide individuals with the support they need in the community, such as post-stroke care, tackling loneliness and helping the elderly. A report on the pilot of this initiative concluded that the project had been broadly beneficial to the health and wellbeing of the community. For example, an estimated 50 unplanned hospital admissions were prevented due to the scheme, patients found that they were seen quicker than when they reported complaints to local health services, and clients reported feeling more confident, more independent and less lonely ${ }^{24}$. This is a clear example of how initiatives can improve the health of their community and thereby lessen the need for formal health and social care services with the support of the Council.

\subsection{Community response to the COVID-19 pandemic}

The beneficial effects of community-led groups and initiatives has perhaps never been felt more acutely than during the COVID-19 pandemic that swept across the globe earlier this year. In the UK, a national lockdown restricted the movement of individuals with the aim of reducing the spread of the virus. However, by virtue of confining people to their homes, the measures also contributed to deteriorating population physical and mental health. This is due to a combination of factors, including by not limited to: reduced social interaction; increased anxiety about personal health; increased anxiety over financial matters; reduced access to open spaces; increased emotional tension within crowded households; reduced ability to partake in physical exercise; and reduced access to health and social services. Formal social care services were put under enormous strain as workers fell ill and had to self-isolate, and demand for services increased as hospitals discharged patients to care homes ${ }^{51}$. As such, unmet need for social care drastically increased, such that around two thirds of people who previously received social care from the local authority reported that their support had reduced in the pandemic ${ }^{51}$. To deal with this shortfall in supply versus demand, new neighbourhood mutual aid groups were formed rapidly across the country. By coordinating members of the community, these groups were able to provide essentials such as food, medicine and emotional support for those shielding or self-isolating, relieving pressure on formal services. Perhaps more importantly, due to the groups comprising a wide range of community members across multiple locations, they were able to much more rapidly identify individuals in need and respond than formal services would have been able to. As such, social prescribing has been a key player in the response to the pandemic, meaning that the voluntary, community and social enterprise sector has often been at the forefront of local responses to the pandemi ${ }^{40}$. In Cambridgeshire alone, over 2,500 people signed up to volunteer at the beginning of lockdown to aid key workers and those who were shielding, clearly demonstrating the willingness and capability of the

\footnotetext{
51 Simon Bottery, 'How Covid-19 Has Magnified Some of Social Care's Key Problems', The King's Fund, 25 August 2020, https://www.kingsfund.org.uk/publications/covid-19-magnified-social-careproblems.
} 
community to come together to help one another ${ }^{52}$. This increased demand for services has required many community initiatives to dramatically change their model of operation. The Cambridge Council for Voluntary Service (CCVS) conducted a survey of charities and community groups in Cambridgeshire, which revealed that the overall response across the county has been positive, with widespread efforts from both residents and organisations to provide the necessary support to community members ${ }^{53}$. The majority of groups and initiatives surveyed reported that they had altered their service model to fit government guidelines whilst still providing some level of support, such as providing services over online virtual platforms or over the phone, or completely changing their model such that they provided support to the emergency response via Mutual Aid groups ${ }^{51}$. Our own questionnaire reported similar results, with a total of $57.9 \%(73 / 124)$ of groups reporting that their organisation had remained active throughout the pandemic (Figure 20). Of those, 6.5\% (8/124) said that their activities had continued undisrupted, while $52.4 \%(65 / 124)$ of groups had altered their service model, for example through cancelling face-to-face events and providing support online.

These data truly demonstrate both the flexibility of these groups and their absolute willingness to help and support their community, bringing into sharp relief the value of social prescribing in responding to a rapidly changing and complex situation for the benefit of community health and wellbeing. The inspiring level of commitment afforded by Cambridgeshire community groups during the COVID-19 pandemic was emphasised by one group leader in our telephone interviews:

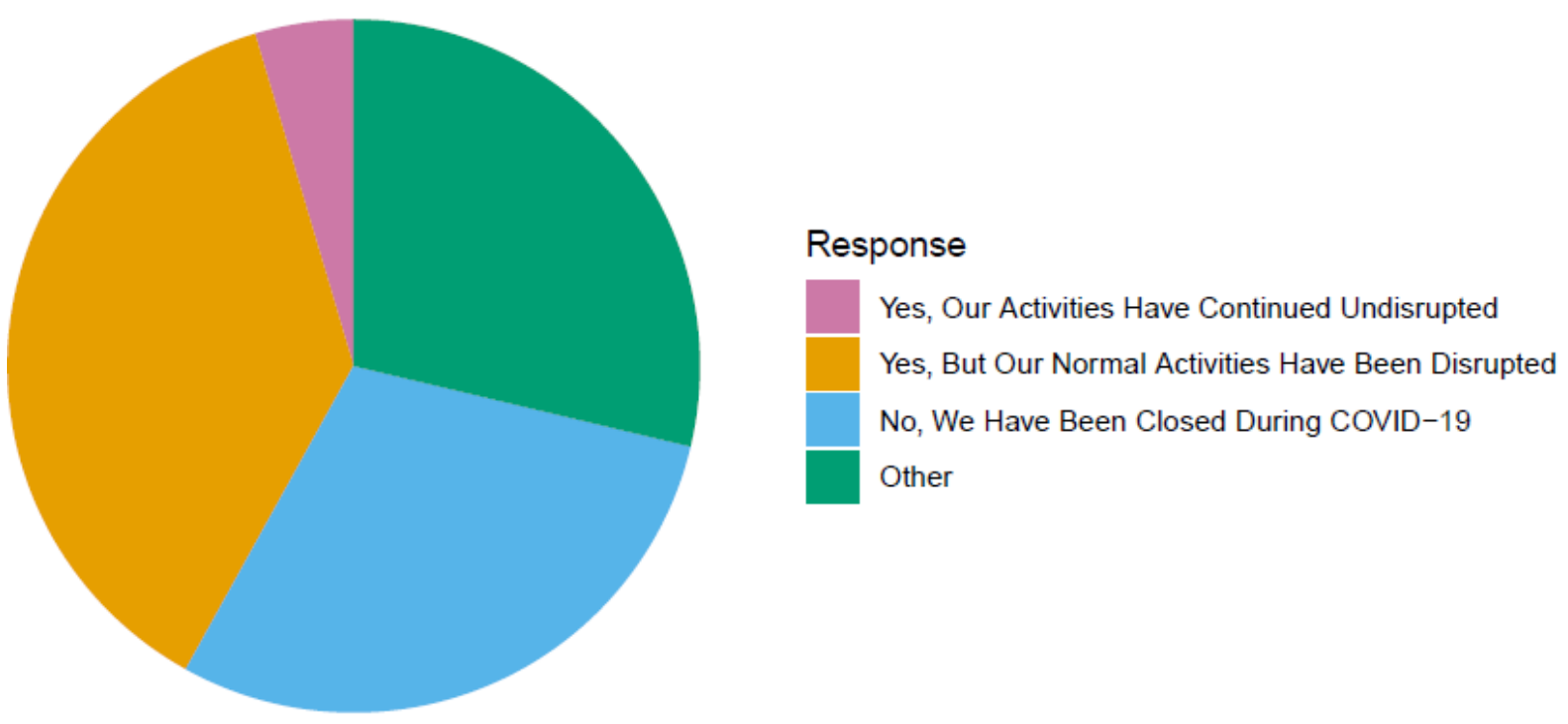

Figure 20: Has your initiative been active during the COVID-19 pandemic?

52 'Coronavirus (COVID-19) - Community Support', Cambridgeshire County Council, accessed 14 October 2020, cambridgeshire.gov.uk/residents/coronavirus/covid-19-coordination-hub-yourcommunity-needs-you.

${ }^{53}$ Cambridge Council for Voluntary Service, 'Survey of Charities and Community Groups', 2020, https://www.cambridgecvs.org.uk/media/Document/446/document/survey\%20presentation.pdf. 
'For the last 6 months, [running our community group] has been a full time job... It's something I've found very hard to switch off from, because when it's the number of your helpline in the public domain, and elderly people who are in distress and don't know where to go call that number, you need to know that you've got people and systems in place that can get to work. It may not be our problem to solve, but we need to make timely and reliable referrals to people who will do something... I can think of 4 or 5 people who we've carried through COVID. We've sorted out their food, we've sorted out their admin, we've sorted out their mental health. One of them we've given job coaching and mock interviews to help [them] get back into employment... If you have those relationships with people you can't just walk away from them.'

\subsection{Recommendations}

The research papers and case studies detailed in this section clearly demonstrate that it is possible to deliver health outcomes outside of formal health and care services. In order to achieve this in Cambridgeshire, we believe that the Council should consider the following:

Recommendation 1: Support communities to devise their own solutions to local health and social care issues.

Our research provides evidence that communities can be engaged around social issues and contribute to solutions, and that they have the assets and capabilities to take control of their own health and reduce pressure on the healthcare system if they are empowered to do so. In addition, they demonstrate that local government can support volunteering and community development across wide interest areas, not necessarily focused on health-associated outputs, and still likely see an improvement in community health and wellbeing. Together, this suggests that communities should be supported to achieve these outcomes. This support can come in many forms, such as:

$\rightarrow$ Providing seed funding for new initiatives.

$\rightarrow$ Providing access to consultants and advice for initiatives.

$\rightarrow$ Organising public consultations to establish the key issues in the area and how they can be addressed by the community.

$\rightarrow$ Rolling out a social prescribing scheme such that health and social care professionals are aware of the health and wellbeing benefits of local initiatives, and can prescribe these to patients who may profit from these.

This will require the continuation of the Think Communities partnership and the integration of Think Communities ideals into all Council directorates (expanded in Recommendation 12). 
Recommendation 2: Map local community assets alongside needs in the Joint Strategic Needs Assessment to gain an idea of where the community can add value, with additional insight work with marginalised communities.

This research suggests that communities not only have needs, but they also have their own assets - such as community venues, outdoor spaces, existing community groups \& networks, and significant knowledge \& skill sets - that can be utilised in order to address key issues in the area. By mapping these assets, the Council will be able to gain a sense of what the community may be able to achieve with their current assets, and in which particular areas they may need additional Council support in order to carry out this role effectively. Particular focus should be paid to deprived or marginalised communities, as this research has demonstrated that these communities are not only the most likely to be detrimentally affected by health and social care issues, and the least likely to have access to effective community initiatives, but also the most likely to benefit from this sort of intervention. 


\section{The effect of growth on health, wellbeing and community-led initiatives}

Whilst it is clear that community-led initiatives can have positive impacts on population health and wellbeing, we cannot ignore the impact of external factors on the ability of these initiatives to operate effectively. In Cambridgeshire, perhaps the most pressing issue facing these initiatives and the communities they serve is growth. Cambridgeshire has experienced extensive growth in recent years, which has certainly had positive financial implications across the region as a whole but has arguably worsened existing inequalities. Investigating the impact of growth on the ability of communities to live well and effectively cooperate is essential when looking at the viability of utilising community-led initiatives to improve health and wellbeing within Cambridgeshire specifically.

\subsection{Avoiding "New Town Blues": Mitigating the impacts of growth within communities}

The presence of community infrastructure, be that physical or social, can be invaluable for the nurturing of support networks between residents. Without it, the health and well-being of residents can be severely affected. Such a phenomenon was observed following the midcentury construction of the "New Towns" within the United Kingdom. The New Towns Act of 1946 instigated an ambitious programme for building new towns by granting the UK government powers to designate areas where new towns were to be built and to subsequently pass development control to a Developmental Corporation. This was accompanied by the promise to create towns that fostered a "spirit of friendship, neighbourliness and comradeship" by Lewis Silkin, the chair of the government's Town and Country Planning department at the time. Consequently, 32 "New Towns" were built in the UK, including Milton Keynes, Stevenage and Redditch. However, the programme subsequently gave rise to a phenomenon that was coined "New Town Blues", characterised by "problems of loneliness, and of physical and psychological disorders" within residents of the New Towns ${ }^{54}$. Although some dispute the existence of such a phenomenon, Clapson argues that, although it is a difficult outcome to quantify, residents of the New Towns indisputably experienced a degree of emotional suffering despite the careful geographical and architectural planning that went into the development of the New Towns. He finds that inhabitants often felt cut off from the wider world, specifically cut off from the larger cities that many residents had moved from. Similarly, a 2006 report noted that within the New Towns there was a tendency for design and physical issues to eclipse community and social provision during the planning process ${ }^{55}$.

\footnotetext{
${ }^{54}$ Mark Clapson, Invincible Green Suburbs, Brave New Towns: Social Change and Urban Dispersal in Postwar England (Manchester University Press, 1998).

${ }^{55}$ Department for Communities and Local Government: London, 'Transferable Lessons from the New Towns', 2006, https://www.westminster.ac.uk/sites/default/public-files/generaldocuments/Transferable-Lessons-from-the-New-Towns.pdf.
} 
The New Town Blues phenomenon, unfortunately, has not been consigned to history. A prime example has been observed within the Cambridge development of Cambourne, a housing development programme founded in 1998 consisting of 4,250 homes over a 417-hectare area. In 2006, a group of practitioners who deliver services in Cambourne met with the Consultant in Public Health to share concerns related to the low level of mental health that they had observed through their work in GP practises, schools, churches and beyond ${ }^{56}$. The mental distress experienced by the residents of Cambourne was not discriminant, afflicting residents from across the social strata. According to the report, the consensus within the meeting was that the cause of such distress was the developers failing to integrate a plan to foster a sense of community within the development. A stark example of this failure was the lack of any provision for informal gathering space where residents could meet casually and develop their own social networks; there were many estate agents and betting shops, but no post office or coffee shop.

However, the Cambourne development programme is not alone in its failure to successfully support community building. A review of the "Lessons learned from Orchard Park", a development in the Cambridge area consisting of 900 homes that began in 2000, concluded that more consideration should have been given to providing a variety of social interactions for early occupants within the development ${ }^{57}$. Similarly, the review suggested that "care should be taken to ensure community development work continues to focus on building resilient empowered communities rather than dependent communities", referring to the need to ensure there are self-sustaining support networks between residents within new developments.

Support networks can be crucial in times of change, and relocating is a time of significant upheaval: residents often move because of a new job, the need to upsize as a result of a new child, or because they are moving into their first residence away from their family home. Therefore, when these transitions coincide with a newfound remoteness from family and friends, the impact on mental health can be seismic. This is captured in interviews with Cambourne residents with one head teacher at a local school:

"The social problems really worry me. It's interesting how change affects people. It creates high levels of anxiety in both children and parents... People can be lonely and anxious. Husbands

\footnotetext{
56 Stephen Platt, 'Lessons from Cambourne', 2007, https://www.carltd.com/sites/carwebsite/files/Lessons\%20from\%20Cambourne\%20Report.pdf. 57 'Review of the Orchard Park Development and Lessons to Be Learnt for Future Major Developments', 2016, https://democracy.cambridge.gov.uk/Data/Environment\%20Scrutiny\%20Committee/20090623/Agend a/ltem\%205\%20\%20REVIEW\%20OF\%20THE\%20ORCHARD\%20PARK\%20DEVELOPMENT\%20AND\%20LESSON S\%20TO\%20BE\%20LEARNT\%20FOR\%20FUTURE\%20MAJOR\%20DEVELOPMENTS_1.pdf.
} 
are away a lot of the day. They leave at 6 and get back late. Women haven't got the support they need." 56

Similarly, a librarian stated:

"Some people came [to Cambourne] because they wanted a change. They might have been starting a family and wanted a new environment for their children. I talked to the mothers and some of them moved because they wanted a fresh start in a new place. This may have created problems because there weren't the usual support mechanisms and facilities. "156

The level of anxiety caused by such upheaval should not be underestimated. Indeed, LaCapra (1972) found that excess rates of suicide are observed in societies undergoing forms of dislocation and loosening of social bands ${ }^{58}$ while other studies observed a lack of social ties or social network as a predictor of mortality rate for almost every cause of death ${ }^{59,60}$.

A failure to address community cohesion not only has implications for the mental health of the residents, but it also impacts crime rates within the development area. A Cambourne Survey of Youth Behaviour found that $30 \%$ of respondents felt that youth behaviour problems were one of the worst things about the area. Indeed, one Cambourne resident interviewed was quoted to have said:

"there was nothing for children to do [in the area], and children began handing around... There are times when as many as 100 kids gather together. There is underage drinking." Ruth Poulton, Chairman, Cambourne Parish Council ${ }^{56}$.

Similarly, there were also complaints from residents in relation to antisocial behaviour and drug-related activity in the area ${ }^{56}$. If left unchecked, increased demands on the health service and on policing equates to higher costs for councils and other public services. This means that it is in the interest of councils to ensure that the development projects which are granted planning permission operate in a way that extensively integrates community cohesion into their development roadmap.

There is a need for building developers to gain a practical understanding of what can be done to encourage social engagement and mutual support networks that are self-sustaining. Social infrastructure has been defined to include "a range of activities, organisations and facilities

\footnotetext{
58 Dominick LaCapra, Emile Durkheim: Sociologist and Philosopher (Ithaca, NY: Cornell University Press, 1972).

59 J. S. House, K. R. Landis, and D. Umberson, 'Social Relationships and Health', Science 241, no. 4865 (29 July 1988): 540-45, https://doi.org/10.1126/science.3399889.

${ }^{60}$ Lisa F. Berkman, 'The Role of Social Relations in Health Promotion', Psychosomatic Medicine 57, no. 3 (June 1995): 245-254.
} 
that can support the development and sustaining of social relation" ${ }^{61}$. Voluntary and community sector infrastructure organisations in the Milton Keynes and South Midlands growth area estimated that the cost of social infrastructure needed in new developments is about $£ 700$ per resident ${ }^{62}$. The following section will bring together information gathered from literary resources, and also primary data gathered from interviewing professionals working within the community development sector, in an attempt to outline ways in which New Town Blues can be avoided by investing and enabling social infrastructure to develop within future developments.

A special case is made for the adoption of the "Master Developer" approach to large scale developments such as those undertaken within defined "Growth Areas". Indeed, this approach was adopted within the Alconbury and Wintringham sites in Cambridge with Urban \& Civic acting as Master Developers. Such an approach lends itself more easily to strong place-making and the development of community infrastructure in a way that developments executed by housebuilders alone cannot. As housing demands continue to rise within the Cambridge area, new towns and housing developments will be needed. Ensuring such developments are executed in a way that positions the community at their forefront will be crucial not only for resident's health and wellbeing, but also for public sector expenditure in the long term.

\subsubsection{Incorporating community from the very beginning}

Housing development can be an inherently divisive practise, and proposed developments are frequently met with strong opposition for a variety of reasons. Residents' views can be troublesome for developers, particularly for those unwilling to cooperate, or to compromise on issues. However, resident input need not be a thorn in a developers' side and when done correctly can lead to more successful, mutually beneficial developments being built.

To understand how resident consultation can be carried out at all stages of development, we interviewed professionals who were involved in the community development strategy of several Cambridge-based new developments that were either completed or were ongoing. All those interviewed stressed the importance of integrating resident consultation at the very start of the development project. This was important to diffuse potential conflict down the line; when residents felt they had agency over the development, an "us and them" dynamic between the public and the developers was far less likely. As a general outline, one interviewee described how their organisation tended to arrange their consulting procedure throughout the development process:

61 'Never Again: Avoiding the Mistakes of the Past', updated 2012 2010, https://youngfoundation.org/wp-content/uploads/2013/01/Never-Again-January-2010.pdf. 62 'Social Infrastructure Planning Obligations - Milton Keynes Council', n.d., https://www.miltonkeynes.gov.uk/planning-and-building/planning-policy/social-infrastructure-planning-obligations. 
"At the beginning of the consultation process we invited residents to events where they could share their priorities, visions, and expectations for the development, with a very vague outline of what the development wanted to achieve. This involved asking residents to write on sticky notes the assets, both social and physical, that they felt should be prioritised. We then held subsequent consultations every 4-5 months, where we would aim to highlight how feedback from the previous consultation had influenced the subsequent development plan. At the final stages of the development process we made models of the development project for residents to view and interact with. We also handed out surveys with both open and closed questions in relation to the development at these events. The key thing that residents want to see that their ideas are being heard and acted upon."

This highlights the need to involve residents' feedback at every stage of development, and many interviewees felt this was key to ensuring that developments would meet the expectations of those moving in. When there is a pressure within developments to deliver high numbers of new homes that turn a profit, concern about wider social issues can become a lower priority and developers can also lack the expertise or incentives to produce housing environments that are socially cohesive.

To counter this, in situations where a planned growth area has been designated, general consultations can be organised by the council to invite neighbouring residents who represent diverse backgrounds to relay their opinions, priorities and expectations in relation to the infrastructure, design and assets within the development of the area. These can then be used to collate a "check list" of criteria, which developers who want to develop the land must demonstrably meet in their plans in order to be considered for the project. This both provides residents with a sense of agency over the project from the beginning and also means that developers must offer a defined set of assets from the start. This would avoid new towns being built that lack obvious community-focussed provisions, such as community halls, GPs, cafes, green spaces, youth centres, and also means that residents do not then have to fight for the insertion of these provisions into an already submitted planning proposal. Such an approach bears resemblance to a neighbourhood plan, but on a microlevel, outlining specific provisions for specific growth areas. An interviewee from Urban \& Civic, the master developer of the new Wintringham development in Cambridge, emphasised that the organisation had undertaken extensive primary research into the other recent developments within the area, such as Cambourne and Love's Farm, the latter being a development in St Neots of 1,350 houses, in order to understand the issues that residents had faced. This even included interviewing members of the Love's Farm Community Association and gaining several rounds of feedback on Wintringham's plans for community development.

It should be mandatory that there is at the very least a functional community centre or town hall completed prior to the first residents moving into the development. A member of the 
Love's Farm Community Association who was interviewed expressed disappointment at having to rely on a local cricket club's bar as a place where social events for new residents were held as a result of there being no community centre or hall available when the first residents arrived.

\subsubsection{Community building throughout development}

Housing developments take time to be completed, and are not filled instantaneously, meaning that there are waves of residents moving in throughout the development process. Ensuring that the first residents who move in, often referred to as the "pioneers", are provided with opportunities to build community networks can be instrumental to subsequent community growth. Residents who we interviewed from Love's Farm described how crucial the establishment of the Love's Farm community association was to the organisation of social events between the pioneer residents and emphasised the crucial role that their Community Development Officer (CDO) played in supporting them to do this, helping them through the process of the organisation's establishment and also in the initial organising of social gatherings. Indeed, the Arbury Park Scrutiny review made future recommendations for new developments to ensure that there is a CDO who is in charge of arranging "regular and varied community activities which bring together residents in small and larger numbers until networks develop and become self-sustaining. ${ }^{163}$ This demonstrates how external support and input can be a catalyst for the formation of community networks when done well and how crucial it is that a CDO enables socialising at the very early stages of development.

The presence of a CDO within the first two years of a housing development opening was cited as being an absolute necessity by Love's Farm residents. Given this, any future development project should be required to employ CDOs, with the number provided relative to the size of the development. It goes without saying that a development consisting of thousands of inhabitants needs several development officers. Research should be carried out to identify the optimal ratio of CDO to residents such that an officer can maintain a good level of familiarity with every resident that they come into contact with. An interviewed member of the CCC who has worked with both the Community Land Trusts and large-scale private developers cited the importance of having CDOs who are able to build a rapport with residents to the level that the majority of residents would feel comfortable "chatting over coffee" with them. The interviewee said this was key to ensuring comprehensive and authentic feedback from residents that in turn allowed residents to feel a sense of agency over the social infrastructure of the area.

Interestingly, residents interviewed from Love's Farm made observations that were mirrored by Cambourne residents in terms of the progression of community links over time. Both referred to an initial buzz of networking within the pioneer residents, who were initially few in number and keen to socialise, that was then followed by a gradual decline in social interaction

${ }^{63}$ South Cambridgeshire District Council, 'Arbury Park Scrutiny Review', 2008, https://scambs.moderngov.co.uk/documents/s26434/Arbury\%20Park\%20-\%20app.pdf. 
as new residents moved in and the development began to grow in size ${ }^{56}$. This was captured by a head teacher from Cambourne who was interviewed:

"Those who came early had a vision, a pioneering spirit, that inevitably has been diluted with later arrivals. ${ }^{\prime 56}$

Love's Farm residents suggested this may have been caused by insufficient physical communal areas which were not varied enough to meet the needs of the diverse population of residents. Indeed, Love's Farm residents criticised the lack of a community centre at the early stages of the development, citing communal space as essential to allowing resident-led groups to form and to be sustained. This again shows how crucial it is that developments integrate community building from the very start of the project, as soon as residents move in, as this is a key period that can determine the success of community building for years to come.

CDOs also have a part to play in the long-term maintenance of social structures within a new development. A Love's Farm Community Association member described an increase in workload as the CDO gradually removed themselves from the community. Given that the Community Association is composed of volunteers, members felt that they were unable to fully support residents in the way they would have liked simply due to their workload constraints. This struggle they felt could not be solved by increased funding provisions: when asked whether they would prefer funding to increase their capacity while maintaining autonomy, or to have an external CDO employed again to support social infrastructure, the latter was said to be strongly preferable. This demonstrates that external support for social infrastructure perhaps should not be viewed as a transient role that is only required for the first few years of development. In reality, new developments can take several years to mature as new residents move in and issues arise as the area matures. Community volunteers are not always able to meet the demands of their peers while also meeting work-life demands. Thus, CDOs could be employed and integrated within the community for many years. Indeed, interviewees expressed frustration at the phenomenon of developers "washing their hands" of their housing developments and the residents within them once construction is completed. Therefore, it could be considered reasonable to expect developers to either directly or indirectly deliver funding for long term CDOs within new towns.

Similarly, residents at Love's Farm were extremely frustrated with lines of communication between residents and those responsible for physical infrastructure maintenance. An interviewee complained of an extended "foggy period" within which responsibility for road and infrastructure repairs is handed over from the developer to the Council. Within this period, residents felt there was no organisation held accountable for dealing with reports of broken lamp posts, potholes, unfinished roads and beyond. This situation left residents feeling extremely frustrated and powerless and, in some cases, regretful to have moved into a newly built area. Such a failure of communication should be addressed for future projects, with all 
residents being clearly informed of who to contact for repairs at different periods within the project, and an efficient complaints system to the council if repairs are not completed. This once again emphasises the importance of employing CDOs who can relay this information within the community over an extended period, rather than for a few initial years.

Providing residents with contact information and general information on the area is an important method to prevent feelings of alienation and remoteness. While interviewing professionals who work on community-engagements within Cambridge, a well touted and relatively easy way to support residents moving into new towns is to provide all households with a directory of all the necessary information that they may need such as the local GPs, schools, public transport routes, hospitals, and local services along with information concerning recreational activities such as restaurants, cinemas, sports fields and clubs. This was something also highlighted in the review of lessons learned from Orchard Park ${ }^{57}$. In future projects, community officers within new town developments could be required to distribute such information to their residents, and continually update it with information relating to local groups and organisations that are formed. This would also relieve the burden of community associations. A member of the Love's Farm community association who was interviewed highlighted the amount of time that members of the association dedicate to putting members of the community in contact with public service providers such as the police or health service practitioners; they suggested that a resource which provided as much as this information as possible would relieve their workload significantly and also prevents residents from feeling frustrated about not knowing who to contact with their issues.

While carrying out this literature review, there was found to be a severe lack of evidence-based literature and recommendations on the specific provisions that new towns need in order for a community to be fostered. With housing demands rapidly increasing, it is crucial that there is evidence-based policy that determines the success of planning applications from developers. A thorough investigation must be undertaken to uncover the quantitative and qualitative needs of residents within communities. This should address questions such as the basic key social infrastructure required, be that community halls, coffee shops, play groups or green spaces. This should also include the optimum number and functions of CDOs for successful community relationships and lines of communication to form between the residents, the Council and the developers. Many new developments have taken place in Cambridgeshire over the past decades that can be studied and subsequently inform future stipulations that developers must meet. Failure to learn from previous mistakes risks not only the mental and physical health of residents themselves but will be costly for public services that must later counteract the social fallout from such ailments.

\subsubsection{Long-term investment for long-term communities: the role of Master Developers in community creation}


For a new development to successfully foster community networks, the developer must be incentivised to adopt a long-term perspective on the place they are developing. The current developments of Alconbury and Wintringham are being developed under a "Master Developer" called Urban \& Civic. Upon discussing the reasons why the Love's Farm development had resulted in such poor community infrastructure and poor dialogue between residents and the developer, an interviewee from Urban \& Civic suggested this was as a result of the development plan not being orchestrated by a Master Developer. Instead, as with many new developments, the responsibility of building the homes lay with a "housebuilder", a company whose aim is to simply build the houses within the development, and to then sell them once completed. These housebuilders do not necessarily have expertise in large-scale placemaking or town planning, and often are not incentivised to create places where social and physical infrastructure are sustainable in the long-term, as their responsibility for an area quickly diminishes once the houses that they built are sold. In contrast, an Urban \& Civic employee suggested that having a project run by a Master Developer promotes longevity within the project and allows housebuilders to be held accountable for failings in infrastructure. This can lead to greater support for social infrastructure from the Master Developer and a significantly higher importance placed on social infrastructure.

For a site to be considered suitable for a Master Development it will usually involve 1,000 houses or more as the projects generally rely on economies of scale. Such sites are appropriate for the development of "growth areas" designated in Local Development Plans. Given the size of these projects, they are delivered over a long period of time, with several rounds of house building, and typically require varying degrees of green spaces, placemaking and community infrastructure delivery. Master Developers will unlock "raw land" through early investment in planning and infrastructure delivery across a large piece of land. This will include delivering drainage and main service upgrades, flood defences, road works, cycle ways, schools, local community centres and beyond. Parcels of land within the development are then sold off to regional or national housebuilders in packages varying between 50-400 dwellings periodically throughout the development. This approach gives housebuilders a low risk project, in which they are not responsible for site-wide planning, infrastructure delivery or environmental considerations. Instead, housebuilders can focus on the quality of their builds and the sale of them. Contrastingly, the Master Developer has strategic control on the project and employs specialists who are responsible for managing the longer-term nature of the project. Indeed, "with Master Developers having a long term interest in these sites, stakeholders can take comfort that MDs have a vested interest in the success of a scheme over an extended period"64. This removes the risk of housebuilders simply cutting ties with communities once houses are sold, leaving residents stranded as was the case in the Love's Farm development.

64 'The Rise of the Master Developer', n.d., http://cbre.vo.Ilnwd.net/grgservices/secure/Master\%20Developer\%20FINAL.pdf?e=1604342773\&h=c 7aeb3538afaf2e0e4ccbff193a6b779. 
Similarly, the housebuilders are contractually obliged to the Master Developer, meaning that if they fail to meet a specified standard of build, or are the cause of resident's complaints, then the Master Developer is able to hold them accountable and demand resolution. This further removes the risk of residents being left with incomplete infrastructure or facilities that do not work, without any means of resolution, as is sometimes the case when housebuilders are the sole developers within a project such as Love's Farm. Similarly, having a Master Developer responsible for dealing with infrastructure issues relieves the responsibilities of communityled initiatives such as Resident's Associations who would otherwise be tasked with the extremely arduous task of chasing contractors and housebuilders. This allows such community groups to dedicate their time to perhaps more socially focussed projects. Indeed, an interviewee from Urban \& Civic who was involved with the Alconbury development stated that Urban \& Civic employees working within Alconbury had even provided their work mobile numbers to residents in some instances, so that residents felt that they would be able to have their matters dealt with directly and could speak to someone who they felt they knew. Such dialogue between resident and developer may prevent residents from feeling powerless and isolated, and instead bestows in them a sense of being supported and having agency.

As well as supporting the long-term integrity of physical infrastructure within communities, Master Developers are also incentivised to foster community networks as the desirability of building sites to housebuilders will depend on the long-term desirability of the areas that they are creating. They are as a result well positioned to dedicate significant resources to fostering community initiatives. An Alconbury-based Urban \& Civic employee described how they had been involved in supporting residents to organise street parties, social clubs, and even a resident's association. Interestingly, they mentioned that within the first few years, this had proved very difficult, and in some cases unsuccessful, suggesting that perhaps it was "too early days" within the development. However, as Alconbury matures, they have observed community networks beginning to be built and the seeds of initiatives beginning to grow. This demonstrates how important a long-term approach is when fostering community networks. Similarly, they outlined their plans for supporting residents in setting up their own Parish Council in the future. In order to do this, their community development officers had been working to develop strong links with residents, in order to both educate residents on what such a process would involve, but also to identify residents who standout as potential "champions", who are well liked or connected within the community who may be appropriate community leaders. They also mentioned that at Alconbury, Urban \& Civic Development Officers were holding increasingly more frequent and varied resident forums addressing various governing, social or physical issues within the community. They see this as a means of gradually giving residents more experience in community management and eventually granting them more agency in the issues that affect them. The interviewee emphasised that this process takes time, and when rushed can "scare residents off" if they feel that being a community representative may be too burdensome or can lead to residents holding positions of responsibility that they are not well trained for. Similarly, Urban \& Civic were planning on 
organising and funding training programmes for residents who were interested in taking up managerial or governing positions within the community but felt they would benefit from further training.

The long-sighted approach also allows Master Developers to be reactive to social and health issues that arise within communities within their developments. Urban \& Civic organise quarterly strategy meetings with those working within the public services within their developments. This provides service providers the opportunity to relay any negative patterns of behaviour or health within residents. Such a process makes it more likely that issues such as antisocial behaviour or mental health are communicated and responded too. This has obvious benefits for the wellbeing of residents but also allows developers to maintain longterm desirability of the development. If such issues are allowed to propagate within developments, there is a risk that demand for land by housebuilders will diminish within the development.

Overall, the scale and length of Master Developer projects positions them "to better draw on the economy of scale to deliver better places for people, whether that's reducing carbon footprints, increasing biodiversity, delivering imaginative play areas for children, creating stronger community engagement and encouraging healthy lifestyles with footpaths and cycleways" ${ }^{\prime \prime 4}$. With austerity measures demanding local authorities take a more commercial approach to house building, partnership arrangements with Master Developers provides them with an opportunity to leverage the land owned within specified Growth Areas outlined in Local Development Plans. Indeed, successful examples of partnerships between developers and local authorities already include the Slough Urban renewal, which is a joint venture between Morgan Sindall Investments and Slough Borough Council, along with the local example of Waterbeach, in which Ministry of Defence has partnered with Urban \& Civic for the development of 6,500 new homes. Such partnerships present a structure of development and growth that is focussed on longevity, thereby promoting the creation of places where community networks can be nurtured.

\subsection{Perceptions of Cambridgeshire community groups on the effects of growth}

The survey demonstrated that most initiatives believe there has been an increase in population in their area in the last 10 years. 48\% (64/133) believed there was 'lots of growth,' and 37\% (49/133) believed there was 'a little growth' while only $0.75 \%(1 / 133)$ believe the population decreased (Figure 21). This widespread population growth could have multifarious effects on health, wellbeing and community-led initiatives, as described in Section 3. 


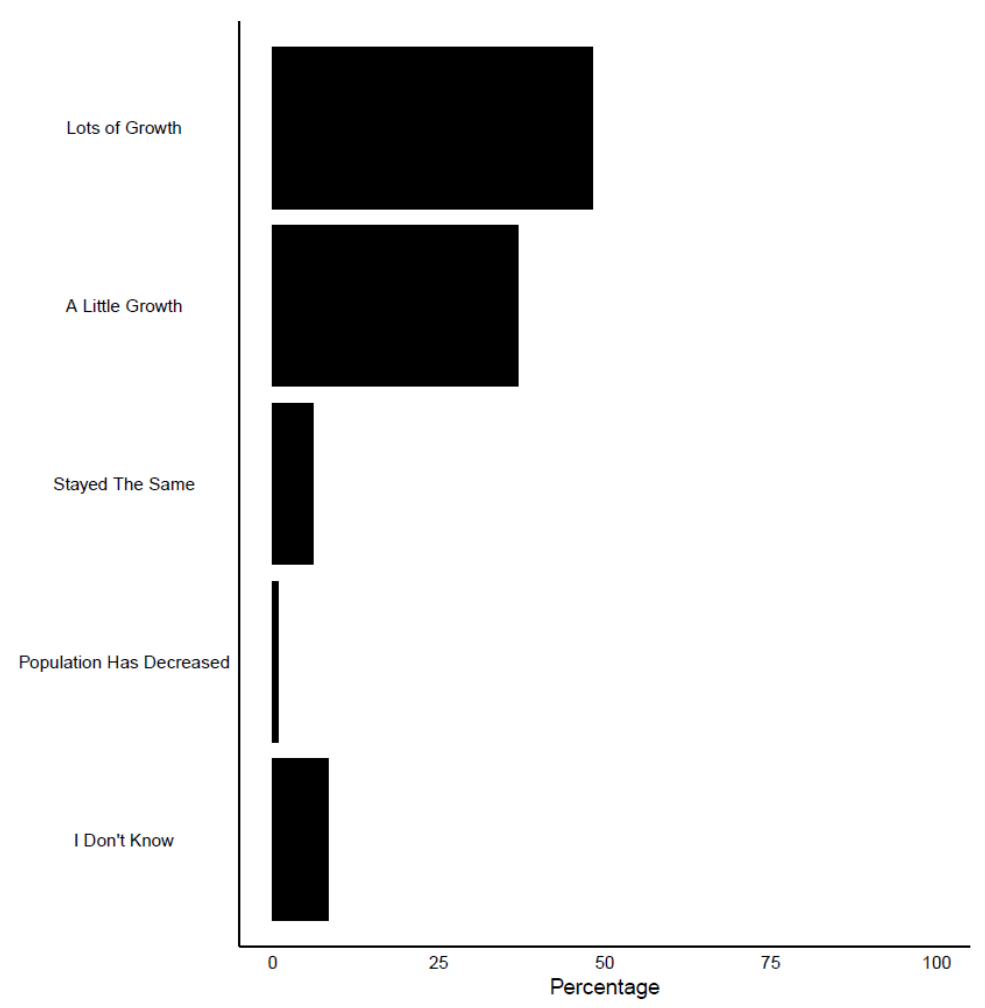

Figure 21: Do you believe there has been an increase in population in your area?

Over half of community initiatives surveyed reported an increase in demand for their services, with 34\% (45/129) stating demand had 'increased a lot,' and 26\% (33/129) stating demand had 'increased a little' (Figure 22). It is also important to recognise that population growth may not be a causal link with increase in demand for all services. For example, one LGBT organisation surveyed suggested the increase in demand seen by their organisation was due to increased awareness and acceptance of LGBT individuals in society resulting in more people living openly, and an increase in hate crimes. In addition, various groups suggested that the increasing financial pressures on citizens, and the decrease in funding available for government/NHS associated schemes, has resulted in increased use of community support groups regardless of population growth. Respondents to the survey also describe the dispersed effects of growth: growth in one area may result in community groups in that area being overloaded and people travelling to other locations to access services, demonstrating that population growth can have effects on community groups geographically distant from the area of growth. 


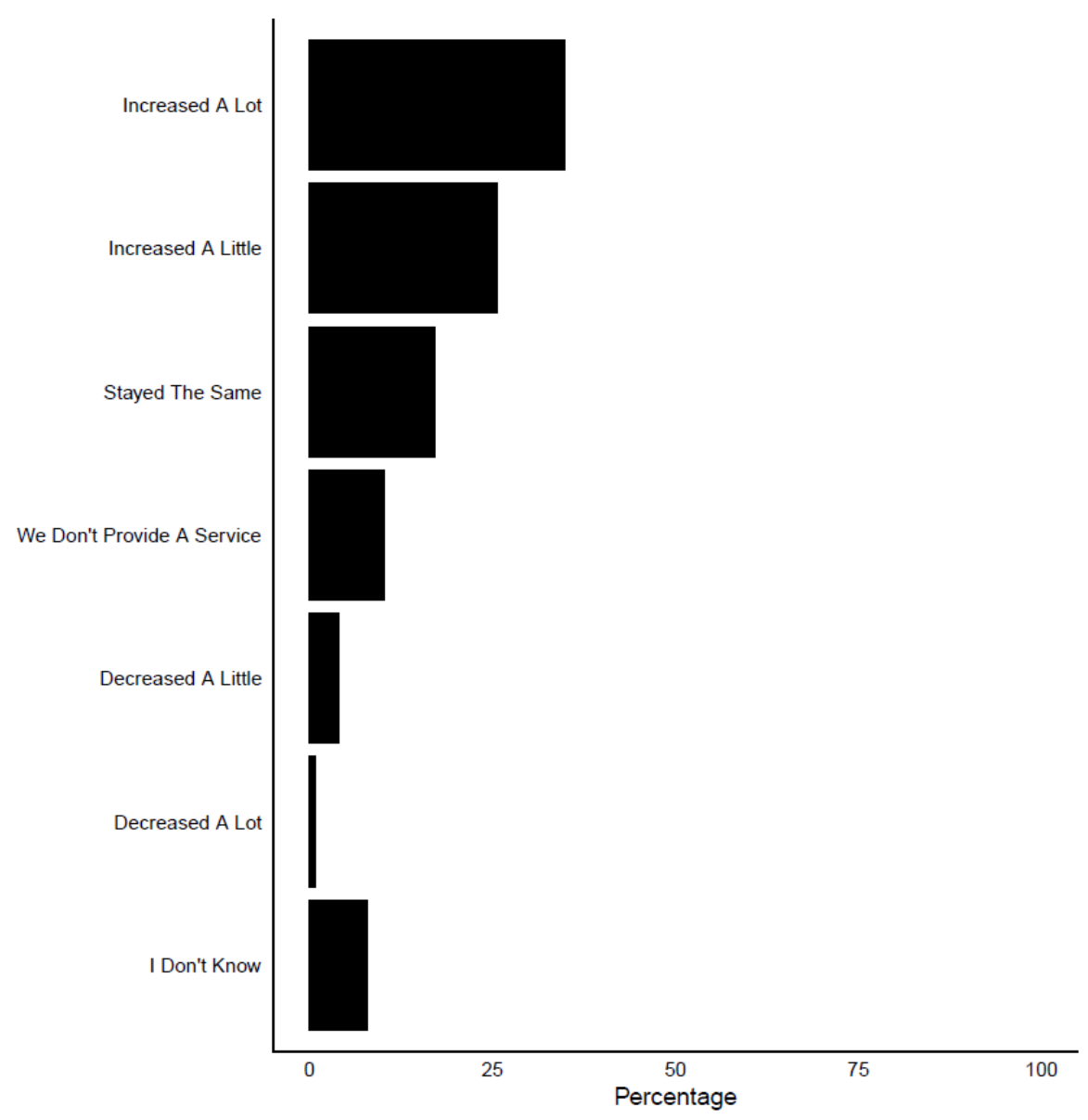

Figure 22: Do you believe there has been an increase in demand for your services?

Whilst demand for services has increased, 39\% (50/128) of respondents stated that population growth has 'had no effect on their organisation.' 35\% (45/128) stated that population growth had a 'somewhat positive' effect, and $12.5 \%(16 / 128)$ stated it had a 'very positive' effect (Figure 23). Comparatively, only $10.9 \%$ (14/128) stated population growth had a 'somewhat negative' effect, and $0 \%$ said it had a 'very negative' effect. This suggests that whilst population growth is occurring, and there is increased demand for services, the increased demand is not necessarily caused by the growth, or the increased demand is not having a negative effect on community groups. 


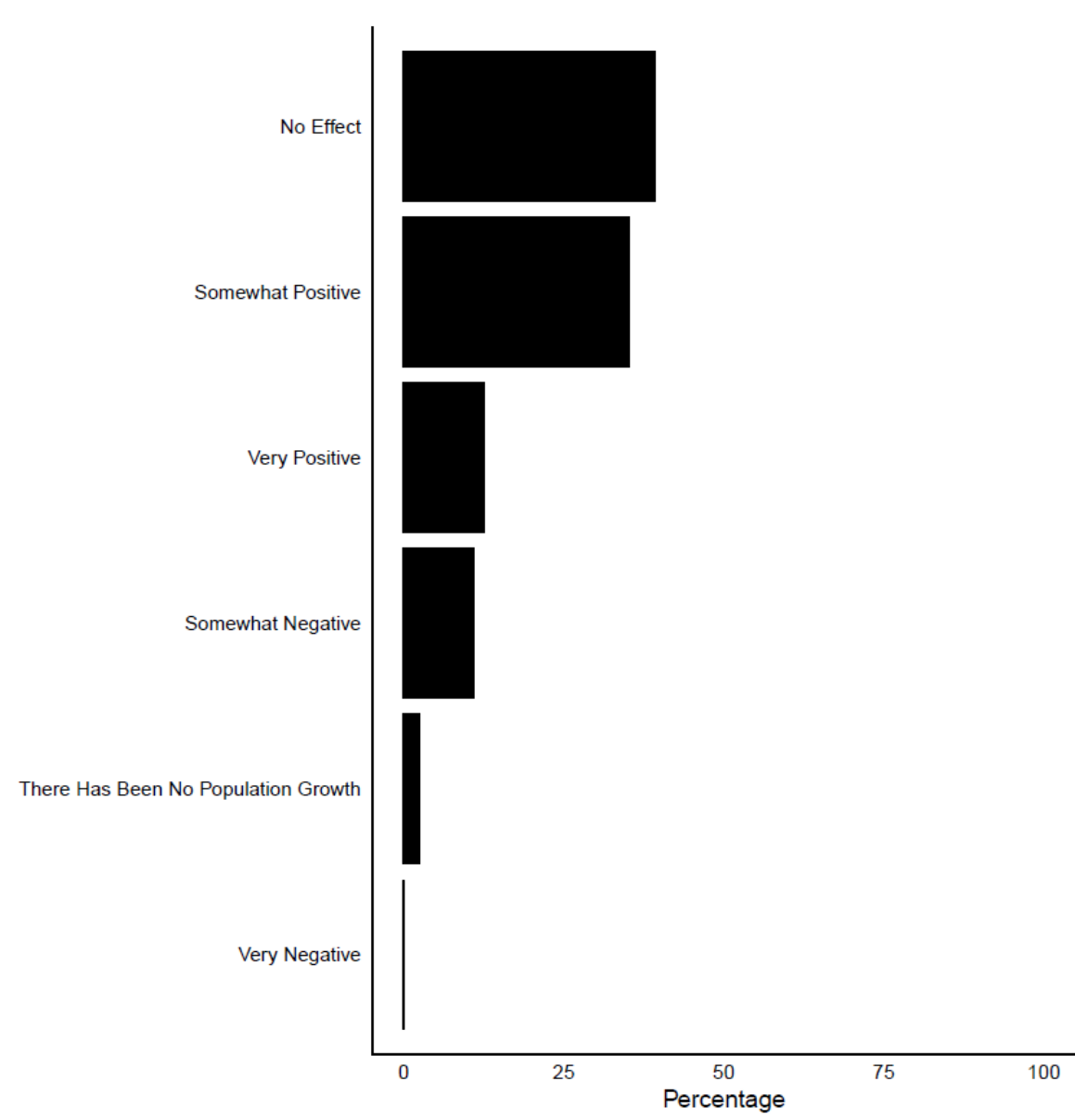

Figure 23: How do you feel population growth has affected your organisation?

Regardless of whether population growth is the cause of the increase in demand for the services of community groups in Cambridgeshire identified here, community groups still perform vital work towards the health and wellbeing of residents. Indeed, one respondent to the survey states that they gain most of their participants through NHS referrals. Therefore, it is essential that community groups are able to keep up with demand. $60 \%(67 / 111)$ of respondents said they are able to keep up with demand. It is noteworthy that demand may have increased with the COVID-19 crisis, and whilst currently able to manage that demand, some organisations are unsure whether they will be able to maintain this level of output longterm should the demand remain. However, it is worth noting that some survey respondents stated that the COVID-19 pandemic has increased community engagement in volunteering, which indeed appears to be a UK wide phenomenon, with over 2000 mutual aid groups listed on the mutual aid website ${ }^{65}$, but even this may not be enough if this momentum is not fostered by local government in the aftermath of the pandemic. Other reasons stated for being unable to keep up with demand include a lack of funding, a lack of appropriate venues/sports spaces, and in particular a lack of volunteers. Interestingly, other organisations responded stating their

${ }^{65}$ Craig Allan, 'Mutual Aid', accessed 29 October 2020, https://www.mutual-aid.co.uk. 
large volunteer base as the reason their organisations could expand and meet the increased demand.

Survey respondents were then asked about how population growth has helped their organisation, and how population growth had negatively impacted their organisation, the results of which can be seen in Tables 3 and 4. The main benefit mentioned within the responses was an increase in membership/participants/users for the community organisations. Interestingly, whilst the increase in participants was mentioned 39 times within the responses, the increase in volunteer numbers was only mentioned 10 times, potentially highlighting a disparity between growth rates of participant and volunteer numbers. In addition to the number of people involved, the diversity of the population and having a younger population were both stated as positive effects of population growth. The increased opportunities to promote their organisation/increased awareness of their organisation, and the opportunity to cover a wider geographical area were mentioned, and though less frequent, the increase in donations, opportunities to fundraise, funding availability and the chance to demonstrate a need for funding were also mentioned.

\begin{tabular}{ccc}
\hline Benefit & $\begin{array}{c}\text { Number } \\
\text { of } \\
\text { mentions }\end{array}$ & $\begin{array}{c}\text { Example quotation } \\
\text { more participants }\end{array}$ \\
\hline more volunteers & $\begin{array}{c}\text { "More people getting involved is always good" } \\
\text { "Positive: increased potential membership base" } \\
\text { "more people means more members and more } \\
\text { income for our organisation" }\end{array}$ & $\begin{array}{c}\text { "We have seen an increase in the number of } \\
\text { volunteers" }\end{array}$ \\
\hline increased diversity & 10 & $\begin{array}{c}\text { "A larger population gives us a larger } \\
\text { catchment of potential volunteers." }\end{array}$ \\
\hline "More people means more variety! We see \\
families from all walks of life at our groups \\
which is lovely."
\end{tabular}




\begin{tabular}{ccc} 
more funding & 1 & $\begin{array}{c}\text { "We see more young people regularly so we are } \\
\text { able to capture the need for our initiative and } \\
\text { funders see the need to approve funds." }\end{array}$ \\
\hline "We have seen an increase in the number of \\
volunteers and donations."
\end{tabular}

Table 3: The benefits of growth to community groups.

\begin{tabular}{|c|c|c|}
\hline Disadvantage & $\begin{array}{l}\text { Number } \\
\text { of } \\
\text { mentions }\end{array}$ & Example quotation \\
\hline less community engagement & 5 & $\begin{array}{c}\text { "By creating an influx of new residents who have } \\
\text { little interest in local initiatives, and community } \\
\text { activities, and who are 'socially disconnected' from } \\
\text { their community." }\end{array}$ \\
\hline lack of suitable venues & 5 & $\begin{array}{l}\text { "More pressure on pitch availability for training and } \\
\text { matches" } \\
\text { "Bigger numbers mean venues may be too small to } \\
\text { accommodate" }\end{array}$ \\
\hline lack of funding & 4 & $\begin{array}{l}\text { "funding hasn't risen in line with the increase in } \\
\text { population" } \\
\text { "Our waiting list has grown disproportionately to our } \\
\text { grant income and ability to deliver our service." }\end{array}$ \\
\hline lack of volunteers & 4 & $\begin{array}{l}\text { "We need to grow our capacity and capability to } \\
\text { reach out to more communities but there are } \\
\text { difficulties in finding sufficient volunteers especially } \\
\text { from BAME communities." } \\
\text { "As noted above, increased membership not } \\
\text { accompanied by wilingness[sic] to volunteer, creating } \\
\text { pressures." }\end{array}$ \\
\hline too much demand & 4 & $\begin{array}{c}\text { "We have had to turn people away when numbers } \\
\text { limit reached" }\end{array}$ \\
\hline traffic & 3 & $\begin{array}{c}\text { "bad traffic on hills road" } \\
\text { "Maybe greater traffic increase might deter travel to } \\
\text { classes" }\end{array}$ \\
\hline $\begin{array}{l}\text { negative impact on } \\
\text { participants }\end{array}$ & 2 & $\begin{array}{l}\text { "Because current planning policies encourage infill, } \\
\text { we are losing gardens in the village so the number } \\
\text { (not just the percentage) of villagers with very little } \\
\text { garden is increasing." }\end{array}$ \\
\hline $\begin{array}{l}\text { lack of long term } \\
\text { commitment }\end{array}$ & 2 & $\begin{array}{c}\text { "People less inclined to attend long term" } \\
\text { "People less committed to the area in the long term } \\
\text { means it's harder to secure volunteers." }\end{array}$ \\
\hline
\end{tabular}


Table 4: The disadvantages of growth on community groups.

When asked about the negative effects of population growth, the most frequently mentioned themes are lack of community engagement, and lack of suitable venues. Overall, however, there appears to be a linked issue: respondents state that growth causes a lack of settled population. These residents are not engaged in the community, nor are they available for a long-term commitment to their community or community groups. As such, community groups struggle to find volunteers. Other issues mentioned included a lack of funding, traffic or crime preventing people attending their community groups, too much demand for their group, and growth having a negative impact on participants.

Overall, community groups do not feel negatively impacted by growth, and whilst demand for their services has increased, most feel able to manage this increase. However, the vital nature of community groups in promoting health and wellbeing and contributing to the quality of life in this County means that support should be in place to aid those community groups who are unable to manage the demand for their services, and for future groups who may be impacted through growth. This survey shows a lack of community engagement and a lack of venues as the key mediators of the negative impact of growth on community groups.

\subsection{Recommendations}

Recommendation 3: Support community centres and infrastructure in new developments.

3.1. When possible, consider forming partnerships with Master Developers when developing large sites, especially those within "growth areas".

3.2. Consult with community groups prior to granting contracts with Developers. Use these consultations to set a minimum standard and overarching infrastructure promises that potential developers must meet in order to be considered.

3.3. Install community spaces before residents move into developments.

3.4. Construct a list of national organisations which can support the setup of local area groups in new communities and make this available to new residents.

3.5. Commission a report on the physical and social requirements of new communities that covers quantitative and qualitative criteria. 
3.6. Lobby for infrastructure that is mindful of health, promoting the development of environments that are green and sociable.

Northstowe, a new town that has been built on the outskirts of Cambridge as part of NHS England's 'Healthy New Towns' initiative, is a great example of how planning should be undertaken in future as the needs and desires of the community have been considered above the needs and desires of business. This approach should be followed when planning the expansion of existing towns or creation of new towns.

Recommendation 4: Include family homes in all new developments.

The survey highlighted that community groups require residents' long-term commitment to their communities to be successful and increase volunteer numbers. Therefore, efforts should be made in future developments to include affordable family homes, in the hope of residents staying in the area permanently. In addition, providing venues for community groups may help people integrate into an area and make them more likely to stay long term.

\section{Recommendation 5: Consider the effects of business growth on communities}

In addition to population growth, survey responses drew our attention to business growth, for example the impacts of the Cambridge Biomedical Campus on surrounding residential areas. They stated the impacts of increased traffic, house prices, and a lack of long-term commitment to the area making volunteer recruitment difficult.

Cambridgeshire County council should:

5.1 Conduct meaningful consultations with communities throughout the development process to make sure growth has a positive effect on surrounding areas.

5.2 All developments, business or housing should have a nominated liaison to work with local residents and community groups and ensure successful growth.

However, this survey did not focus on business growth specifically, and further work needs to be done to fully assess how communities can be supported through local business growth.

Recommendation 6: Improve the provision of affordable venues in existing communities

Cambridgeshire County Council should:

6.1. Conduct research into the availability of community facilities, to identify facility 'black holes.'

6.2. Conduct research to identify specialised facilities that are lacking in each region 
6.3. Ensure that initiatives that improve or provide new venues are informed by public consultation.

6.4. Consider using money that has previously been put into funding pools to provide free or subsidised facilities for community groups, whether these be libraries, other council owned facilities such as Child and Family Centres, or schools.

\subsection{Prioritise areas with poor health outcomes}

6.6. Ensure that any new venues are physically accessible. This means that adequate transport links should be set up to and from the community hub in order to ensure that all community members can partake in community groups if they desire, with adequate cycle routes, pedestrian access and parking, and that all facilities are accessible for those who may be differently abled.

An expansion of this recommendation is provided in Recommendation 11.2, which considers how the Think Communities programme and Libraries First model could use community hubs as a means to improve coordination and cohesion between community groups and other actors.

Recommendation 7: Improve the advertisement of community-led groups to boost volunteer recruitment

The survey shows that a lack of community engagement, and a lack of long-term commitment, both contribute to the lack of volunteers for community groups. Cambridgeshire County Council should support community groups with volunteer recruitment by:

7.1. Support and enhance VCS infrastructure support services (see Recommendation 14)

7.2 Use existing VCS infrastructure to host a large-scale volunteer event, in which community groups can have stalls promoting their groups, and potential volunteers can find opportunities. This could be online during the pandemic.

Other ideas include free printing for flyers and posters, promoting advertising opportunities in schools and libraries, subsidising advertisements in newspapers or on the radio, or sending out information alongside council tax bills. This would ensure that opportunities reach every household in Cambridgeshire. 
We found the County Council Directory of Services to be a poor resource that is difficult to use and does not cover the breadth of community groups within Cambridgeshire. To improve the advertisement of community groups, and also improve the access of council workers to community-specific knowledge (Recommendation 12), it will be vital to improve this resource. As the directory will be a key enabler of the Think Communities objectives, we recommend that the Directory of Services becomes the responsibility of the Think Communities partnership. This will also allow local knowledge from each partner organisation to inform the resource.

8.1. Work with District Councils and VCS infrastructure support services to expand and align databases of community-initiatives

8.2. Group initiatives based on district as well as theme - a good example of this is 'Connect to Support Hampshire'66.

8.3. Include a link for community groups to list their services on the directory

8.4. Show which organisations are actively recruiting volunteers

8.5. Ensure that there is up-to-date contact information for every group and that organisations that are no longer active are removed

8.6. Advertise the application and produce physical copies to be distributed at local community centres, shops, libraries and GP practices.

Such a resource would also be invaluable for social prescribers and other community-facing workers, such as social workers and teachers, who may be able to identify individuals who could benefit from such services

\section{Recommendation 9: Support volunteer continuity post-pandemic}

Cambridgeshire County Council should put infrastructure in place to maintain the momentum of new volunteers in the pandemic and signpost people to other opportunities post-pandemic. This may help maintain community cohesion and increase volunteer numbers. This is especially important, as pre-pandemic, volunteer numbers throughout the country were remaining largely stable (e.g. $\mathrm{NCVO}^{67}$ ). Therefore, this may be an invaluable opportunity to recruit new volunteers.

66 'Connect to Support Hampshire', accessed 15 October 2020, https://www.connecttosupporthampshire.org.uk/directories\&Type=Local.

67 'Volunteering', NCVO, n.d., https://almanac.fc.production.ncvocloud.net/volunteering/. 
Cambridgeshire County Council should:

9.1. Signpost people who volunteered in the pandemic to other volunteering opportunities post-pandemic.

9.2. Improve public awareness and understanding of community needs to encourage people to volunteer. 


\section{With great devolution of power, comes great responsibility: localism that empowers rather than exacerbates}

\subsection{Localism in the UK}

Within the UK, devolution remains a divisive policy. In 2010, the UK Government introduced the 'localism' agenda, which, in conjunction with the "Big Society", sought to shift power and responsibilities from central governments to the private and voluntary sectors, communities and individuals within their respective localities ${ }^{68}$. In theory, local authorities were to be recast as 'enablers', rather than providers, of public services ranging from development to healthcare and social care ${ }^{69}$. On the surface, the notion that an increase of public participation in policy leads to an empowered demos appears intuitive. Localism has the potential to bring 'decisionmakers closer to citizens to enable them to participate more effectively in shaping the public policy decisions and service outcomes that impact upon their lives ${ }^{\prime 70}$. In doing so, localism promises to engage and empower neighbourhoods ${ }^{67}$, and provide citizens with the opportunity to take responsibility for issues affecting their communities ${ }^{71}$ while also increasing trust and a shared feeling of identity ${ }^{72}$. However, critics of localism proclaim that it is simply a means by which the government can cut public services, leaving local communities with no choice but to fill the gaps left in the support services which are relied upon by the most vulnerable within society ${ }^{73}$. Levilas (2012) suggests that localism can be interpreted as either a 'hermeneutics of suspicion' in which austerity-related policy allows parochialism and inequality to grow, or a "hermeneutics of faith" in which local people harness their new found power to further social justice, participation and tolerance ${ }^{74}$. With this in mind, the following section explores various perspectives on localism in an attempt to understand how the localist agenda can be optimised so that individuals can be supported in developing innovative and inclusive policy agendas and local services within their communities. This will be followed by a

\footnotetext{
${ }^{68}$ Edward Hall and Sarah McGarrol, 'Progressive Localism for an Ethics of Care: Local Area CoOrdination with People with Learning Disabilities', Social \& Cultural Geography 14, no. 6 (1 September 2013): 689-709, https://doi.org/10.1080/14649365.2013.803290.

69 Andy Westwood, 'Localism, Social Capital and the "Big Society"', Local Economy 26, no. 8 (1 December 2011): 690-701, https://doi.org/10.1177/0269094211422195.

70 J. Painter et al., 'Connecting Localism and Community Empowerment: Research Review and Critical Synthesis for the AHRC Connected Community Programme.', Monograph, Project Report. Durham University, Department of Geography and School of Applied Social Sciences, Durham. (Durham: Durham University, Department of Geography and School of Applied Social Sciences, October 2011), http://dro.dur.ac.uk/9244/.

71 Liz Richardson, 'Working in Neighbourhoods, Active Citizenship and Localism', JRF, 29 March 2012, https://www.jrf.org.uk/report/working-neighbourhoods-active-citizenship-and-localism.

72 Gerry Stoker, 'New Localism, Participation and Networked Community Governance' (Manchester: University of Manchester. Institute for Political and Economic Governance, 2007).

73 Neil Hanlon, Greg Halseth, and Alec Ostry, 'Stealth Voluntarism: An Expectation of Health Professional Work in Underserviced Areas?', Health \& Place, Health Geographies of Voluntarism, 17, no. 1 (1 January 2011): 42-49, https://doi.org/10.1016/j.healthplace.2010.05.005.

${ }^{74}$ Ruth Levitas, 'The Just's Umbrella: Austerity and the Big Society in Coalition Policy and Beyond', Critical Social Policy 32, no. 3 (1 August 2012): 320-42, https://doi.org/10.1177/0261018312444408.
} 
narrowing of focus on how specifically health-oriented initiatives can be engineered and led by communities.

One of the dominant concerns of those who are sceptical of localism is that it encourages a "post-code lottery" in terms of community provisions. In theory, better resourced communities stand a better chance of adapting to neighbourhood-run support systems compared to localities with restricted community funds or those with general populations which lack the temporal, professional or social capital demanded by localist agendas ${ }^{75}$. It has been argued that a localist approach assumes that communities and neighbourhoods are homogenous and equally resourced when in fact the reality is quite the opposite ${ }^{76}$. Consequently, localism runs the risk of exacerbating the already present inequalities that exist between places and communities.

\subsection{Neighbourhood Planning: localism in action}

The uptake rate of the Neighbourhood Plan initiative, one of the flagship policies of the UK coalition government's localist agenda, validates concerns of a geo-economical divide in community resources. Generally, the initiative endeavoured to allow communities to produce a Neighbourhood Development Plan outlining the community's vision for future statutory land use planning policies. If successfully passed, which requires over $50 \%$ of the vote from a neighbourhood referendum, then a Neighbourhood Plan 'take[s] precedence over existing non-strategic policies in the local plan for the neighbourhood, where they are in conflict' (NPPF, 2012). However, the path to an approved Neighbourhood Plan is long, taking on average 29 months and requiring a considerable amount of time and expertise from participants; there are many examples of Neighbourhood Plans being initiated but never completed ${ }^{73}$. Reported difficulties and the time consuming-nature of the process has "meant that urban and more deprived communities have been slower to take up or progress, or have been deterred by the burdens involved"77. Similarly, a survey carried out by an online group called "Neighbourhood Planning" involving 45 'Frontrunner' areas, which were areas that received extra public funding and support in preparing their Neighbourhood Plans, found that 'most of those who responded said that communities lack resources and expertise". However, respondents also claimed that the Neighbourhood Planning process "provides plenty of opportunities for built environment professionals with knowledge of the planning system to

\footnotetext{
75 Simin Davoudi and Paul Cowie, 'Are English Neighbourhood Forums Democratically Legitimate?', Planning Theory \& Practice 14, no. 4 (1 December 2013): 562-66, https://doi.org/10.1080/14649357.2013.851880.

76 Gavin Parker and Kat Salter, 'Taking Stock of Neighbourhood Planning in England 2011-2016', Planning Practice \& Research 32, no. 4 (8 August 2017): 478-90, https://doi.org/10.1080/02697459.2017.1378983.

77 Susannah Gunn and Elizabeth Brooks, 'The Community's Capacity to Plan: The Disproportionate Requirements of the New English Neighbourhood Planning Initiative', in Reconsidering Localism, $2015,147-167$.
} 
make their contribution to the big society" ${ }^{\prime 78}$. Such comments elude to an environment which favours those privileged with professional expertise at the expense of those who do not. These imbalances have a knock-on effect in the success of community-led planning. Parker \& Salter (2017) observed a vast North-South divide in terms of the number of Neighbourhood Plans produced: $41 \%$ of Neighbourhood Plans that were initiated were based within the South-East and South-West of England. Similarly, 37\% of the Neighbourhood Plans which were finalised and passed were based in the South-East of England. The rate of Neighbourhood plans initiated was also lowest for the North of England. By using the Index of Multiple Deprivation at the LPA level, which places the most deprived areas into the $5^{\text {th }}$ quartile, and the least deprived into the $1^{\text {st }}$, Parker \& Salter (2017) found that $23 \%$ of the designated Neighbourhood Plan Areas existed within locations falling within the upper two quartiles of the deprivation index, whereas only $7.5 \%$ were found within areas classed as belonging in the lowest quartile of the deprivation index. Taken together, this evidence supports the concerns that there can be weaker uptake of community-led initiatives within disadvantaged areas, something that can in some cases be associated with the time and organisation skill-set demanded by such an undertaking. If left unchecked, such discrepancies, paired with an increased reliance on community-led public services, have the potential to lead to an enhancement of inequalities between areas.

Equity, rather than equality, may pave the way forward, however. Returning once again to Neighbourhood Planning as an exemplar of localism in practise, the majority of areas that finalised their plans the quickest were "Frontrunners" that had received $£ 20,000$ towards developing their plan and also received support from local authorities ${ }^{73}$. These frontrunners included both urban and rural areas and were evenly spread across England. This demonstrates that external support can be effective to "enabling" communities to organise and develop their own policy, regardless of socioeconomic status. Communities are diverse, and the underrepresented and marginalised can be easily overpowered or shouted over. However, if given the right tools and opportunities, less privileged communities can be empowered and given a voice. The following section focuses on how several underrepresented groups that exist within communities can be either let down or supported by localism. Being aware of such opportunities and hurdles has implications for equality at both the intra- and inter-community level and can be the difference between a self-selecting localism which simply perpetuates divides, and one which furthers democratic governance.

\subsection{Devolution vs democracy: giving everyone a voice}

When devolving power to localities, there is a danger that the nature of political and social participation will result in a "favouring of better educated, well-off and more vocally social

\footnotetext{
78 neighbourhoodplanning, 'Neighbourhood Planning: Lessons from the Frontrunners', 10 November 2011, https://neighbourhoodplanning.wordpress.com/2011/11/10/neighbourhood-planning-lessonsfrom-the-frontrunners/.
} 
groups, who have the time, capacity, and inclination to engage" ${ }^{\prime 73}$. Within this context, "the most organised and articulate, i.e. those able to mobilise and draw on networks of social capital, (are) likely to be the most able to manipulate the new environment to serve their own ends". Selen and Hendricks (2011) call upon theories of "deliberative democracy" as a way to avoid this ${ }^{79}$. Deliberative democracy is based on the idea that "those affected by a collective decision have the right, capacity, and opportunity to participate and deliberate in the making of those decisions" ${ }^{\prime 76}$. Specifically, they suggest that a focus on macro-democracy, which places an emphasis on the role that social movement networks, local associations, and the media (be that social or otherwise), can be informative ${ }^{80}$. Accordingly, to provide a sufficient platform to achieve deliberative democracy, public deliberation should be encouraged within various environments simultaneously; this involves everyday informal talks amongst citizens and social movements, being considered on a par with formal decision-making structures such as public assemblies and participation. Indeed, no single forum is sufficient and deliberative democracy can only be achieved when public deliberation is respected with a plethora of social institutions, arenas and spaces ${ }^{81}$. In order for local authorities to act as "enablers" they must re-evaluate the spaces that they consider amenable to public deliberation and the actors within these spaces. Barnes et al. (2004) claims that "the institutional design of participatory spaces has a significant impact of who participates and under what terms" ${ }^{\prime \prime 2}$.

Von Lieres and Kahane (2007) suggest that a particularly effective way of supporting inclusivity in deliberative forums is to create 'separate spaces' where members of marginalised groups can reflect on dynamics of power and exclusion, and 'negotiate questions of common agendas, strategies, and destinies' ${ }^{83}$. An example of "separate spaces" was demonstrated within the Romanow Commission established by 2001 by the Canadian Government. The commission structured a separate track for deliberative engagement with aboriginal people called the Aboriginal Forum which "'offered a context within which members of marginalised groups could build confidence and capabilities and their culturally specific modes of communication could find expression". Similarly, Zapata (2009) describes how within the Valley Futures Project in California, a scenario planning process, adopted strategic recruitment techniques to ensure broad community representation of culturally diverse groups, and the procedures encouraged

\footnotetext{
${ }^{79}$ Selen A. Ercan and Carolyn M. Hendriks, 'The Democratic Challenges and Potential of Localism: Insights from Deliberative Democracy', Policy Studies 34, no. 4 (1 July 2013): 422-40, https://doi.org/10.1080/01442872.2013.822701.

80 Democracy and Difference, 1996, https://press.princeton.edu/books/paperback/9780691044781/democracy-and-difference. 81 Archon Fung and Erik Olin Wright, Deepening Democracy: Institutional Innovations in Empowered Participatory Governance, The Real Utopias Project 4 (Conference 'Experiments in Empowered Deliberative Democracy', London: Verso, 2003).

82 Marian Barnes et al., 'Recent Research: The Micro-Politics of Deliberation: Case Studies in Public Participation', Contemporary Politics 10, no. 2 (1 June 2004): 93-110, https://doi.org/10.1080/1356977042000278756.

83 Bettina Von Lieres and David Kahane, 'Inclusion and Representation in Democratic Deliberations: Lessons from Canada's Romanow Commission', in Spaces for Change?: The Politics of Citizen Participation in New Democratic Arenas, 2007.
} 
multiple forms of communication, such as storytelling ${ }^{84}$. Employing unconventional forms of deliberation has been suggested to invert the usual bias towards wealthy, well-educated and high-status individuals and groups ${ }^{85}$. Similarly, Barnes et al. (2004) found that emotional and figurative speech communicated through a storytelling format can help encourage participation of those who are normally underrepresented in decision making processes. This encompassed older people, disabled people, and people with learning difficulties or mental health problems.

Creating a dialogue within communities that is modelled on a bottom-up, rather than topdown approach, can be key to gathering honest and representative feedback and community perspectives, which in turn can lead to effective community-led services. When faced with an "outsider", individuals may be reluctant or feel uncomfortable relaying their opinions or sharing their views if they feel they will be judged, misunderstood or simply ignored. A response to this is to appoint community members as the data collectors or interviewees. The Lambeth First initiative is an example of an inclusive and successful programme which did this and in doing so fostered greater community links, employability, inclusion and business. The programme was funded to train unemployed local people from the Stockwell area as community researchers in order to carry out interviews with a representative sample of local people in order to assess their perceptions of the area and how it may have changed over the last seven years. In order to be recruited onto the scheme, applicants were required to be a resident of the area and be either a lone parent not in work, on incapacity benefits, unemployed for more than six months, unemployed and disabled but able to work or on benefits for more than six months. Of the 50 applicants, 34 were enrolled onto the training programme, which provided them with training in personal development and interpersonal skills; training for community consultants; interview skills and questionnaires, and piloting questionnaires. Out of all the participants, 18 were then offered 14 weeks of employment upon completion of the training course. The community researchers carried out over 900 interviews with local residents ${ }^{86}$. Overall, the Lambeth First initiative brought immediate benefits to the individuals involved as it provided trainers with palpable transferable skills that boosted their employability, while also supporting conversations between local people around the development of their area and communities. Perhaps unsurprisingly, the project was selected for a regeneration award by the Local Government Chronicle.

\subsection{Bringing marginalised groups to the forefront}

\footnotetext{
${ }^{84}$ Marisa A. Zapata, 'Deliberating across Differences: Planning Futures in Cross-Cultural Spaces', Policy and Society, Deliberative Governance in the Context of Power, 28, no. 3 (1 October 2009): 197-209, https://doi.org/10.1016/j.polsoc.2009.08.002.

85 Iris Marion Young, Inclusion and Democracy (Oxford University Press, 2002).

${ }^{86}$ Stockwell Partnerships, 'Stockwell Urban II: Forward Strategy, Training and Employment Project Evaluation Report to Research Management and Outcomes Group', 2008, https://www.stockwell.org.uk/wp-content/uploads/2013/05/090325_Evaluation-report-A4-StockwellUrban-II.pdf.
} 
For localism to be truly inclusive, specific marginalised groups within communities must be actively engaged with and supported to spearhead services and initiatives: without this, localism will simply become an austerity measure which facilitated the reduction of public services. Minorities are 'already less likely to be involved in local decision making and are substantially under-represented at every level of the political system, be it parliament, local councils or devolved assemblies' ${ }^{\prime 87}$. Without inclusive decision making, localism runs the risk of giving rise to populism, and much needed services and provisions being shunned by a small, narrow- but equally minded few. This is particularly pertinent when communities are given agency over planning and development in their areas: building applications for mosques, provisions for asylum seekers, and provisions for traveller or gypsy sites run the risk of being left off the planning agenda if those connected to such sites are absent from community forums ${ }^{83}$.

Decentralised service provision also leaves room for unaccounted discrimination and abuse of power, meaning local authorities must be resolute in setting clear structures of accountability and protocols of complaints ${ }^{88}$. Similarly, they suggest that an "agreed set of rights and entitlements for key public services should be established such as wait times and standards of care should be agreed to and thoroughly enforced". This ensures that users of public services can be reassured that they are receiving an equitable service, regardless of where they live or who is providing the service. It is also paramount that service providers are continually held accountable for their level of inclusivity and reach. To ensure this, delivering organisations should ensure to continually collect data that will enable them, and outsiders, to scrutinise the equality implications of their work. Similarly, it should be the responsibility of local authorities to inform local service-providing organisations that they will be covered by the public sector equality duty by virtue of the fact they will be exercising a public function ${ }^{84}$. This will mean that the relevant service providers will be required to consider how their policies or decisions affect people who are protected under the Equality Act. If they fail to do this, they may be liable to be challenged in court by users who feel their service is discriminatory.

Elderly residents within communities are also less likely to be engaged with local service development; evidence suggests that people over the age of 75 are less likely to feel they can influence decisions that affect them locally more than any other group ${ }^{89}$. However, localism presents significant opportunities to empower those later in their life. Neighbourhood planning can be used to protect green spaces, local shops and community transport infrastructure, while the ability to nominate assets of community value also presents an opportunity to protect community centres and halls. Once again engagement is key and must

87 Vicki Butler, 'Local Communities, Diverse Voices', 2011, https://www.runnymedetrust.org/uploads/publications/pdfs/TUCLocalismGuide-2012.pdf. ${ }^{88}$ Phil McCarvil, 'All Things Being Equal: Equality and the Localism Act', 2011, https://www.runnymedetrust.org/uploads/publications/pdfs/TUCLocalismGuide-2012.pdf. 89 Gemma Bradshaw, 'Inclusive Localism', 2011, https://www.runnymedetrust.org/uploads/publications/pdfs/TUCLocalismGuide-2012.pdf. 
be an active rather than passive process. In collaboration with Age UK Rotherham, Rotherham Borough Council devised a "Home from home" scheme in which sessions were run in local residential homes to support residents and their families in expressing their view about the care they were receiving. Greater local engagement can empower older people and alleviate feelings of loneliness or isolation. An example of a programme which encourages mutual support, which can be seen as a means of ridding feelings of being burdensome, can be found in Age UK Bromley's community volunteers Time Banking scheme, which allows people 'to deposit time spent helping others, until they need to "withdraw" it to receive help themselves ${ }^{\prime 85}$. These examples demonstrate how innovative schemes can support elderly people in being empowered through localism, rather than becoming even more isolated.

Localism also poses potential risks to achieving gender equality within communities. The unpaid caring responsibilities carried by women vastly outweigh those by men. Around the world, women spend two to ten times more time on unpaid care work than men ${ }^{90}$. This means that any policy which changes the way in which care services are provided or simply reduces the level of car services cut, will almost certainly disproportionately affect women. A policy report published by the OECD claims "how society and policy makers address issues concerning care has important implications for the achievement of gender equality: they can either expand the capabilities and choices of women and men, or confine women in traditional roles associated with femininity and motherhood" ${ }^{\prime 36}$. The report continues: "every minute more that a woman spends on unpaid care work represents one minute less that she could be potentially spending on market-related activities in her educational and vocational skills". It is, therefore, paramount that localism does not fail women in this regard by simply leading to a greater burden of unpaid care responsibilities which act to hinder a women's education, employability, financial independence, and their right to safety from sexual and physical abuse $(\mathrm{OECD})$. In fact, the report specifically stipulates that in order to reduce inequalities in unpaid work, there must be "better access to public services, childcare and care for the elderly [which] allows for a better work-life balance". For localism to not fail women, the care provisions derived from community forums must not rely on majority female volunteers and must go above and beyond what previously existed as the status quo is clearly already insufficient. This further emphasises the need for organisations to continually record and publish data on the impact of their work from an equalities perspective so that they can be held accountable.

Localism does nonetheless present a much-needed opportunity to place women's voices front and centre of voluntary and community-led groups such that services can be designed and delivered in a way which liberates and empowers women. A report commissioned by Oxfam found that within central Local Strategic Partnerships (LSPs), only $28 \%$ of chairs were women and of those that they surveyed $72 \%$ of LSPs claimed they did not provide any specific support

90 Gaëlle Ferrant, Luca Maria Pesando, and Keiko Nowacka, 'Unpaid Care Work: The Missing Link in the Analysis of Gender Gaps in Labour Outcomes', 2014, 12. 
for women to engage in their business or structure ${ }^{91}$. Similarly, they found over $80 \%$ of LSPs did not monitor women's representation and of those that did, only four monitored gender representation in any formal way. This example not only demonstrates a lack of women's leadership and engagement within community- level governing structures but also an absence of data needed to tackle such inequalities. The report goes on to propose ways in which LSPs, but also by extension to local authorities and service-providing organisations generally, can ensure they support community-led initiatives that promote gender equality. They suggest that the government should set up and resource a scheme for local bodies to learn from good practice in representing women in decision-making; this could also fall under the remit of local authorities. They also suggest collecting, analysing, using and reporting on genderdisaggregated data as part of routine performance management.

Overall, in order for localism to lead to empowerment and inclusion, community-led initiatives must be representative of their respective communities at every level, be that at the level of service provision, management or leadership. The Council can encourage this by placing an emphasis on council grant application forms for provision of data on and examples of how community-led initiatives have considered and implemented actions that promote inclusion and access. Decision making processes at every level should be carried out through a range of focus groups, meetings and discussion groups that are tailored to the respective demographics within a community and data should always be collected from any of these events so that their success in achieving inclusion can be discerned. Importantly, these platforms should also be organised and run in collaboration with members of the community. Given that virtual meetings and online calls have become the norm in the post-COVID era, governing committees and meetings can be made more accessible to those who may otherwise find it difficult to leave the house at certain times due to childcare, professional work or schooling. Similarly, the ability to record virtual meetings and communicate via online communication platforms means that meetings need not be confined to a defined period of time, which can lead to a lack of representation and engagement. Instead, discussions can instead be accessed at any time by all interested parties, and commented on at a later date, supporting a dialogue that is continuous, reactive and, most importantly, inclusive.

\subsection{Recommendations}

\section{Recommendation 10: Increase volunteer diversity}

There has been large amounts of research into barriers to volunteering for different demographics, this is summarised in the review by Southby et al. (2019) who demonstrate that

\footnotetext{
91 'Getting Women into Local Strategic Partnerships: Knowing Your Community, Improving Public Services | Oxfam Policy \& Practice', Policy \& Practice, n.d., https://policypractice.oxfam.org.uk/publications ${ }^{*}$.
} 
5. With great devolution of power, comes great responsibility: localism that empowers rather than exacerbates

different demographics of people face different barriers to volunteering ${ }^{92}$. Zaitsu et al. (2018) also found that increased diversity in community groups correlated with improved self-rated health status, demonstrating that increasing the diversity of volunteer recruitment may improve health ${ }^{93}$.

Cambridgeshire County Council should:

10.1. Investigate the backgrounds of people who volunteer in Cambridgeshire.

10.2. Provide specific support to encourage underrepresented groups into volunteering.

10.3. Make the provision of inclusion data and strategies to promote inclusivity mandatory within council grant applications for community-led initiatives

92 Kris Southby, Jane South, and Anne-Marie Bagnall, 'A Rapid Review of Barriers to Volunteering for Potentially Disadvantaged Groups and Implications for Health Inequalities', VOLUNTAS: International Journal of Voluntary and Nonprofit Organizations 30, no. 5 (1 October 2019): 907-20, https://doi.org/10.1007/s11266-019-00119-2.

${ }^{93}$ Masayoshi Zaitsu et al., 'Participation in Community Group Activities Among Older Adults: Is Diversity of Group Membership Associated With Better Self-Rated Health?', Journal of Epidemiology 28, no. 11 (5 November 2018): 452-57, https://doi.org/10.2188/jea.JE20170152. 


\section{The effects of CCC decision making on community-led initiatives}

This section has been informed by questionnaire responses and telephone interviews. Written responses are noted in blue, and spoken quotes are in orange.

\subsection{Opinions of Cambridgeshire-based community-led initiatives on County Council involvement}

One section of our questionnaire aimed to examine awareness, understanding and opinions of the effects of CCC decision making on community-led initiatives. Firstly, we asked whether the community group leaders thought that the actions of the CCC had an overall positive, negative or neutral effect on their initiative (Figure 24). The most common response (39.0\%) was that they felt that the CCC had no effect on their initiative. The responses to this question indicated a lack of overall understanding regarding the role of the CCC, not only in supporting community-led initiatives but also more generally - this question gave the highest percentage of 'I don't know' responses (16.9\%) out of all the questions in the survey. $40.4 \%$ of respondents also left additional comments (Table 5). Reasons for the council having a positive effect included funding, use of council-owned premises, support and advice, use of libraries, and advertisement. Examples of negative effects included delays in council service provision, a lack of suitable facilities, diminishing funding availability, and cuts to local services that put pressure

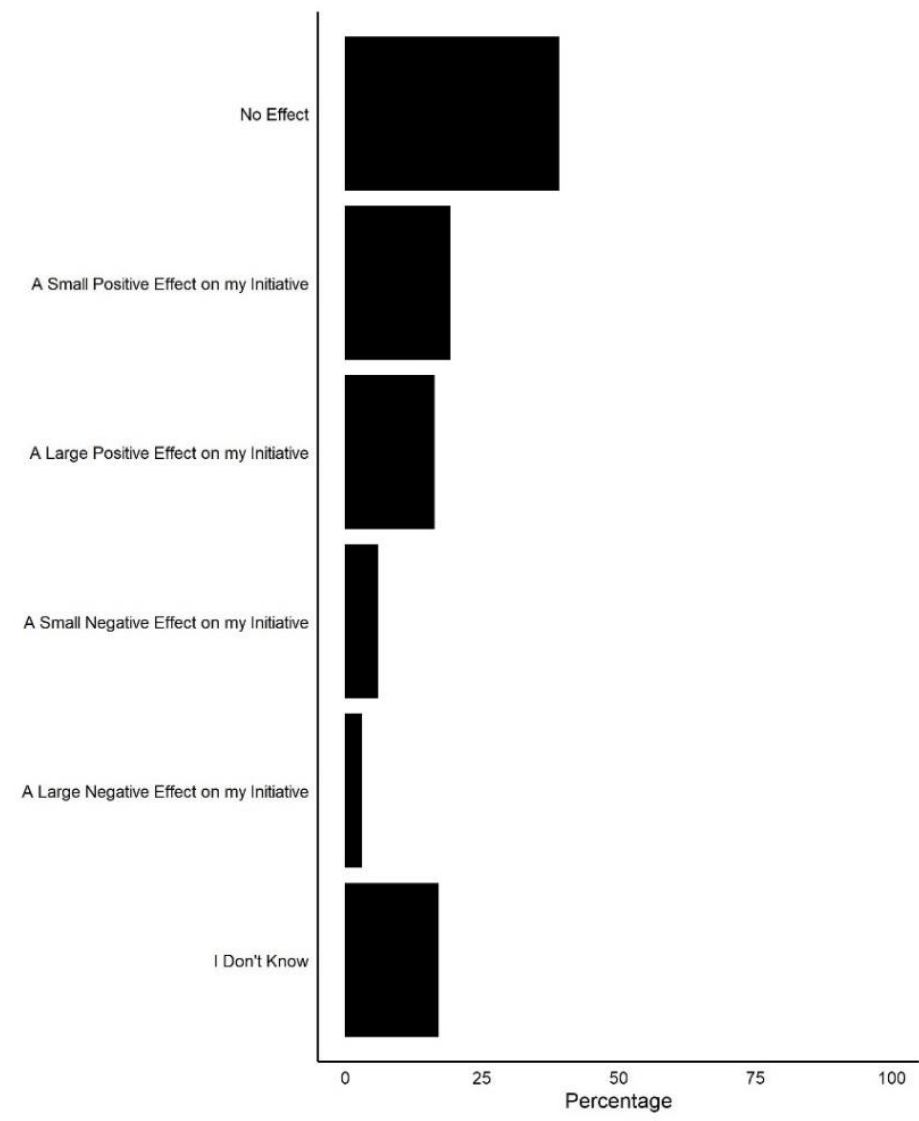

Figure 24: What effect has CCC had on your initiative? 
on voluntary organisations to fill the gaps. A number of respondents stated that the majority of their interactions are with the District, Town or Parish councils rather than the CCC.

\begin{tabular}{|c|c|c|}
\hline & Theme & Example quotations \\
\hline \multirow{5}{*}{$\begin{array}{l}\text { Positive } \\
\text { effects }\end{array}$} & Funding & $\begin{array}{c}\text { 'The Innovate and Cultivate funding gave us the initial } \\
\text { boost to set up our committee, devise our policies and help } \\
\text { us get up and running with locating and training our first } \\
\text { batch of volunteers.' } \\
\text { '...we would not be here but for a brilliant initiative and } \\
\text { seed-funding from Healthy Fenland Fund.' }\end{array}$ \\
\hline & Use of premises & $\begin{array}{l}\text { 'The County Council has allowed [our initiative] to use the } \\
\text { premises for the cooking of meals that are being distributed } \\
\text { as part of hampers.' }\end{array}$ \\
\hline & Support and advice & 'We have used safeguarding advice and model policies.' \\
\hline & $\begin{array}{l}\text { Dependence on } \\
\text { libraries }\end{array}$ & $\begin{array}{l}\text { 'Recent move to use library community room as main venue } \\
\text { for club meetings.' } \\
\text { '...our interactions with the county libraries have been } \\
\text { excellent.' }\end{array}$ \\
\hline & Advertisement & 'helping to promote us' \\
\hline \multirow{4}{*}{$\begin{array}{l}\text { Negative } \\
\text { effects }\end{array}$} & $\begin{array}{c}\text { Delays in service } \\
\text { provision }\end{array}$ & $\begin{array}{l}\text { 'We often find ourselves lobbying the County Council for } \\
\text { proper enactment of services which should be provided by } \\
\text { default (grass cutting, road maintenance etc). Often this is } \\
\text { much harder than it should be, taking volunteer resources.' }\end{array}$ \\
\hline & $\begin{array}{c}\text { Lack of affordable } \\
\text { facilities }\end{array}$ & $\begin{array}{c}\text { 'there is a chronic lack of facilities that can have block } \\
\text { bookings for competitive clubs like ours.' } \\
\text { '[facilities] had become very costly in the past.' }\end{array}$ \\
\hline & $\begin{array}{l}\text { Diminishing funding } \\
\text { availability }\end{array}$ & $\begin{array}{c}\text { 'Over the last } 16 \text { years we have seen a massive reduction in } \\
\text { the funding provided by CCC for open-access youth work } \\
\text { which has forced us to seek funding from individual Parish } \\
\text { Councils meaning that smaller villages are unable to afford } \\
\text { our services.' }\end{array}$ \\
\hline & $\begin{array}{l}\text { Cuts to local services } \\
\text { putting pressure on } \\
\text { voluntary } \\
\text { organisations }\end{array}$ & $\begin{array}{l}\text { 'Because local Adult Carer Services struggle to fulfil all their } \\
\text { duties under the Care Act a greater burden falls on families } \\
\text { and our support is not able to cover all the gaps.' } \\
\text { 'The [youth service] cuts have had a very negative impact } \\
\text { on what [our organisation] is able to provide.' }\end{array}$ \\
\hline No effect & $\begin{array}{l}\text { Relationship is with } \\
\text { District, Town or } \\
\text { Parish Councils rather } \\
\text { than CCC }\end{array}$ & $\begin{array}{l}\text { 'Our main source of practical help during [COVID-19] } \\
\text { lockdown was via district and especially parish councils. In } \\
\text { "normal" times the only Council we have much to do with is } \\
\text { the Parish Council.' }\end{array}$ \\
\hline
\end{tabular}

Next, we asked whether or not CCC has any direct involvement in their initiative, and if so, in what capacity. $70.3 \%$ of groups said that CCC had no involvement, while $18.8 \%$ said that they

Table 5: Example comments in response to the question 'The actions of Cambridgeshire County Council have...'. Comments are grouped by theme.

received Council funding, $10.9 \%$ use space or facilities owned by the Council and $7.0 \%$ have 
been promoted by the Council in the form of advertisements (Figure 25). Interestingly, when only groups with an income of less than $£ 5,000$ were considered, the percentage of groups which said the Council had no involvement increased to $81.4 \%$ (Figure 26). Other examples of involvement mentioned in the comments included provision of equipment, providing insurance and funding of partner agencies.

We also asked whether they were aware of any Council policies that indirectly affect their initiative. As we acknowledged that some people may be unaware of the Council's remit, we gave examples of public transport, education, social services and strategic planning. $45.9 \%$ of respondents answered this question. Positive examples of indirect involvement included council-run initiatives and events, and the provision of advice and support (Table 6). Negative examples included lack of public transport links hindering the ability of both workers and service users to access their groups, lack of facilities, social services, grass cutting, housing and school policies. Other examples with neutral connotations included local plans, strategic planning, environmental policy and planning permissions. A couple of groups acknowledged the impact of cuts to Council funding on the services they provide.

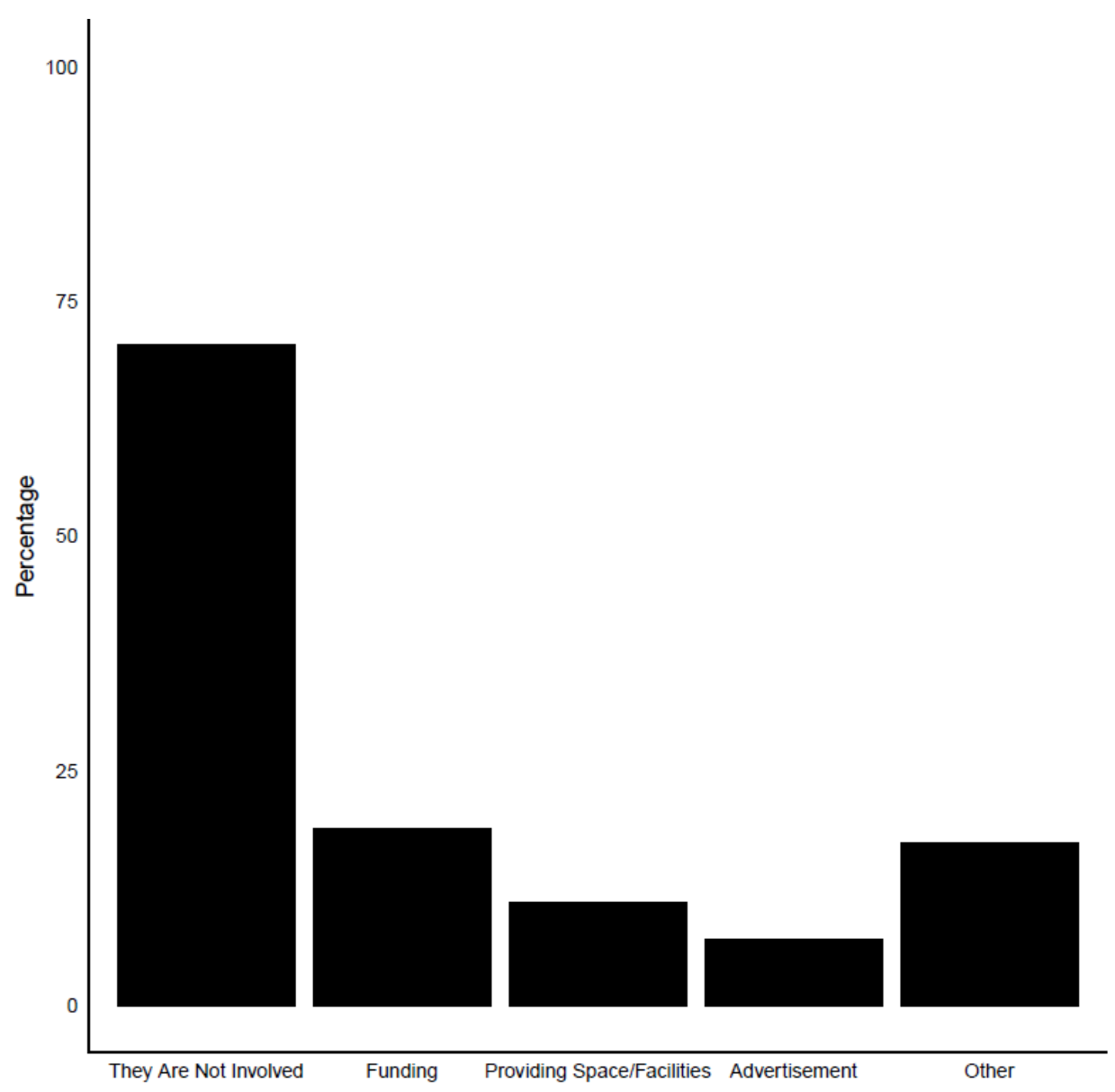

Figure 25: In what capacity is CCC directly involved with your initiative? 


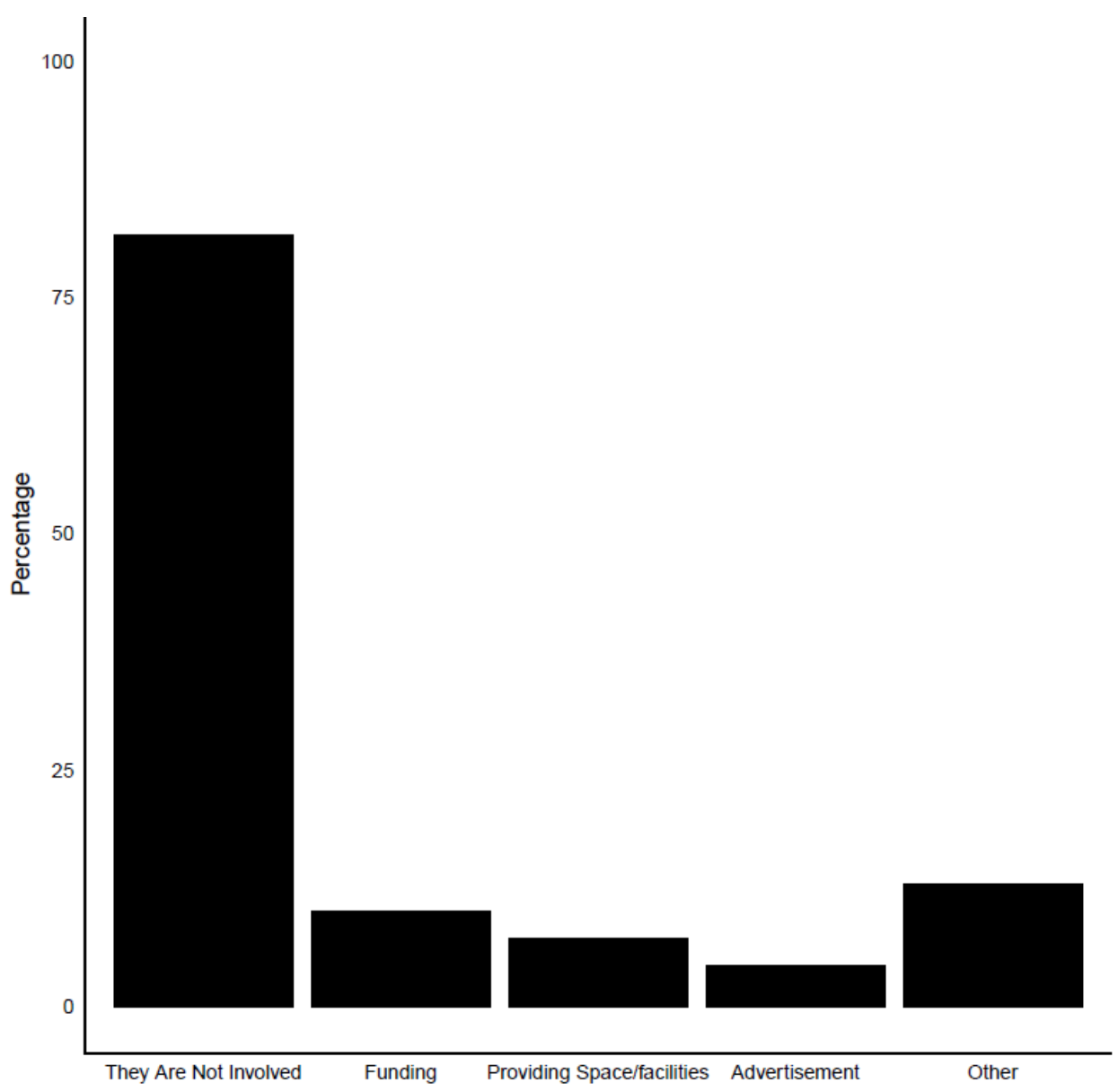

Figure 26: (For groups with an income less than $£ 5,000$ ) In what capacity is CCC directly involved with your initiative?

\begin{tabular}{|c|c|c|}
\hline & Theme & Example quotations \\
\hline \multirow[t]{2}{*}{ Positive } & $\begin{array}{l}\text { Involvement in } \\
\text { council } \\
\text { initiatives }\end{array}$ & $\begin{array}{c}\text { 'been involved in both transport strategy and the market town initiative - } \\
\text { been hugely helpful to get [our town] on the map at county level' }\end{array}$ \\
\hline & $\begin{array}{l}\text { Advice and } \\
\text { support }\end{array}$ & 'Providing advice and support, links to resources and guidance.' \\
\hline \multirow[t]{3}{*}{ Negative } & Transport & $\begin{array}{c}\text { 'public transport prices (including discounting policies), transport routes, } \\
\text { and timetables as well as the availability and cost of parking, disabled } \\
\text { parking, cycle parking and cycle routes are important considerations for } \\
\text { our members who chose (or have to use) all these modes of transport } \\
\text { and also affect where we locate our premises. 'better transport' is helpful } \\
\text { for members and staff but better will be different for each individual.' } \\
\text { 'The ability of our members to easily travel to volunteer for us at a variety } \\
\text { of sites in Cambridge and South Cambs is important, and is dependent on } \\
\text { transport links, parking etc.' }\end{array}$ \\
\hline & Facilities & $\begin{array}{l}\text { 'high cost of rent of premises' } \\
\text { 'Lack of facilities for the disabled' }\end{array}$ \\
\hline & $\begin{array}{l}\text { Social care } \\
\text { policy }\end{array}$ & $\begin{array}{c}\text { 'Many Adult Social Care policies have an indirect negative impact on } \\
\text { what we do. Policies on implementation of the Care Act Mental Capacity } \\
\text { Act and Mental Health Act spring to mind.' }\end{array}$ \\
\hline
\end{tabular}


Neutral Local plans 'Local Plans [affect] our families with regards to changes to their neighbourhoods'

Table 6: Example comments in response to the question 'Are you aware of any Council policies that indirectly affect your initiative (e.g. public transport, education, social services, strategic

planning etc.)? This could include policies that have an impact on the ability of your staff/volunteers to carry out their roles, or the ability of the people that use your services to access your initiative. Please describe the effect these policies have on your initiative'. Comments are grouped by theme.

\subsection{How could CCC help community-led initiatives?}

Finally, we asked whether the community group leaders had ideas for how the CCC could help their initiatives. $54.1 \%$ of the questionnaire respondents answered this question. Answers fit into a number of themes, summarised in Table 7 and discussed in more detail in the following sections. These answers led us to develop four more major recommendations, described in detail in Section 6.4:

1. Use the Think Communities approach to transform relationships with community-led groups by:

a. Improving coordination and cohesion (Recommendation 11)

b. Expanding Think Communities to cover all Council sectors, above and beyond Social Care (Recommendation 12)

2. Make funding sustainable and accessible for small start-up initiatives (Recommendation 13)

3. Strengthen and assist voluntary and community sector (VCS) infrastructure support services (Recommendation 14)

\begin{tabular}{ccc}
\hline Theme & Example quotations & Recommendation \\
\hline $\begin{array}{c}\text { Increase } \\
\text { recognition and } \\
\text { understanding } \\
\text { benefits that they bring to the communities in Cambridge } \\
\text { City would be welcome.' }\end{array}$ & $\begin{array}{c}\text { 'Being aware of the gaps that services face when it comes } \\
\text { to supporting young people and the importance of funding } \\
\text { for local projects and services that help support them.' }\end{array}$ & \\
$\begin{array}{c}\text { Improve } \\
\text { relationships }\end{array}$ & $\begin{array}{c}\text { 'Better direct relationships with officers responsible' } \\
\text { 'By helping us navigate who best to engage within the } \\
\text { Council' }\end{array}$ & 11 and 12 \\
$\begin{array}{c}\text { Acknowledge and } \\
\text { utilise community } \\
\text { knowledge }\end{array}$ & $\begin{array}{c}\text { 'Brusting and utilising our 'on the ground' knowledge' } \\
\text { Conduct } \\
\text { meaningful } \\
\text { consultations }\end{array}$ & 'Ask for more bottom-up feedback from grass roots level' \\
\hline
\end{tabular}




\begin{tabular}{|c|c|c|}
\hline Improve facilities & $\begin{array}{c}\text { 'Help to provide venues' } \\
\text { '[encourage] schools to be flexible in their approach to } \\
\text { providing accommodation' } \\
\text { 'The biggest problem [we] face (generally speaking) is } \\
\text { suitable, affordable and secure buildings in which to base } \\
\text { [ourselves].' }\end{array}$ & 3,6 and 11 \\
\hline $\begin{array}{l}\text { Less bureaucracy, } \\
\text { more adaptability }\end{array}$ & $\begin{array}{c}\text { 'less 'RED Tape' ' } \\
\text { '[The fund] has become too complicated to apply for.' }\end{array}$ & 11,12 and 13 \\
\hline Sustainable funding & $\begin{array}{c}\text { 'ensuring that funds are available to help us build our } \\
\text { capacity for providing services that help the Council } \\
\text { deliver its objectives' }\end{array}$ & 13 and 14 \\
\hline Increase promotion & $\begin{array}{c}\text { 'We could benefit from free advertising' } \\
\text { 'Maintaining directories of clubs and associations for } \\
\text { residents to search' }\end{array}$ & \multirow[t]{2}{*}{7 and 14} \\
\hline $\begin{array}{l}\text { Aid recruitment of } \\
\text { volunteers }\end{array}$ & 'help find and retain volunteers' & \\
\hline $\begin{array}{l}\text { Provide advice and } \\
\text { information }\end{array}$ & $\begin{array}{c}\text { 'advice on legislation' } \\
\text { 'advise us of any financial support that could be available } \\
\text { to us' } \\
\text { 'Training/advice on improving website and running social } \\
\text { media campaigns' }\end{array}$ & 14 \\
\hline
\end{tabular}

Table 7: Example comments in response to the question 'How could Cambridgeshire County Council help your initiative?' Comments are grouped by theme and the resulting recommendations (Section 6.4).

\subsubsection{More recognition and understanding}

Several groups highlighted the importance of their initiatives to their communities, describing how their services 'fill the gaps' left by local Council services and relieve pressure on Council workers and funds. For example, one group working in the adult care sector stated:

'... the average cost of a person entering the care system is approx 40-50,000 per annum. In the last 10 years [our initiative] has helped 14 people stay in their homes.'

Both in the written questionnaire (Table 7) and telephone interviews, a theme that appeared was the desire for more recognition for and better understanding of the work that they do. One group spoke about this in detail, highlighting that better recognition and understanding would lead to better coordination between their group and the CCC, therefore helping to identify ways that their group could take pressure off CCC services:

"[Our interactions with CCC are] very dependent on how much social care want us to be involved and have an understanding of our involvement with the families. Some of [the officers] will understand it really well and realise that we have a good insight into our families' lives because we've known them for a while and we see them regularly. Others will just think that we're a play group and that we don't have that much interaction... 
[We get] taken for granted a little bit... we do that lower-level support of families that they're not able to do because they don't have the money or the time to do it...

[We're] identifying people that would never be on the radar of the County Council because they don't meet the criteria... and it goes unnoticed."

\subsubsection{Improve relationships}

Another popular theme in answers to this question referred to inefficient interactions and relationships with Council workers and directorates. When asked whether they thought that the community initiative would have benefited from closer relationships from CCC officers, one community group lead said:

'[It] would have helped to have that assistance...this is a particular weakness of Cambridgeshire County Council, we just haven't had those relationships... With Huntingdonshire District Council...we have had a really good relationship with them and really good direct officer relationships... With CCC... it's always been really hard to find someone who will take responsibility for getting something sorted, basically their approach has been much more hands-off.'

'Having direct lines of communication with a dedicated officer or someone who was tasked to work with us and advocate for us [would've been good]. We have a County Councillor - that should be [their] role... our relationship with [them] hasn't been brilliant... we found that [they] haven't used [their] position and influence to advocate for us in the way that we might have hoped... If we'd had a clearer line of [communication], that would've been really helpful.'

It was commonly reported that interactions are better with officers who understand the community and the community groups active in those areas, which provides support for the idea of improving knowledge and understanding of community groups within the CCC (6.2.1). For example, one group lead compared interactions between the CCC Cycling Team and County Highways:

'We have a really good relation with officers in the County Cycling Team... they know the area, they know us, they know what we're interested in. They have moved to a quite collaborative mind-set... We have never succeeded in building a relationship with County Highways... I would really like a relationship with [them] because I think there are things we could draw their attention to about the specific local context of a scheme.'

One group lead noted that interactions with the CCC during the COVID-19 pandemic have been effective and timely, and should inform strategies for improving relationships with VCS group beyond the pandemic: 
'[One way in which we interact with CCC] has been through the support they provide for people who are shielding... on the whole [these interactions] have worked pretty well'

\subsubsection{Acknowledging and utilising community knowledge}

As well as feeling like their work goes unrecognised, many groups also felt like their work is underutilised, and that their 'insider knowledge' could be used to improve Council services and the popularity of Council initiatives.

One group lead gave an example of where road closures during COVID-19 had been implemented without consultation. They felt that better relationships with County Highways would have led to a better outcome both for the residents and for the Council.

'Because they have [closed roads] under emergency powers, they do it, and then consult afterwards, and that's an approach that automatically engenders hostility... because people do not feel like they're included in decision making about their area... It's been very clumsily communicated, there's been no attempts to say to local people... this will be better for you... They could've done a better job of selling it in its local context... we could've helped give them that local context.'

\subsubsection{Meaningful consultations}

Following on from the previous point, it was suggested multiple times that one way to better understand the work of community groups (6.2.1) and gather community knowledge (6.2.3) is through public consultation. One group lead highlighted the importance of any consultation being both early and meaningful:

'They talk about consultation all the time, it's become a joke because there are so many consultations that go on in [our area] because there are so many schemes being delivered by the County, the City, the Combined Authority. They all do consultations, and none of the bits join up, and most of the time it feels like it's paying lip service to the idea of consultation... [Change] is ad-hoc, sprung on people, done very insensitively, and the project management is disastrous.'

Speaking specifically about the Cambridge Biomedical Campus, one group lead noted:

'There's never been a point where there's been a debate about its desirability or its practicality, it's always been a given that growth of the Campus is a good thing... We struggle to have a voice because the Campus is this wonderful global trophy for Cambridge, and the discomforts of its immediate neighbours are of much less interest.' 
While another spoke about how consultations they have been involved in regarding Child and Family Centres have been ineffective:

'We used to get invited onto Child and Family Centre Partnership board meetings... but they were always quite sporadic, you never knew who was going to turn up... it felt like a chore to go to them because they were sold as this thing that they had to do to tick a box to make sure that they were involving their user groups, rather than it actually being meaningful.'

\subsubsection{Improve facilities}

As described in Section 4, a lack of venues was identified as a key mediator of the negative impact of population growth on community groups in Cambridgeshire. Out of 79 people who responded to this question, 17 (21.5\%) specifically mentioned the lack of affordable facilities, and it was also a common theme in the telephone interviews. One group lead noted that their community support group has no access to suitable facilities to host events or store equipment, which is instead stored by various members of their group:

'The one thing I have learnt doing this over the last 5 years is that if you do not have places to do things, your job will be 15, 20, 30 times harder... I am desperate for physical space.'

\subsubsection{Less bureaucracy, more adaptability}

It is apparent that interactions with the CCC that involve applications, including for funding or permission to host events, are hindered by overly bureaucratic processes.

'In order to close a residential road for 3 hours [for Play Streets], you have to give 8 weeks' notice and you have to get a petition signed by $50 \%$ of the residents... Back in May and Early June, you couldn't go round door knocking then, asking for signatures [due to the COVID-19 pandemic]. I made some representation that they ought to relax their criteria for this year, and I got absolutely nowhere. That makes me really cross because I come at it from a community development point of view, and the way you develop community is by creating opportunities

for people to come together... it is indicative of a very internally referenced frame-of-mind which is all about what suits them, rather than what would actually help residents.'

People who had, or had considered applying for the CCC Innovate and Cultivate fund were asked about their experiences of applying. A family support group, who had previously looked into applying but had never done so, said that they were put off by hearing 'how time intensive the application process is and the amount of evidence you need to provide in terms of long term outcomes'. They said that this was a particular problem for their type of group, as 'we often don't hold this sort of evidence as families leave us after three years max, sometimes earlier'. In addition, they said that they have had 'mixed messages about our 'fit' with the fund', having 
been told on some occasions that their group would be a suitable applicant, and being told other times that they wouldn't - 'there seems to be a different understanding of what/who the fund is meant for depending on who you speak to'.

The founder of a community support group, who received cultivate funding on the third time of application, spoke about how despite their extensive career background in business, they still had to 'learn' how to apply over a period of 2 years before writing a successful application.

'I didn't know how to write policy documents... I had about 10 documents I had to [write in order to apply]...If it had been someone else who had knowledge of local government and had done these sorts of things before, my process would've been quicker.'

When asked about the problems with the application and funding process, they spoke about a lack of help and advice, particularly on receiving a rejection, and the time-consuming evidence reporting:

'Whenever I was rejected I always made the phone call... I thought 'I have to find out where I've gone wrong'. They should certainly be more proactive and say 'look, love your ideas, what we want from you is...' and just not wait for me to go to them... just take the time to hold people's hands because we're not used to talking in that format.

'I do quarterly reports for [the cultivate funding]. It is [quite a lot of work], all for [around $£ 2,000]$. I mean, it's what I used to have to do [in my business] for half a million pounds in the EU.'

\subsubsection{Sustainable funding}

19 of the 79 people who responded to this question said they would benefit from direct funding from the Council, for example through the Communities Capital Fund or CCC Innovate and Cultivate. 4 respondents noted that they simply required more information about sources of funding, and 11 said that the Council could help boost their funds indirectly, for example, by providing more affordable venues. Groups with an income of under $£ 5,000$ were more likely to mention the need for funding, or the lack of affordable venues (Table 8).

\begin{tabular}{llll}
\hline Topic mentioned & All groups (out of 79) & $\begin{array}{l}\text { Groups with income } \\
\text { under } \mathbf{E 5 , 0 0 0} \text { (out of } \\
\mathbf{4 1 )}\end{array}$ & $\begin{array}{l}\text { Groups with income } \\
\text { over } \mathbf{E 5 , 0 0 0} \text { (out of } \\
\mathbf{3 8}\end{array}$ \\
\hline Funding (direct) & $19(24.1 \%)$ & $11(26.8 \%)$ & $8(21.0 \%)$ \\
\hline $\begin{array}{l}\text { More information } \\
\text { about funding }\end{array}$ & $4(5.1 \%)$ & $1(2.4 \%)$ & $3(7.9 \%)$ \\
\hline
\end{tabular}

Table 8: Number of groups mentioning the need for funding, information about funding, or facilities, in response to the question 'How could the Council help your initiative?'. 


\begin{tabular}{llll}
\hline Funding (indirect) & $11(13.9 \%)$ & $7(17.1 \%)$ & $4(10.5 \%)$ \\
\hline Facilities & $17(21.5 \%)$ & $10(24.4 \%)$ & $7(18.4 \%)$ \\
\hline
\end{tabular}

There was a strong link between the themes of recognition and funding, with a number of groups suggesting that there is little recognition that the actions of these groups are saving the CCC money, and that some of the savings made should go towards these groups.

'When we already volunteer our time to clear up litter in our area, we shouldn't have to volunteer more time trying to raise funds. We are obviously saving the council a lot of money they would of had to spend on street cleansing[sic], it would be nice if they recognised that and sent the group some of that saving.'

'We work in child and family centres and pay rent there... We're doing some of the universal work that potentially the County Council should be doing, or might have done in years past... and yet we're paying rent for the privilege of doing that.'

Another suggestion for how the Council could provide indirect financial support was through the provision of free expert services, such as insurance or printing.

\subsubsection{Increase promotion}

Assisting the advertisement of community initiatives was also identified as a mechanism to mitigate the negative effects of population growth on community initiatives (Section 4). Strategies to improve promotion in regards to volunteer recruitment were outlined in Recommendation 7, and will have the added benefit of increasing promotion to potential service users.

\subsubsection{Provide more advice and information}

Several respondents noted that more information about available funding would be useful (Table 7). When asked whether they were aware of any funding available for community-led initiatives, only 37 respondents said they were. 14 of these specifically noted funds available from the CCC, including the Innovate and Cultivate fund (7), the Community Reach Fund (3), Community Capital Fund (2) and Local Highway Improvement Funding (2). 2 respondents noted funding from the Support Cambridgeshire organisations, while 5 mentioned the Cambridgeshire Community Foundation Fund and 8 mentioned funds from Districts, Town or Parish councils. The need for advice on how to apply for funding and how to write policy and safeguarding documents was also frequently brought up.

\subsubsection{Recruitment of volunteers}


A number of groups highlighted difficulties in retaining volunteers in situations of high population growth and fast population turnover. A discussion of this problem and the potential solutions are described in Section 4.

\subsection{Council support in the time of COVID-19}

As described in Section 3.6, community-led groups and initiatives have been the key to mitigating the negative effects of the COVID-19 pandemic on community health and wellbeing. A key concern is how to now maintain the momentum gathered on these initiatives and to support them to continue their work throughout and following the pandemic.

In our questionnaire, we asked whether groups had accessed support from the CCC during the pandemic. $8.5 \%(11 / 130)$ groups said they had accessed support from CCC in the form of advice, while 6.2\% (8/130) had received funding from the Council to provide COVID-19 related support in the community (Figure 27). Although $10.0 \%$ of people selected 'Other', most of the comments were unrelated to CCC COVID-19 related support.

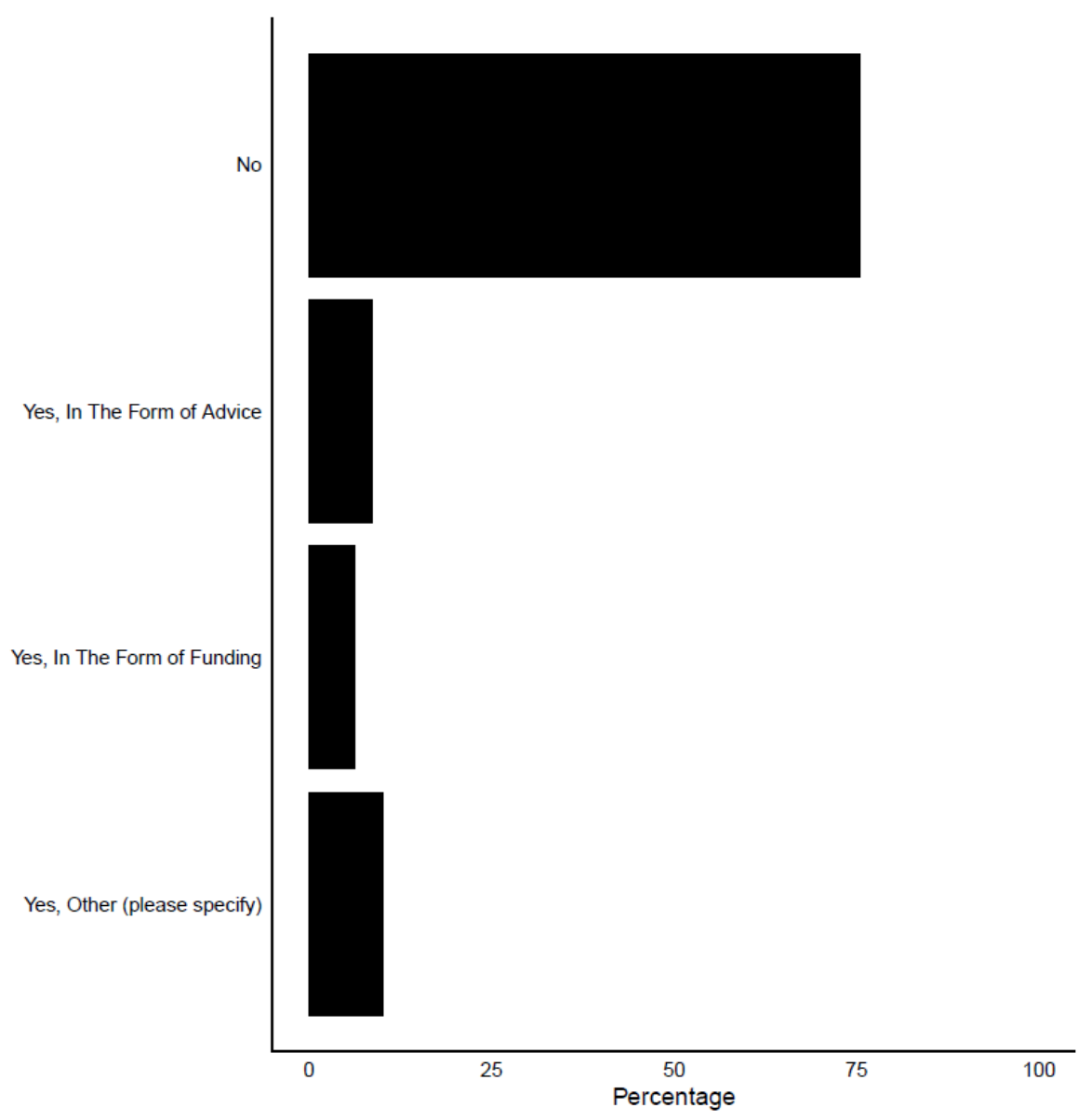

Figure 27: Did you receive support from the CCC during the pandemic? If so, in what form? 
We also asked how the CCC could be supporting community-based initiatives during the pandemic. We have decided to not make specific recommendations based on these responses as we consider the role of the CCC during the pandemic to be beyond the scope of our question. However, as we believe these answers may be of general interest, we have included some below (Table 9). The answers fit into four general themes, and generally correspond to the suggestions already made in response to 'How could the Council help your initiative?' (Table 7): sustainable funding, meaningful consultations, advice and information, and ensuring lessons are learnt. The anonymised responses have been shared with Transformation Manager Becca Gipp to inform a related research project commissioned by the Cambridgeshire and Peterborough Local Resilience Forum.

Our results align with those of the CCVS survey introduced in Section 3.653. Most organisations surveyed by CCVS were concerned about a lack of funding, with the total income loss from voluntary services during the pandemic across Cambridgeshire predicted to be $£ 34,593,000$. Concerns were also raised regarding the availability of volunteers, the mental health of volunteers in responding to such a crisis, and a lack of resources to allow the initiatives to adapt further.

Having observed how crucial these services have been throughout the pandemic, and having acknowledged the potential benefits of these initiatives for overall health and wellbeing (Section 3), these results suggest that the CCC should prioritise funding and providing adequate resources to voluntary services moving forward. Priority should be given to those which service marginalised and disadvantaged communities; we know that these communities often exhibit the worst health outcomes, and this has been no different during the COVID-19 pandemic, with infection rates and mortality rates being disproportionately higher in these communities ${ }^{94}$. There may be numerous reasons for this, such as these individuals being more likely to be employed as key workers, or more likely to live in multi-person households. However, one reason may be that these communities are less likely to be supported by voluntary and community services (Section 5), meaning support for those more vulnerable members of the community has not been available. This must be addressed by promoting and supporting community development in the most disadvantaged areas first and foremost.

\begin{tabular}{ll}
\hline Theme & Example quotations \\
\hline Sustainable funding & 'Assurances around on-going funding' \\
& 'financial help for cancelled fund raising[sic] events' \\
& 'We are now quite financially strained, due previous outstanding charges \\
& and we have reduced subscriptions this term as meeting[sic] are no longer \\
\hline
\end{tabular}

${ }^{94}$ Cato T. Laurencin and Aneesah McClinton, 'The COVID-19 Pandemic: A Call to Action to Identify and Address Racial and Ethnic Disparities', Journal of Racial and Ethnic Health Disparities, 18 April 2020, 1-5, https://doi.org/10.1007/s40615-020-00756-0. 


\begin{tabular}{ll}
\hline & the same and some members have not participated. So some council \\
& grants could have been beneficial.' \\
\hline Meaningful & 'Forums that draw communities groups together for information on how \\
consultations & 'The County can support' \\
& 'The lack of consultation about the closure of Mill Road bridge was hugely \\
\hline Provide more advice & 'By ensuring that there is clear information about infection rates and other \\
and information & useful data across the County.' \\
'advise how we can apply for funding now that our own fundraising \\
activities have ceased' \\
'We know how to contact the relevant service personnel to seek advice. It \\
would be even better if the Council can reach out to the community \\
groups more proactively to offer help.' \\
'The CCC could look at what has gone well and not so well and then form \\
a strategy for preserving the good things that have happened in \\
communities. Now that people have learned to talk to each other and to \\
help each other it would be good to keep this going before the lessons \\
have been forgotten. I think its[sic] very easy to concentrate on COVID-19 \\
and suddenly realise its[sic] Post-Covid-19 and now what do we do?' \\
'more strategic thinking not just about the immediate situation but the \\
long term benefits and opportunities of learning from COVID and \\
lockdown'
\end{tabular}

Table 9: Example comments in response to the question 'How else could Cambridgeshire County Council be supporting community-based initiatives during the COVID-19 pandemic?'. Comments are grouped by theme.

\subsection{Recommendations}

\section{Lessons from the NCPs: Use the Think Communities approach across all Council sectors to transform relationships with community-led groups}

The Think Communities partnership approach, initiated in 2018 as a collaboration between Cambridgeshire and Peterborough partner organisations, aims to create a shared vision on how to develop community resilience in a way that is place-based, people-centred and solutions-focussed ${ }^{23}$. Our research provides evidential support for the ideas underpinning this approach, while also highlighting areas for improvement and additional strategies that could be assimilated into this framework.

The current priorities for the Think Communities partnership are:

1. Outbreak management

2. Support for carers

3. Support for older people

4. Increased take-up of Technology Enabled Care (TEC)

5. Support for children and adolescents

6. Tacking food and fuel poverty and security 
7. Improving social mobility

8. Implementing place-based commissioning

We propose two additional priorities for the Think Communities partnership moving forwards, as priorities shift from outbreak management:

1. Provide a framework for coordination and cohesion

2. Continue to expand Think Communities to cover all Council sectors, above and beyond Social Care

Recommendation 11: The Think Communities Partnership should prioritise provision of a framework for coordination and cohesion

One of the hypotheses underpinning the commission of this report was that 'community groups do better when left to their own devices'. The feeling of community-groups towards this notion was summarised by one community group lead:

'Being left to our own devices has resulted in something much more sustainable... but I don't think we've been well enough supported... it's a case of supporting better but not interfering or taking over, but providing resources, support and better lines of contact and communication.'

'It's not about the County Council trumping what everybody else does... It should be about people understanding what the statutory services are, what the county council are doing... and an understanding of what the voluntary sectors are doing.'

From our research, we believe that the key to supporting community groups will be the formation of a framework that improves coordination and cohesion between different VCS actors and local government. While Think Communities is already working towards this objective, we believe its potential impact on community initiatives means it should be a major goal. One of the outcomes of the Neighbourhood Cares pilots was a framework that local VCS groups were able to operate within, but not bound to, allowing groups to access information about related services, and improve cohesion between actors. Applying such a framework to the Think Communities project would have the co-benefit of delivering the suggestions made by community groups in our research (Table 7), namely:

1. Increasing recognition and understanding of the utility and scope of communityled groups

2. Improving relationships between community-led groups and Council directorates

3. Utilising community knowledge to inform strategy

4. Reducing bureaucracy 
We have identified three ways of improving coordination and cohesion: community development workers, community hubs, and funding for partnership projects.

Recommendation 11.1: Integrate community development workers into the Think Communities place-based workforce

One of the key features of the Neighbourhood Cares pilot was the placement of workers within the community, who helped to facilitate interactions between service users, community groups, domiciliary care providers and Council services. From the perspective of communityled initiatives, such a figure in the community would have a large impact on improving cohesion and points 1-4 above. One community support group, who were formed on a new development, spoke positively about the role of a temporary BPHA Housing Officer in setting up sustainable foundations for the community group and facilitating connections with the Council. They described how a more permanent community development worker would help relationships both between community groups and between community groups and the Council.

'If there was somebody working full-time in the community to help draw some of these [initiatives] together... somebody to work alongside... the community chaplain... the school and those who already have a pastoral role in the community [that would be positive].'

Examples of how other local authorities have previously utilised and integrated community development worker roles are provided in research commissioned by the Community Development Exchange ${ }^{95}$.

Think Communities have been allocated up to $£ 1,686,000$ from the Transformation Fund to develop a place-based workforce that will deliver the Think Communities objectives. This will include 'place co-ordinators' for each of the five districts, as well as ten 'community connectors'. Our research provides evidential support for this strategy. Given the challenges faced by community groups that we have identified, we suggest that the community connector role should involve:

I. Providing a link between community-led groups and both the District and County Councils and their services, from social care to Highways and Transport, including facilitation of meaningful consultations.

II. Providing a link between community-led groups and private service providers.

III. Acting as a catalyst for groups within new developments.

IV. Advising and supporting new and existing groups through:

95 'Empowerment in Action Case Studies of Local Authority Community Development', The British Library (The British Library, n.d.), https://www.bl.uk/collection-items/empowerment-in-action-casestudies-of-local-authority-community-development. 


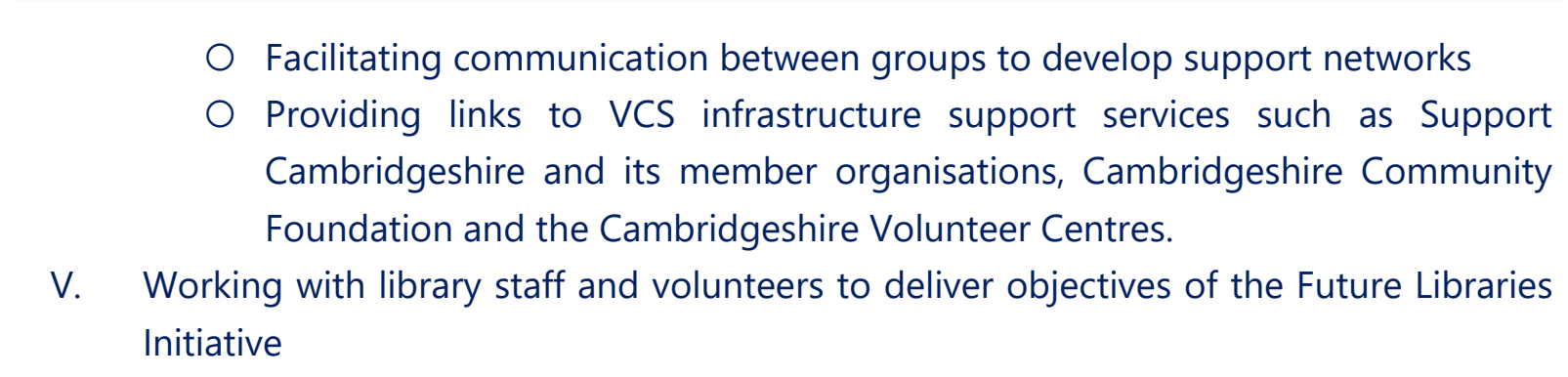

In terms of resource prioritisation and in line with our statements about the importance of health and wellbeing and the effect of community-led initiatives on health outcomes, we suggest that service delivery areas with the worst health indicators should be prioritised for service coverage by these roles.

Recommendation 11.2: Use Think Communities and the Libraries First Model to develop community hubs as a base for community groups

Our research highlights that the lack of affordable facilities is as much of a difficulty for community groups as funding. It was also identified as an important issue in our research on the potential effects of growth on community groups (Section 4). In Recommendations 3 and 6 , we laid out suggestions to improve the provision of affordable venues. There are also opportunities for this problem to be addressed in line with both the Think Communities and Future Libraries Initiative projects.

The current 'Libraries First Model' has an aim of encouraging the use of libraries for services and events delivered by library staff or external local organisations, which could be commissioned directly by the Library Service. Our research provides a case for the use of libraries for local community groups, rather than those organised by the service or Council. We believe that the free provision of library facilities for community groups which have a low income would allow these groups to flourish and develop stronger connections.

In regards to the Future Libraries Initiative, we suggest:

I. Ensuring that the community engagement stage of the 'Co-Design' phase specifically involves community groups that work in the areas surrounding the seven pilot libraries.

II. Developing the 'Libraries First Model' to have a specific focus on providing facilities for local community-led groups with low incomes.

While we believe that the use of libraries as community hubs is an excellent strategy, it is important to note that libraries may not be a suitable space for all groups, for example Men's Sheds, sports or gardening groups. It is these same groups that will have struggled to provide online services during the COVID-19 pandemic, and therefore we believe the provision of suitable facilities for these groups is even more imperative (See Recommendations 3 and 6). 
Recommendation 11.3: Fund partnership projects

In order to facilitate the formation of networks of community groups, we suggest that the Think Communities partnership considers awarding grants for place-based partnership projects that involve multiple groups that work within a particular service delivery area and share common goals.

Recommendation 12: Continue to expand Think Communities to cover all Council sectors, above and beyond Social Care

As detailed in previous sections, community-led groups in Cambridgeshire interact with a range of Council services and departments. Community-led groups offer an access point for Council workers to interact with Cambridgeshire communities, which will likely increase the success of both the community groups and also Council services and initiatives through the transfer of local contextual information (6.2.3. Acknowledging and utilising community knowledge). In line with the Think Communities workstream 'Workforce Reform', we believe that the partnership should aim to transform the ways in which Council directorates think about and interact with communities. This should go beyond the community-facing workforce. Our suggestions are:

12.1. Use the proposed workforce development programme to educate all council workers about the benefits of community-led initiatives in improving health and wellbeing (see Section 3 ), reducing the burden on council services and the use of community-led groups in providing place-based contextual information.

12.2. Mandate all Council directorates to develop a Think Communities policy that is outcomebased and outlines how their department will improve relationships with community-based groups.

12.3. Think Communities should take responsibility for the County Council Directory of Services (Recommendation 8) and develop it into a shared resource for County, District and Town Councils and other partners as a source of local information, in line with strategies to improve the use and availability of 'place-based' data and the creation of 'area profiles'. This will also be vital to improving the promotion of community groups to potential volunteers and service users (Recommendation 7).

Evidence from a survey of CCC workers who were redeployed from their substantive post to support COVID-19 response services has indicated that involvement in community-facing work can give workers new skills as well as improving job satisfaction. Over half of respondents felt like they had learnt new skills, while $48.4 \%$ said they would think differently about their 
substantive role as a results of their redeployment. This provides support for extending the Think Communities approach across all directorates beyond People and Communities.

\section{Recommendation 13: Support the provision of sustainable and accessible funding}

As highlighted in 6.2.6. Less bureaucracy, more adaptability and 6.2.7. Sustainable funding, we have identified some key issues with the current funding framework used by CCC, namely:

$\rightarrow$ Intensive application processes that prevent people from applying

$\rightarrow$ Inadequate communication regarding expectations and 'fit' for particular funds

$\rightarrow$ Annual funding mechanisms leading to economic insecurity

$\rightarrow$ Demanding monitoring and review procedures

The beneficiaries of existing CCC funds such as the Innovate and Cultivate fund and the Communities Capital Fund have predominantly been established charities and parish councils that have been awarded relatively large sums of money. Our research indicates that small community-based groups and initiatives can have a big effect on community health outcomes, as well as reducing pressure on local authority services. Furthermore, small local groups that are embedded in the community, aware of local needs, and are well-connected and supported via other mechanisms proposed in this report, are a key enabler of the Think Communities objectives. The COVID-19 pandemic has shown the necessity of such groups for developing resilience within communities. Small groups with restricted service delivery areas require relatively little money in comparison to that currently given out by the Council, but also require financial security that isn't provided by one-off annual grants.

'An annual payment of as little as $£ 50$ for each of our groups would go a long way to supporting our ongoing activities.'

We recommend that the CCC and the Think Communities partnership:

13.1. Supports the provision of small but sustainable grants

$\rightarrow$ For example, a system where grants are awarded bi-annually for a minimum period of 3 years, under the condition that updates to constitutions and safeguarding documents are agreed with the funder, and a short outcomebased report is provided before each re-iteration of the funding (see point III).

$\rightarrow$ Moving towards an approach of funding smaller community-based projects should form part of the emerging strategy to change the way Early Intervention and Prevention strategies are commissioned. 
13.2. Matches the amount of money applied for or awarded to the amount of documentation required for application and review

13.3. Awards recurring grants based on proposals that are focussed on a rolling set of 'outcomes' rather than 'outputs'

$\rightarrow$ Often, local government can be too focused on precisely what the initiative is doing, rather than the impact the initiative is having on the everyday life of people who take part. CCC should focus on the difference made by outputs, not on the outputs themselves.

$\rightarrow$ We suggest that all applications require groups to use SMART objectives to describe their plans for the following funding period, setting goals that are 'specific', 'measurable', 'achievable', 'relevant' and 'time-bound' ${ }^{\prime 96}$.

$\rightarrow$ In the 'measurable' field, applicants should describe how they will evaluate the success of the project, and then use these techniques to provide evidence for the next funding round. It should be made clear that reiterations of funding are not dependent on all the objectives being met, as long as there is evidence of progress.

$\rightarrow$ Allowing groups to choose how their goals are measured will allow them to choose a method of evidence collection that is achievable for them - for example, some small groups may not have the capacity to deliver extensive surveys, but may instead provide written notes of support from service users.

13.4. Consider funding place-based partnership projects (Recommendation 11.3), to support the development of networks of community-based groups.

13.5. Allocates funding in a proportionate way such that the most deprived areas and those with the highest comorbidity burden receive renewed investment first and at higher levels than other areas, as these neighbourhoods represent the greatest potential for improving health, wellbeing and financial savings.

Recommendation 14: Strengthen and assist voluntary and community sector (VCS) infrastructure support services

Three areas that were identified for improvement; promotion, advice and information, and recruitment of volunteers (6.2.8-6.2.10), are all services provided by VCS infrastructure support services. Several of these services run throughout Cambridgeshire, including Cambridge Council for Voluntary Service (CCVS), Hunts Forum and Cambridge ACRE, which work independently but also form the partnership organisation, Support Cambridgeshire, which is funded by the CCC and aims to bring together these three partners to deliver better

96 'Setting Smart Objectives', CMI (blog), 30 March 2020, https://www.managers.org.uk/knowledgeand-insights/resource/setting-smart-objectives/. 
outcomes for local organisations. There is also Voluntary and Community Action East Cambridgeshire, Cambridgeshire Community Foundation and a number of Volunteer Centres.

Throughout the questionnaire and telephone interviews, it was apparent that the opinion of these services from groups that have accessed their support was high. For example, one group said that the main way that the CCC could help their initiative would be by 'Continuing to support Hunts Forum, Support Cambridgeshire and ACRE. We have found these organisations helpful.' A founder of a new community support group agreed:

'[Hunts Forum] are inspirational. They know everything, they know everybody... They go beyond just saying 'look here for information'. They'll sit down with you and say this is how you alter [your funding application]. They put you in touch with other people who have been through the mill. They'll share good practice documents, they'll share constitutions and safeguarding and GDPR documents... I can't praise them highly enough... I would promote Hunts Forum quite heavily if you want to start growing little initiatives.'

In the questionnaire, we asked whether the groups were aware of these organisations. 98 (67.1\% of total questionnaire respondents) people had heard of at least 1 of the 7 named organisations (Figure 28). Whereas $73.5 \%, 33.7 \%$ and $50.0 \%$ of question respondents had heard of CCVS, Hunts Forum and Cambridge ACRE, respectively, only $20.4 \%$ had heard of Support Cambridgeshire. 4 respondents additionally left positive comments about the impact these organisations have had on their groups, while 5 respondents noted that although they had heard of these groups, they did not have any contact with them. 6 respondents left negative comments, largely regarding a lack of funding opportunities available from these organisations. 


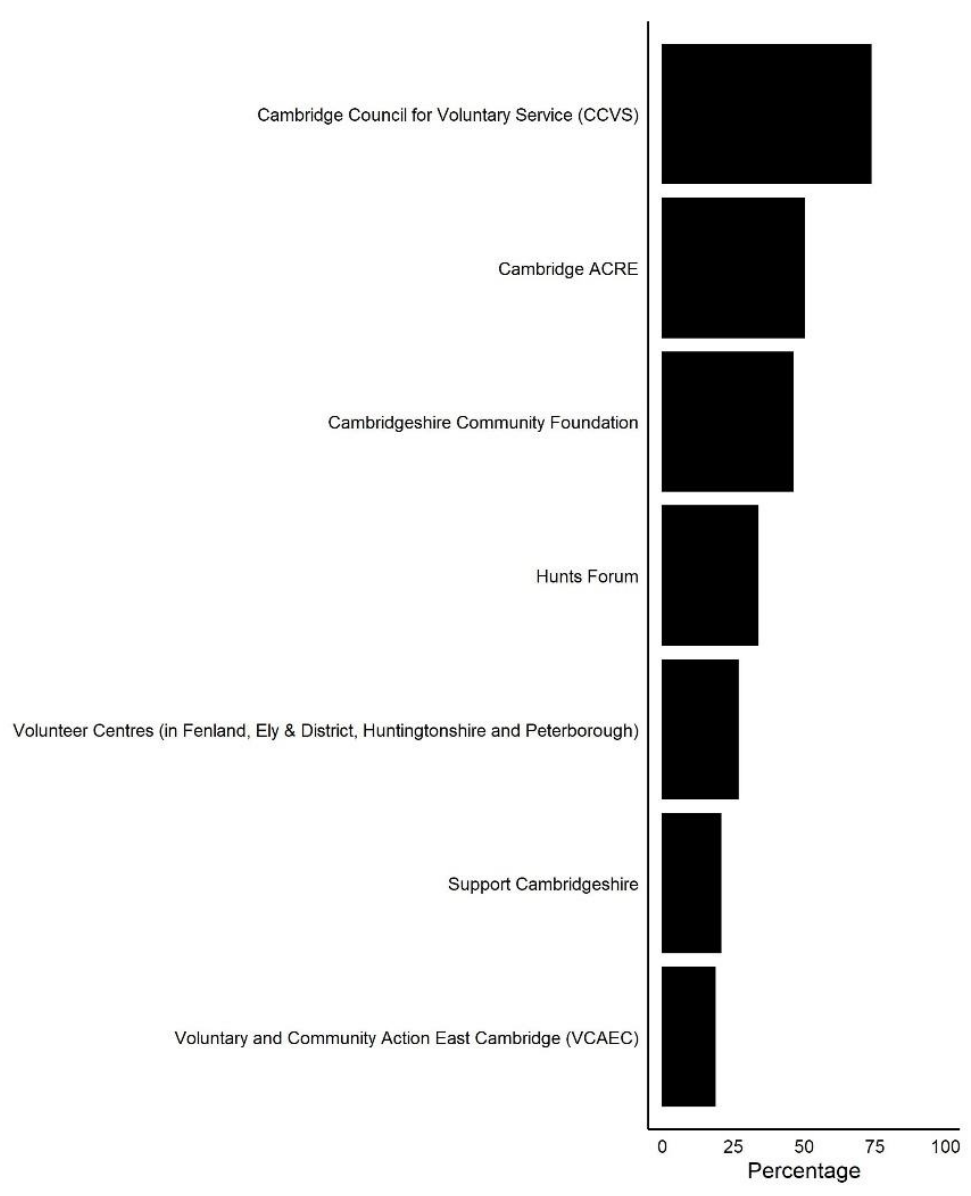

Figure 28: Are you aware of these voluntary and community sector (VCS) infrastructure support services?

A concerning aspect of this data is that when considering only those groups with an income of less than $£ 5,000$, the percentage of groups that had heard of at least one of the groups dropped to $56.4 \%$, and out of those, the proportion that had heard of each organisation all dropped significantly (Figure 29). We can infer that these VCS support networks are not reaching the small and new community groups as well as the larger more established groups. 


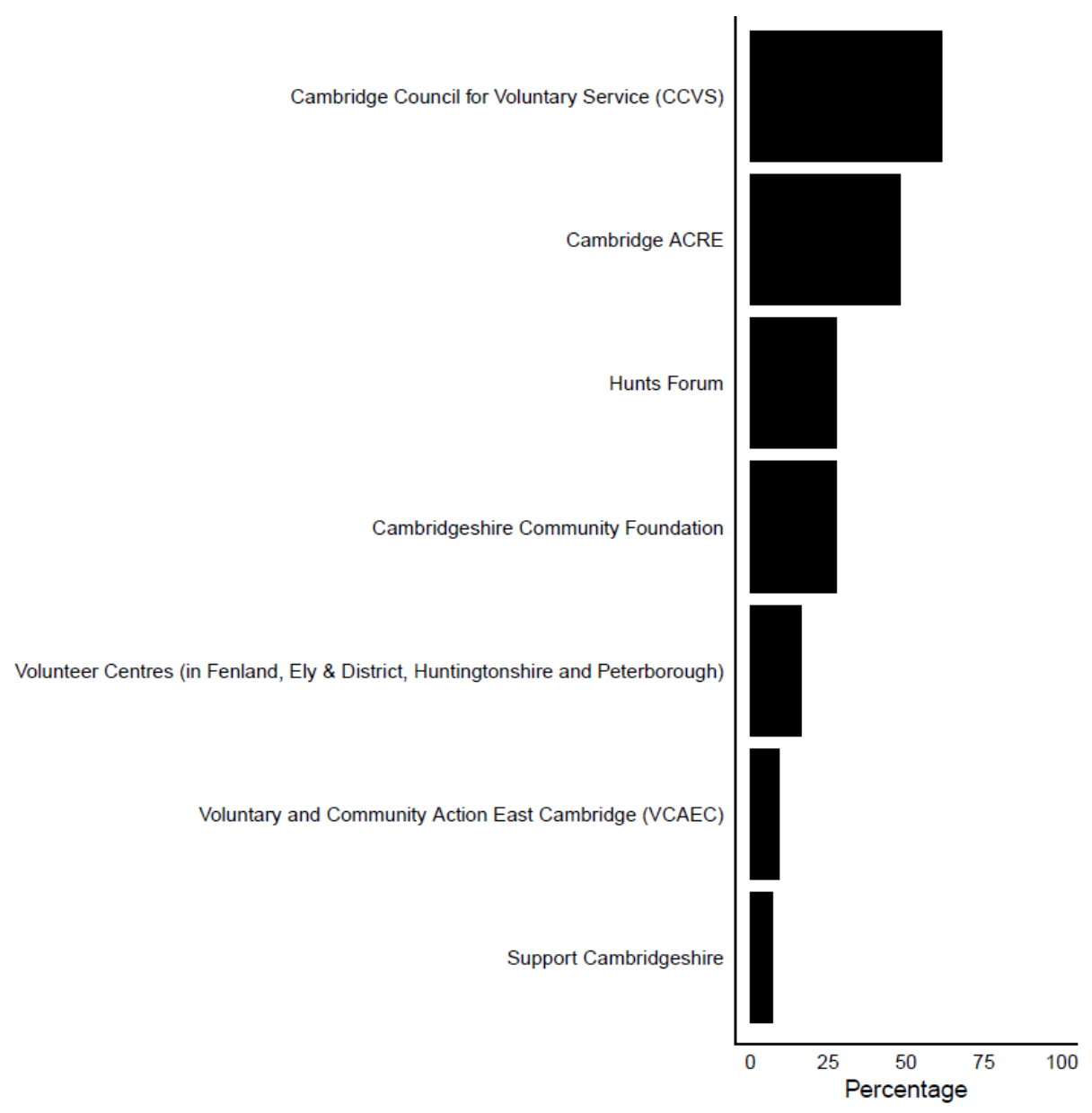

Figure 29: (For groups with an income less than $£ 5,000$ ) Are you aware of these voluntary and community sector (VCS) infrastructure support services?

In some follow-up interviews, we tried to determine how groups were finding these organisations. When asked how they initiated a relationship with Hunts Forum, one person said:

II went to an awful lot of networking events in my first year [of setting up the group]... I would go and meet people and exchange business cards... I met the lady who worked for Hunts Forum at a networking event at the Cambridge Science Park.'

In order for these services to work optimally, the way in which these services are advertised needs to be improved.

We believe there is an opportunity for the CCC to support the foundation and development of community initiatives, in line with the Think Communities approach, through supporting these organisations. In particular, as we have identified that a lack of information about funding opportunities has been a problem for many groups, we envisage that CCC could improve this through Support Cambridgeshire and related groups. We acknowledge that the 
Support Cambridgeshire 4 Community Grant Finder portal is an excellent resource, but services like this just aren't reaching the groups who need it.

We recommend that the CCC:

14.1. Continues to re-commission Support Cambridgeshire alongside Peterborough City Council

14.2. Advertises these services through their website (including in the Directory of Services) and local bulletins

14.3. Acknowledges that not all community groups may be comfortable with using the internet to access information, and works with Support Cambridgeshire to deliver targeted outreach programmes

14.4. Considers how the VCS infrastructure support services will integrate into the Think Communities programme. For example:

$\rightarrow$ Liaise with all organisations within Cambridgeshire to coordinate services across the established service delivery areas

$\rightarrow$ Create networks between these organisations and council workers by involving them in the workforce development programme

$\rightarrow$ Collaborate with these organisations on a shared database of community organisations (see Recommendation 8).

Increasing awareness of other funding opportunities, through VCS support networks, as well as providing smaller, more sustainable grants to localised community groups (Recommendation 13), will have the co-benefit of reducing the amount of money that CCC expends on grants. 


\section{Recommendation Analysis}

\subsection{Complex systems theory}

Before discussion of the recommendations for the Council, we first preface this section within the broader context of complex systems theory ${ }^{97}$. A complex system is an entity composed of multiple interacting parts whose overall behaviour is greater than the sum of its constituent parts and include phenomena such as ecosystems, the human brain, and most relevant to this report, societies and their forms of government. The United Kingdom, therefore, represents an example of a complex system and hence requires governmental organisation that accommodates this societal structure. Towards this end, the UK's introduction of devolution a little more than 20 years ago complies with this definition by allowing more decentralised governing of local areas rather than placing the entire burden on national government. This structure allows subnational/local areas to make and perform decisions semi-autonomously to address concerns specific to them that they would ultimately be more knowledgeable about and, therefore, more capable of solving once given the appropriate resources and support.

However, in order for this scheme to carry on effectively, local and national government as well as communities and local government must work effectively in tandem or risk being overwhelmed by area-specific stresses (e.g. local) and/or inefficient in delegating needed resources (e.g. national). Therefore, in order for the Council to implement our recommendations listed below, it must, first and foremost, work to keep a continuously open line of communication between the Council and local community-led initiatives. This is important since, at each level, the group (Council or community) needs to have operating capabilities equal in complexity to their environment so their abilities are adequate to the scale of their responsibilities. This ensures that all levels (local and national) of the system run smoothly and are capable of doing multiple things simultaneously without major disturbances to productivity.

${ }^{97}$ Alexander F. Siegenfeld and Yaneer Bar-Yam, 'An Introduction to Complex Systems Science and Its Applications', ArXiv:1912.05088 [Physics], 10 December 2019, http://arxiv.org/abs/1912.05088. 


\subsection{Recommendations}

Fundamental to community-based approaches to improving health and wellbeing is prioritising the question 'What keeps us healthy?' rather than 'What makes us ill?' Local government's primary aim, therefore, must be to grow the knowledge, skills and confidence of individuals and communities to recognise the needs of their community and manage their own health accordingly. To achieve this, local government needs to sit on the top rung of the Wilcox Ladder of Participation (Figure 30); enabling rather than leading. This means that it should provide support to independent initiatives, allowing the initiatives to make their own decisions corresponding to the needs of their community, and only provide expert support and guidance where required. This is quite a step up from standard practice, where local governments may consult communities on service commissioning but generally do not empower the community to provide the service themselves. These considerations are the basis for the Think Communities and Early Prevention and Intervention approaches already being employed by Cambridgeshire County Council. Our research provides resolute support for these initiatives, and therefore we encourage the Cambridgeshire Public Services Board to continue to give its full support and commitment to the implementation of Think Communities.

Our full list of recommendations, which have been described in more detail in the context of the relevant sections of this report, is listed below:

Recommendation 1: Support communities to devise their own solutions to local health and social care issues.

$\rightarrow$ Providing seed funding for new initiatives.

$\rightarrow$ Providing access to consultants and advice for initiatives.

$\rightarrow$ Organising public consultations to establish the key issues in the area and how they can be addressed by the community. 
$\rightarrow$ Rolling out a social prescribing scheme such that health and social care professionals are aware of the health and wellbeing benefits of local initiatives, and can prescribe these to patients who may profit from these.

Recommendation 2: Map local community assets alongside needs in the Joint Strategic Needs Assessment to understand where the community can add value, with additional insight work with marginalised communities.

Recommendation 3: Support community centres and infrastructure in new developments.

$\rightarrow$ When possible, consider forming partnerships with Master Developers when developing large sites like those within "growth areas".

$\rightarrow$ Consult with community groups prior to granting contracts with Developers.

$\rightarrow$ Install community spaces before residents move into developments.

$\rightarrow$ Construct a list of national organisations which can support the setup of local area groups in new communities, and make this available to new residents.

$\rightarrow$ Commission an extension report on the physical and social requirements of new communities that covers quantitative and qualitative criteria.

$\rightarrow$ Lobby for infrastructure that is mindful of health, promoting the development of environments that are green and sociable.

Recommendation 4: Include family homes in all new developments.

\section{Recommendation 5: Consider the effects of business growth on communities}

$\rightarrow$ Conduct meaningful consultations with communities throughout the development process to make sure growth has a positive effect on surrounding areas.

$\rightarrow$ All developments, business or housing, should have a nominated liaison to work with local residents and community groups and ensure successful growth.

Recommendation 6: Improve the provision of affordable venues in existing communities

$\rightarrow$ Conduct research into the availability of community facilities, to identify facility 'black holes.'

$\rightarrow$ Conduct research to identify specialised facilities that are lacking in each region

$\rightarrow$ Ensure that initiatives to improve or provide new venues are informed by public consultation.

$\rightarrow$ Consider using money that has previously been put into funding pools to provide free or subsidised facilities for community groups.

$\rightarrow$ Prioritise areas with poor health and socio-economic outcomes.

$\rightarrow$ Ensure that any new venues are physically accessible. 
Recommendation 7: Improve the advertisement of community-led groups to boost volunteer recruitment

$\rightarrow$ Support and enhance VCS infrastructure support services

$\rightarrow$ Use existing VCS infrastructure to host a large scale volunteer event, in which community groups can have stalls promoting their groups, and potential volunteers can find opportunities.

\section{Recommendation 8: Improve the County Council Directory of Services}

$\rightarrow$ Work with District Councils and VCS infrastructure support services to expand and align databases of community-initiatives.

$\rightarrow$ Group initiatives based on district as well as theme.

$\rightarrow$ Include a link for community groups to list their services on the directory.

$\rightarrow$ Show which organisations are actively recruiting volunteers.

$\rightarrow$ Ensure that there is up-to-date contact information for every group.

$\rightarrow$ Advertise the application and produce physical copies to be distributed at local community centres, shops, libraries and GP practices.

\section{Recommendation 9: Support volunteer continuity post-pandemic}

$\rightarrow$ Signpost people who volunteered in the pandemic to other volunteering opportunities post-pandemic.

$\rightarrow$ Improve public awareness and understanding of community needs in order to encourage people to volunteer.

\section{Recommendation 10: Increase volunteer diversity}

$\rightarrow$ Investigate the backgrounds of people who volunteer in Cambridgeshire.

$\rightarrow$ Provide specific support to encourage underrepresented groups into volunteering.

$\rightarrow$ Make the provision of inclusion data and strategies to promote inclusivity mandatory within council grant applications for community-led initiatives

Recommendation 11: The Think Communities Partnership should prioritise provision of a framework for coordination and cohesion

$\rightarrow$ Integrate community development workers into the Think Communities place-based workforce

$\rightarrow$ Use Think Communities and the Libraries First Model to develop community hubs as a base for community groups

$\rightarrow$ Fund partnership projects

Recommendation 12: Continue to expand Think Communities to cover all Council sectors, above and beyond Social Care

$\rightarrow$ Use the proposed workforce development programme to educate all council workers about the benefits of community-led initiatives in improving health and wellbeing. 
$\rightarrow$ Mandate all Council directorates to develop a Think Communities policy that is outcome-based and outlines how their department will improve relationships with community-based groups.

$\rightarrow$ Think Communities should take responsibility for the County Council Directory of Services and develop it into a shared resource for County, District and Town Councils and other partners as a source of local information, in line with strategies to improve the use and availability of 'place-based' data and the creation of 'area profiles'.

\section{Recommendation 13: Support the provision of sustainable and accessible funding}

$\rightarrow$ Support the provision of small but sustainable grants

$\rightarrow$ Match the amount of money applied for or awarded to the amount of documentation required for application and review.

$\rightarrow$ Award recurring grants based on proposals that are focussed on a rolling set of 'outcomes' rather than 'outputs'.

$\rightarrow$ Consider funding place-based partnership projects, to support the development of networks of community-based groups.

$\rightarrow$ Allocate funding in a proportionate way such that the most deprived areas and those with the highest comorbidity burden receive renewed investment first and at higher levels than other areas, as these neighbourhoods represent the greatest potential for improving health, wellbeing and financial savings.

Recommendation 14: Strengthen and assist voluntary and community sector (VCS) infrastructure support services

$\rightarrow$ Continue to re-commission Support Cambridgeshire alongside Peterborough City Council.

$\rightarrow$ Advertise these services through the CCC website (including in the Directory of Services) and local bulletins.

$\rightarrow$ Acknowledge that not all community groups may be comfortable with using the internet to access information, and work with Support Cambridgeshire to deliver targeted outreach programmes.

$\rightarrow$ Consider how the VCS infrastructure support services will integrate into the Think Communities programme. 


\subsection{Theory of Change}

The following theory of change logic model summarises our recommendations and highlights the expected intermediate and final outcomes, providing a basis for future evaluation of the recommended implementation.
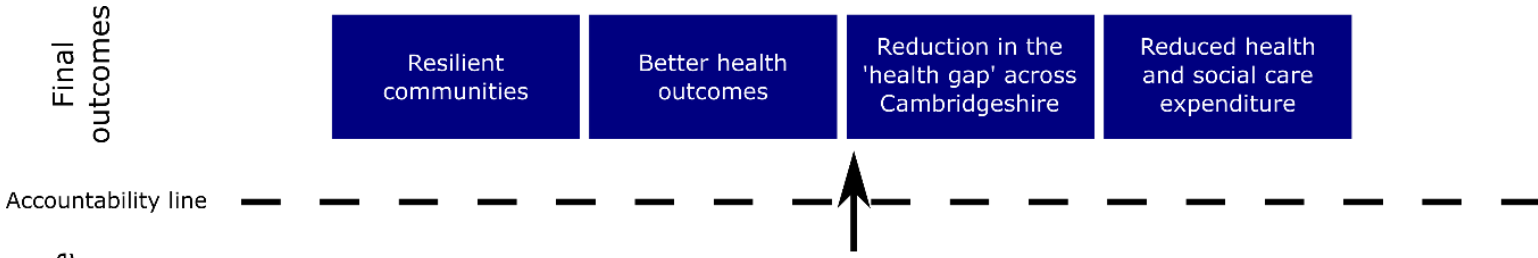

\begin{tabular}{|c|c|}
\hline \multirow{4}{*}{ 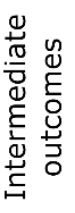 } & \\
\hline & Community groups that are well-supported, accessible to all, working effectively and resilient in a context of rapid growth \\
\hline & A coordinated preventative health and social care network, consisting of the VCS, private and public sectors \\
\hline & Reduced burden on formal health and social care \\
\hline \multirow{8}{*}{ 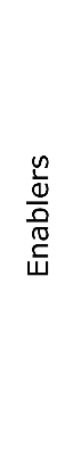 } & $\begin{array}{c}\text { A coodinated County, District and Town Council workforce that understands the importance of community development } \\
\text { and the utility of community-led groups }\end{array}$ \\
\hline & The Think Communities partnership and place-based workforce \\
\hline & Volunteers who are educated about the needs in their community \\
\hline & VCS support infrastructure services that are well advertised, funded and accessible \\
\hline & The NHS, linked to other enablers through social prescribers \\
\hline & Appropriate and affordable facilities \\
\hline & Developers \\
\hline & Private care providers \\
\hline \multirow{14}{*}{ 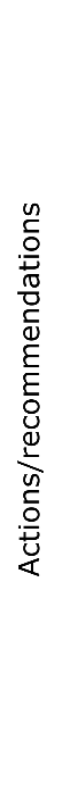 } & Support communities to devise their own solutions to local health and social care issues \\
\hline & $\begin{array}{l}\text { Map local community assets alongside needs in the Joint Strategic Needs Assessment to understand where the community } \\
\text { can add value, with additional insight work with marginalised communities }\end{array}$ \\
\hline & Support community centres and infrastructure in new developments \\
\hline & Include family homes in all new developments \\
\hline & Consider the effects of business growth on communities \\
\hline & Improve the provision of affordable venues in existing communities \\
\hline & Improve the advertisement of community-led groups to boost volunteer recruitment \\
\hline & Improve the County Council Directory of Services \\
\hline & Support volunteer continuity post-pandemic \\
\hline & Increase volunteer diversity \\
\hline & The Think Communities Partnership should prioritise provision of a framework for coordination and cohesion \\
\hline & Continue to expand Think Communities to cover all Council sectors, above and beyond Social Care \\
\hline & Support the provision of sustainable and accessible funding \\
\hline & Strengthen and assist voluntary and community sector (VCS) infrastructure support services \\
\hline
\end{tabular}




\subsection{Conclusion}

In summary, this research has shown that it is possible to empower communities to provide their own solutions to many health and social care issues, with associated benefits for the local economy. It has further highlighted areas that may pose a challenge to developing communities, specifically related to growth and inclusivity. With this evidence in mind, we have proposed recommendations for Cambridgeshire County Council to consider in order to support community development that may, ultimately, improve community health outcomes. 